Local and remote microcirculatory effects of transient ischemia of the lower extremities in rats

Dénes Garab, MSc

Ph.D. Thesis

University of Szeged, Faculty of Medicine

Institute of Surgical Research

Szeged

2014 


\section{LIST OF FULL PAPERS RELATING TO THE SUBJECT OF THE THESIS}

I. Hartmann P, Greksa F, Garab D, Varga R, Széll M, Keresztes M, Sántha P, Boros M, Szabó A. Microcirculatory consequences of osteoporosis. Timisoara Med. Journal 2010; 60:100-106

II. Szabó A, Hartmann P, Varga R, Jánvári K, Lendvai Z, Szalai I, Gomez I, Varga G, Greksa F, Németh I, Rázga Z, Keresztes M, Garab D, Boros M. Periosteal microcirculatory action of chronic estrogen supplementation in osteoporotic rats challenged with tourniquet ischemia. Life Sci. 2011; 88(3-4):156-162 (IF: 2.451)

III. Garab D, Fet N, Szabó A, Tolba RH, Boros M, Hartmann P. Remote ischemic preconditioning differentially affects $\mathrm{NADPH}$ oxidase isoforms during hepatic ischemia-reperfusion. Life Sci. 2014; 105(1-2):14-21 (IF: 2.555)

\section{LIST OF ABSTRACTS RELATING TO THE SUBJECT OF THE THESIS}

IV. Garab D, Bodnár D, Nyíri S, Pócs L, Janovszky A, Boros M, Szabó A. Periosteal microcirculatory effects of limb ischemic preconditioning in ovariectomized rats. Eur Surg Res. 2014; 52:pp 130 


\section{LIST OF ABBREVIATIONS}

AD-SoS amplitude-dependent speed of sound

ALT alanine-aminotransferase

ANOVA analysis of variance

AST aspartate-aminotransferase

E2 $17 \beta$-estradiol

ELISA enzyme-linked immunosorbent assay

HMGB1 high-mobility group protein B1

$\mathrm{H}_{2} \mathrm{O}_{2} \quad$ hydrogen peroxide

CGRP calcitonin gene-related peptide

ICAM-1 intercellular adhesion molecule-1

IPC ischemic preconditioning

IL interleukin

IR ischemia-reperfusion

IVM intravital videomicroscopy

LDH lactate-dehydrogenase

MPO myeloperoxidase

NO nitric oxide

NOS nitric oxide synthase

NOX NADPH oxidase

O2C "oxygen to see" (modified lightguide spectrophotometry)

OVX ovariectomy

PAF platelet activating factor

PMN polymorphonuclear leukocyte

RBCV red blood cell velocity

$\mathrm{rHb}$ tissue hemoglobin content

rIPC remote ischemic preconditioning

ROS reactive oxygen species

$\mathrm{S}_{\mathrm{O} 2} \quad$ tissue oxygen saturation

TNF- $\alpha$ tumor necrosis factor-alpha

XOR xanthine oxidoreductase

VCAM-1 vascular adhesion molecule-1 


\section{CONTENTS}

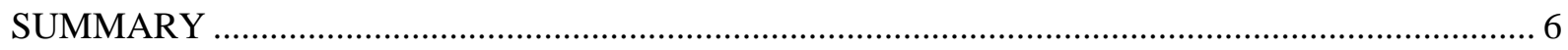

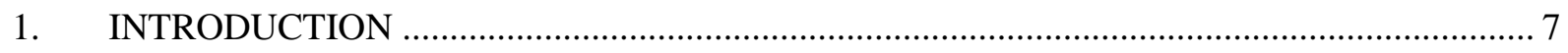

1.1. Local biochemical and microcirculatory manifestations of ischemia-reperfusion (IR) injury

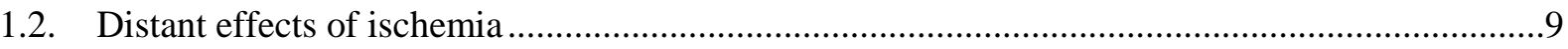

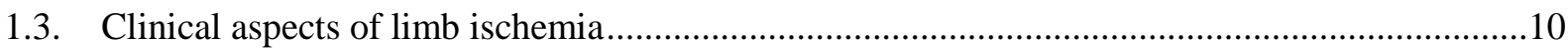

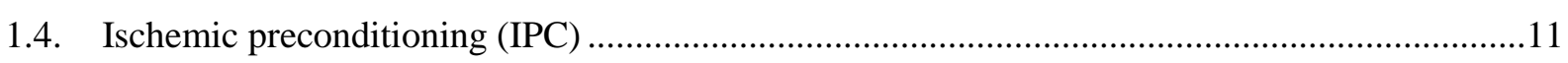

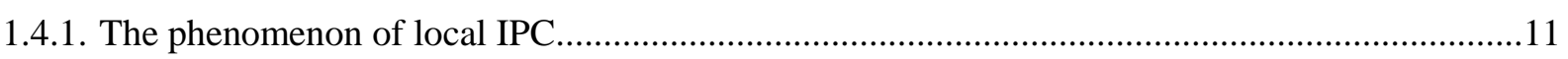

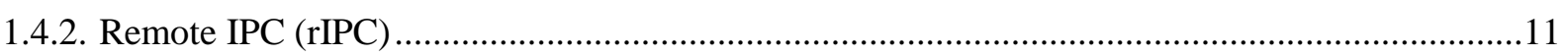

1.4.3. IPC during orthopedic-trauma surgery: mechanisms and clinical applications ...........................12

1.4.4. The potential role NOXs in ROS-mediated tissue injury and IPC .............................................13

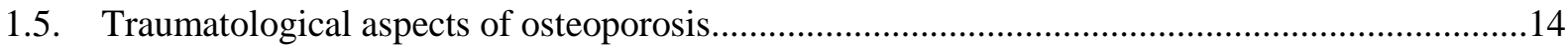

1.5.1. Pathogenesis and clinical symptoms of osteoporosis. Possible role of the periosteum in

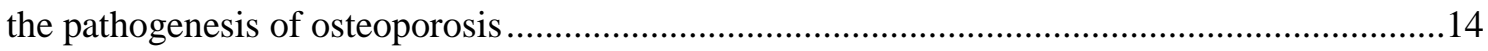

1.5.2. Inflammatory complications related to estrogen loss and replacement .....................................15

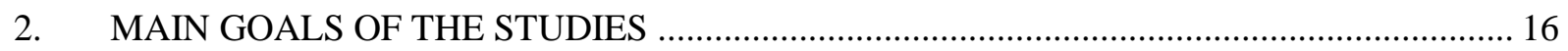

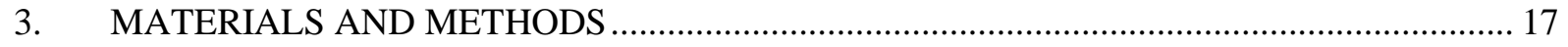

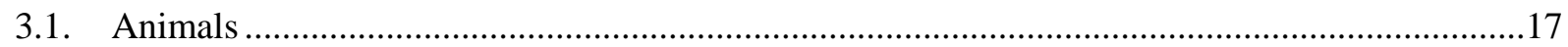

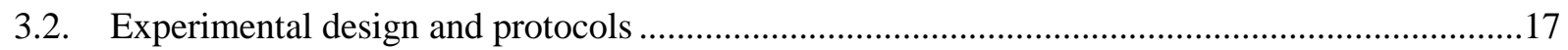

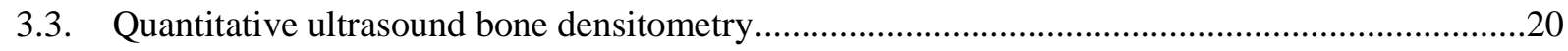

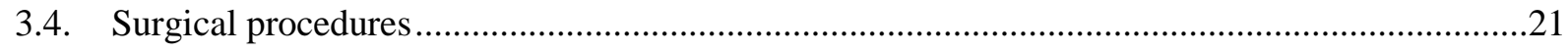

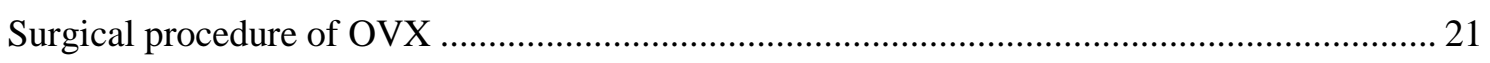

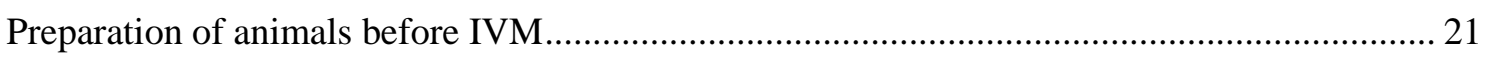

Preparation of the tibial periosteum for IVM measurements in rats ........................................ 21

Preparation of the liver for IVM measurements in rats ............................................................... 21

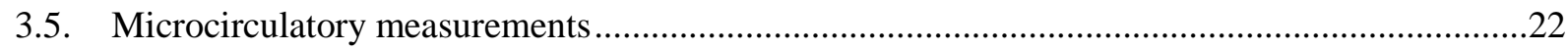

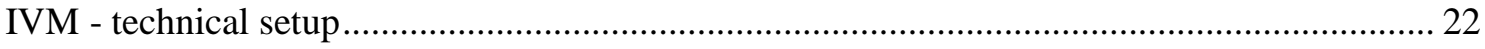

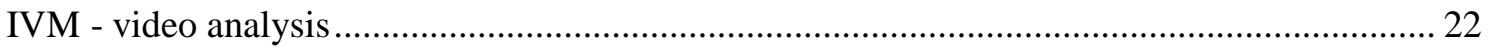

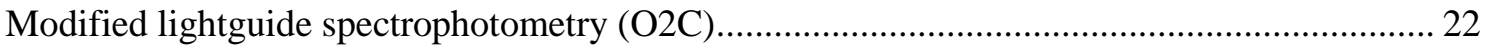

3.6. Immune labeling and flow cytometric analysis of adhesion molecule CD11b

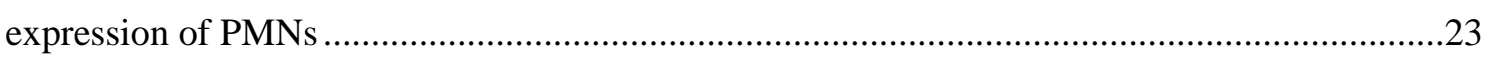

3.7. Determination of plasma TNF- $\alpha$ and high-mobility group protein B1 (HMGB1) levels ............23

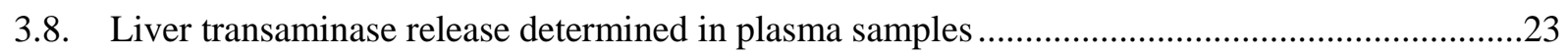

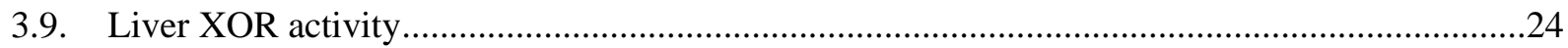

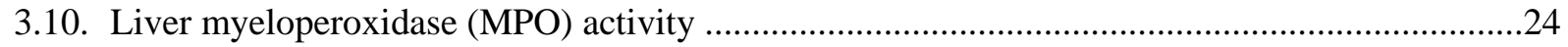

3.11. Western blot analysis of liver NOX2 and NOX4 protein expression .......................................24

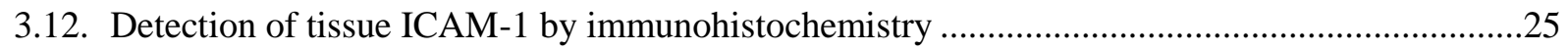




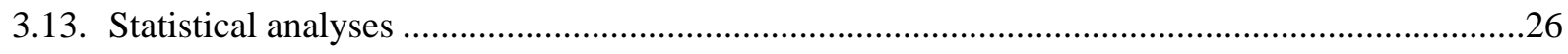

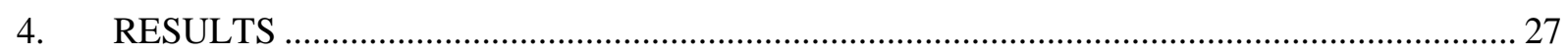

4.1. Effects of OVX and chronic estrogen therapy on bone density and postischemic tibial

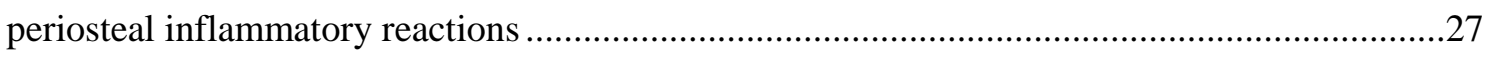

4.2. Effects of local IPC on the postischemic tibial periosteal microcirculatory inflammatory reactions in the presence of estrogen depletion ................................................29

4.3. Effects of rIPC on inflammatory consequences of partial liver IR .......................................31

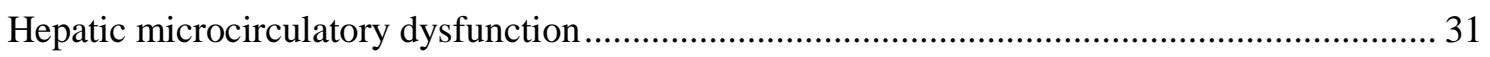

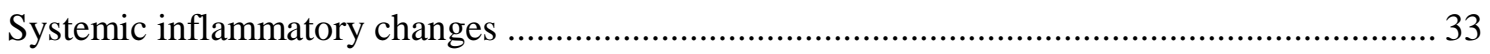

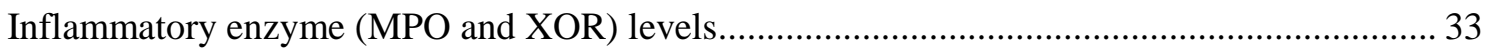

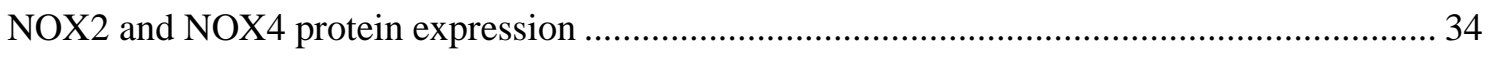

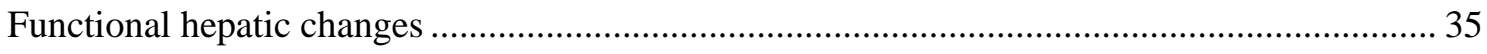

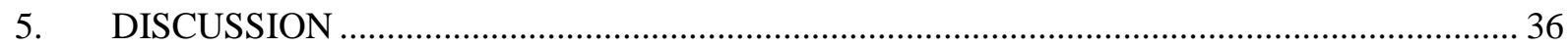

5.1. Effects of OVX and estrogen supplementation on local postischemic periosteal

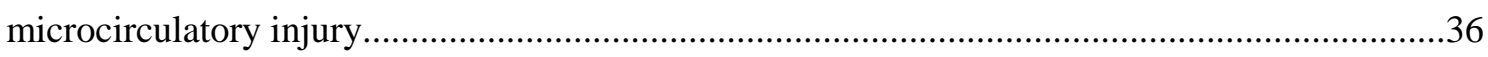

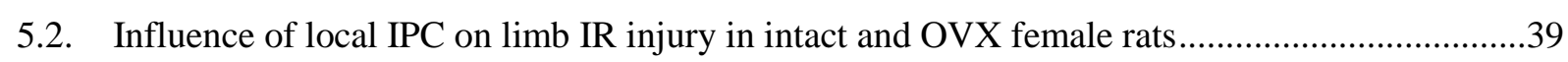

5.3. Remote effects of limb IPC. Beneficial microcirculatory and biochemical effects on

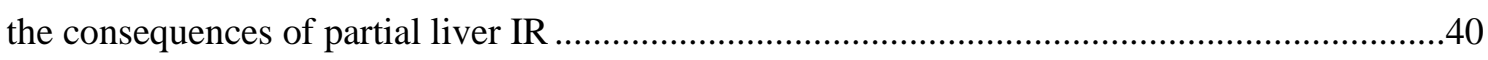

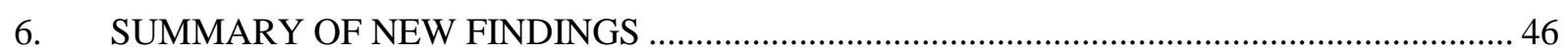

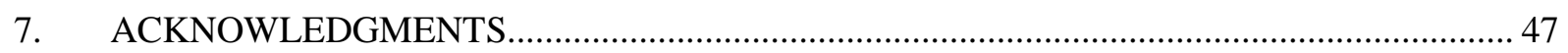

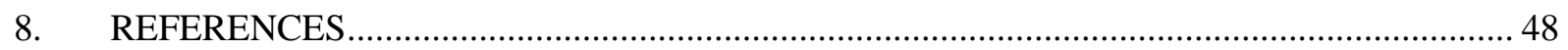

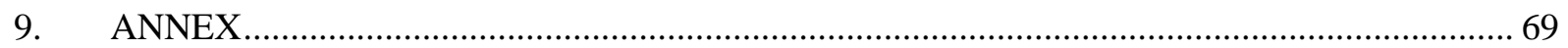




\section{SUMMARY}

Tourniquet-induced limb ischemia is a generally applied maneuver in orthopedictrauma practice which brings about marked local and systemic inflammatory effects. The affected tissue undergoes typical biochemical and microcirculatory changes of ischemiareperfusion (IR) injury, primarily the periosteal microcirculation being affected in this process. The potential negative clinical outcome may include perturbed bone healing, delayed union or pseudoarthrosis formation. Since a tourniquet applied around the limb causes IR of an appreciably high amount of tissue, venous effluent or afferent neurogenic signals of the affected limb bring about further systemic inflammatory reactions. On the other hand, the metabolites released after limb IR may be involved in the protection of remote (or inter-organ) ischemic preconditioning (IPC), a phenomenon in which transient, brief periods of ischemia followed by short intervals of reperfusion afford protection against subsequent ischemia by increasing the ischemic tolerance of the tissues of remote organs.

The major aim of our study was to examine the local and remote microcirculatory effects of transient lower limb ischemia. In this context, our first objective was to observe the effects of osteoporosis and the consequences of estrogen therapy on the local periosteal microcirculatory reactions in a clinically relevant time frame in rats subjected to ovariectomy (OVX). The results showed that OVX does not predispose the periosteal microcirculation to enhanced IR-induced inflammatory complications such as local leukocyte activation and inflammatory cytokine release, whereas estrogen therapy has a pronounced ameliorating effect in the periosteal microcirculation. Further, we demonstrated that the beneficial microcirculatory effects of local IPC are lost after OVX, suggesting that endogenous estrogen plays a potential role in the protection provided by IPC.

In the second major part of the studies, the potential impact of IPC elicited at the limb on the postischemic liver injury (remote IPC) was examined from several aspects of inflammatory activation on liver IR injury, with special emphasis on the free radicalproducing nicotinamide adenine dinucleotide phosphate-oxidases (NOXs). The data revealed that remote IPC reverses a hepatic microcirculatory perfusion deficit and inflammatory reactions, restores tissue oxygenation and reduces proinflammatory cytokine and necroenzyme levels. These beneficial effects are associated with a reduced NOX2 expression, suggesting a potential role of NOX2 in the mechanism of protection provided by remote IPC. 


\section{INTRODUCTION}

\subsection{Local biochemical and microcirculatory manifestations of ischemia-reperfusion}

(IR) injury

Re-establishment of the blood flow after tissue ischemia leads to a controversial circulatory phenomenon usually termed IR injury. Temporary ischemia per se initiates harmful processes in the endothelial cells and the surrounding tissues because of the severely compromised blood flow and the oxygen and energy deficits of the affected tissues. Although reestablishment of the circulation is essential for survival, it usually worsens the tissue damage caused by the ischemic phase alone (Nishida $\mathrm{T} 1987$, Reynolds JM 1989).

An IR injury is characterized by various detrimental local and remote effects. The local reaction is closely linked to the nearly immediate production of reactive oxygen species (ROS), a phenomenon known as the oxidative burst. This intracellular biochemical reaction is based on sequential univalent reductions of molecular oxygen, leading to the generation of superoxide radicals, and then to hydrogen peroxide $\left(\mathrm{H}_{2} \mathrm{O}_{2}\right)$ and hydroxyl radicals. One of the major sources of superoxide generation is the enzyme xanthine oxidoreductase (XOR). The oxidase form of XOR is irreversibly converted from xanthine dehydrogenase during ischemia, which generates superoxide anions from hypoxanthine and molecular oxygen, basically from the ATP content of the cells (McCord JM 1982, Kurose I 1994a). Another important source of ROS formation is nicotinamide adenine dinucleotide phosphate-oxidase (NADPH oxidase, NOX), a membrane-bound enzyme complex found in the plasma membrane and in the phagosomal membranes of polymorphonuclear neutrophil leukocytes (PMNs) (Rybicka JM 2010).

At the microcirculatory level, these reactions are exacerbated by inhibition of the biological activity of nitric oxide (NO), a highly effective vasodilator molecule with important anti-adhesive characteristics (Gaboury J 1993). A variety of cells, including vascular endothelial cells, synthesize NO from the guanido group of L-arginine, and the inhibition of NO synthesis evokes the recruitment of adherent PMNs (Kubes P 1991, 1993). The inactivation of NO by its reaction with superoxide causes peroxynitrite formation, which exerts further detrimental effects (Beckman JS 1996). Ultimately, the oxygen- and nitrogen-centered radicals damage cellular components such as DNA, membrane lipids and proteins (Freeman BA 1982, Powell SR 1992). 
The subcellular biochemical changes are closely linked to deteriorations in the microcirculation. ROS and peroxynitrite cause impaired endothelium-dependent vasodilation and increased microvascular permeability (Björk J 1982, Parks DA 1983, Beckman JS 1996). Furthermore, tissue damage leads to an enhanced release of proinflammatory cytokines (e.g. interleukins (ILs), platelet activating factor (PAF) and tumor necrosis-factor alpha (TNF- $\alpha)$ ), which results in an increased expression of adhesion molecules responsible for the interactions between endothelial cells and PMNs (Pohlman TH 1986, Sugama Y 1992). Moreover, ROS formation directly induces the adhesion of PMNs in the postcapillary venules (Suzuki M 1989, 1991), together with platelet-leukocyte adhesion and platelet aggregation (Iuliano L 1994, Leo R 1997). Finally, the recruited PMNs transmigrate from the endothelial surface of the lumen to the surrounding tissues across the postcapillary venules. Activated PMNs secrete further ROS, enhancing the inflammatory reactions in the microcirculation (Grisham MB 1986, Wankowicz Z 1988).

It is well established that leukocyte-endothelial cell interactions are decisive events among the complications of IR injury, because the extent of tissue damage and the number of recruited PMNs are interrelated phenomena (Harris AG 1996). As a consequence of an oxidative burst, the damaged endothelial cells produce various chemotactic factors (e.g. PAF, leukotriene $\mathrm{B}_{4}$ and chemokines), which facilitate the movement of leukocytes toward the affected site of inflammation (Kurose I 1994b, Wanner GA 1996). The recruitment process involves at least two different stages, an initial low-affinity binding and a later high-affinity interaction that results in firm adhesion. The first step is "rolling" or tethering and momentary halting of the movement of PMNs along the vessel wall. It is mediated by cell surface glycoproteins known as selectins. The L-selectins are expressed constitutively on the leukocyte surface, but the binding affinity increases via activation of the cell (Li X 1998). The P- and E-selectins are expressed on the endothelial cell surface. The P-selectins are constitutively stored in a preformed state in the Weibel-Palade bodies of the endothelial cells, and translocated to the outer cell membrane within a few minutes after stimulation by thrombin, histamine or ROS (Lorant DE 1991). E-selectin appears on the endothelial surface 1-2 hours following inflammatory stimulation by endotoxin and proinflammatory cytokines (e.g. IL-1, TNF$\alpha$ ) (Chamoun F 2000). The next step in this process is the firm adhesion or "sticking" of the PMNs to the inflamed endothelium via integrins. For strong adhesive interactions, PMNs shed L-selectins and increase the expression of 32 integrins (CD11a,b,c/CD18) 
(Springer TA 1990), especially CD11b/CD18, which is induced by IR injury (Kurose I 1994b, Koike K 1995). At the endothelial site, the receptors of different integrins are to be found (intercellular adhesion molecules-1 and -2 (ICAM-1 and ICAM-2), vascular adhesion molecule-1 (VCAM-1) and platelet endothelial cell adhesion molecule-1), which are members of the immunoglobulin supergene family of cell surface molecules (Williams AF 1988). ICAM-1, abundantly present on the endothelium as the main receptor for 32 integrins (Diamond MS 1990), is upregulated in response to cytokine stimulation (Groves 1992; Gaboury JP 1995). Last, but not least, the diapedesis of PMNs to the inflamed tissues occurs through tight junctions between the adjacent endothelial cells (Ginzberg 2001).

Swelling of the endothelial cells and edema formation resulting from the plasma leakage into the surrounding tissues through postcapillary venules (Mazzoni MC 1989, Gute DC 1998) are also typical manifestation of IR injury and, as a consequence of plasma loss, the blood is concentrated (Menger MD 1997). All these events may lead to the "no-reflow" phenomenon, the occlusion of capillaries by the plugging of blood cells at the time of reperfusion (Menger MD 1992).

\subsection{Distant effects of ischemia}

Apart from its local inflammatory effects, the ischemia of certain organs causes inflammatory reactions at distant anatomical sites. Generally speaking, inflammatory mediators released as a consequence of the reperfusion of any organ may activate endothelial cells in remote organs (that are not exposed to the initial ischemic insult), this resembling the phenomenon of the systemic inflammatory response syndrome (Carden DL 2000). In a classical experiment, plasma taken from a rat previously subjected to limb ischemia caused the oxidative burst of naive PMNs in vitro (Goldman G 1990), suggesting the role of released humoral factors in this reaction. Intestinal ischemia induces simultaneous increases in intestinal and lung phospholipase A2 activities and PMN accumulation (Koike K 1992), which appear to be also mediated by XOR (Koike K 1993). In another study, IR-induced lung injury appeared to be mediated by complement C5a (Fleming SD 2003).

Several studies have been conducted that involved limb IR. It was shown that limb IR causes systemic inflammatory reactions (Szabó A 2009) and hepatic injury via reactions mediated by circulating proinflammatory cytokines (e.g. TNF- $\alpha$, PAF, IL-1 $\beta$ and IL-6) and activated PMNs (Lawlor DK 1999). Limb ischemia also brings about marked microvascular permeability and hemorrhage in the affected muscle and in the 
remote lung, in association with simultaneous TNF- $\alpha$ and IL-1 release (Seekamp A 1993). Hepatic injury may occur as a remote consequence of limb IR. The damage is characterized by hepatic PMN recruitment via Kupffer cell-dependent activation, and it has been suggested that PMNs are the common link between the two organs (Vega VL 1999).

\subsection{Clinical aspects of limb ischemia}

Most clinical cases of limb ischemia result from chronic peripheral vascular diseases caused by atherosclerosis or diabetes, whereas acute cases are mostly due to arterial thrombosis, embolism, or less frequently trauma or tumors. Acute iatrogenic limb IR occurs during vascular surgery and orthopedic-trauma practice. In the former cases, subrenal clamping of the aorta may cause severe local tissue (primarily muscle) hypoxia, which may further lead to myonephropathic-metabolic syndrome.

In orthopedic-trauma surgery, transient limb ischemia achieved with a tourniquet (wrapping a band around the extremity) is used primarily for emergency or surgical indications. It is frequently applied during elective orthopedic interventions, when the procedures (e.g. autotransplantion or free flap transfer) require a bloodless operative field. The advantages of a tourniquet include a clear operating field, reduced overall blood loss and decreased risk of microemboli at the time of release (Sharma JP 2012). This manuever, however, leads to ischemia of the affected extremity, with the subsequent detrimental effects relating to the inevitable reperfusion phase and consequent iatrogenic IR injury. Along with the targeted bone and surrounding soft tissues, the periosteum is also affected in this process. Apart from important nutritive functions and vessel and nerve content, the periosteum plays an important role in the bone metabolism, mostly via its osteoprogenitor cell content, which is necessary for proper bone healing. The pivotal role of the periosteum is underlined by clinical observations that periosteal damage leads to perturbed bone healing as delayed union or pseudoarthrosis formation (Gustilo RB 1990, Esterhai JL 1991, Utvag SE 1998). Although transient limb ischemia can certainly cause microvascular disturbances in the periosteum (Wolfárd A 2002), the previous studies were mainly focused on the consequences of flow reduction and soft tissue trauma-induced local microcirculatory reactions (Rucker M 2001, Menger MD 2003, Schaser KD 2003), and the microcirculatory reactions in response to IR injury have not been well characterized. 


\subsection{Ischemic preconditioning (IPC)}

\subsubsection{The phenomenon of local IPC}

IPC is a method aimed at increasing the ischemic tolerance of the tissues. During IPC, transient, brief periods of ischemia are followed by short intervals of reperfusion, affording protection against subsequent prolonged and deleterious ischemia. This approach was first described in connection with the heart (Murry CE 1986), but was later demonstrated in many organs (Gho BC 1996, Cheung MM 2006). Ischemic postconditioning was also recently described during the reperfusion period after a sustained ischemic episode (Tsang A 2004), but this topic is not included in the present thesis. The protection afforded by IPC involves the action of several endogenous vasodilator mediators, including NO, adenosine and carbon monoxide (for reviews, see Walsch SR 2007, Tapuria N 2008). One important aspect of IPC is the microcirculatory reaction with protective consequences in the postischemic vasculature (Koti RS 2002, Mallick IH 2005, Starr A 2008). IPC moderates the oxidative burst by decreasing the intracellular production of ROS (Quarrie R 2012) and also extracellular ROS from adherent leukocytes or liver Kupffer cells (Tejima K 2004). IPC downregulates the expression of adhesion molecules responsible for PMN adhesion and transmigration, and hence it alleviates tissue damage (Duda M 2006). As ATP is metabolized rapidly in consequence of an oxygen deficiency during ischemia, adenosine production is increased. The enhanced adenosine release evoked by IPC stimulates endothelial nitric oxide synthase (NOS), leading to NO release, improving the microcirculation and tissue oxygenation (Peralta C 1997). Moreover, IPC activates various intracellular protein kinases (e.g. PKC, p38 MAPK) mediating the gene transcription of proteins that have protective roles in IR (Mitchell MB 1995, Nakano A 2000, Yellon DM 2003). Neurogenic components of this protection have also been demonstrated (Chai W 2006). Human studies have revealed the reduction of postischemic organ injuries, for instance in the liver, where IPC is elicited by intermittent portal inflow occlusion during liver resection (Clavien PA 2000). In experimental settings, IPC exerts protection by affecting the adenosine- and cAMP-dependent pathways, the modulation of intracellular redox homeostasis and the functional activity of the mitochondria (Arai M 2000, Lee WY 2005, Rolo AP 2009).

\subsubsection{Remote IPC (rIPC)}

It has also been demonstrated that IPC has similar favorable effects when it is brought about on other (even distant) organs remote from the one exposed to the major IR 
insult. This phenomenon is called remote ischemic preconditioning (rIPC) or interorgan preconditioning. The first observation, which demonstrated intraorgan preconditioning in the heart (Przyklenk K 1993), was followed by a study presenting a classical rIPC setup when IR of the kidney limited the infarct size of the myocardium (McClanahan TB 1993). Remote effects of IPC were later seen in many other organs, such as the intestine (Wang YP 2002), the kidney (Takaoka A 1999) and the limb (Kharbanda RK 2002). Although the mechanism of rIPC has been investigated intensively, certain biochemical details are still not known. Messenger molecules (e.g. NO, adenosine, bradykinin, opioids, calcitonin gene-related peptide (CGRP), PKC, TNF- $\alpha, \mathrm{NF} \kappa \mathrm{B}, \mathrm{IL}-1 \beta$ and IL-6) taking part in the transmission of protection from the site of IPC to the distant organ have been identified (Küntscher MV 2002, Brzozowski T 2004, Hu S 2012). Within this complex system, humoral and neurogenic pathways may overlap (Wei D 2012). Eventually, rIPC prevents oxidative stress, reduces the permeability and retains the membrane integrity of the mitochondria, and conserves the ATP level of cells in the target organ (Dong HL 2010, Cao Y 2011, Mansour Z 2012). As concerns the liver, the effects of rIPC included ameliorations in aminotransferase levels, improvements in hepatic blood flow and peripheral oxygen saturation and hepatic venous nitrate/nitrite levels (Kanoria S 2006) being additionally mediated by heme oxygenase-1 (Lai IR 2006).

\subsubsection{IPC during orthopedic-trauma surgery: mechanisms and clinical applications}

The IPC of the extremities has numerous clinical advantages as compared with other organs. IPC is relatively easy to perform on limbs or arms, and can be carried out noninvasively. The intervention affects a relatively large tissue mass, and the extent of the exerted defensive mechanism is proportional to it, which means a robust protective signal against the subsequent IR insult. Indeed, previous studies have demonstrated favorable local microcirculatory effects during limb IPC (Szabó A 2009) and a potential neurogenic component of IPC has also been described (Hartmann P 2011), showing that tissue hypoxia and inflammatory mediators produced during IR stimulate transient receptor potential vanilloid receptor-1 expressed by $\mathrm{C}$-afferent neurons, which have a crucial role in the preventive process. This effect may be mediated by the release of neuropeptides such as CGRP, one of the most powerful endogenous vasodilators. Furthermore, rIPC involving IR through the use of a lower extremity was shown to exert marked therapeutic benefit at the heart (Zitta K 2014), the lung (Harkin DW 2002), the kidney (Park KM 2001) and the liver (Kanoria S 2006). 


\subsubsection{The potential role NOXs in ROS-mediated tissue injury and IPC}

Some of the beneficial distant effects of IPC are mediated by changes in gene expression of the cellular redox homeostasis, bringing about a lower degree of ROS in the endothelial compartment (Koti RS 2002, Mallick IH 2005). Signaling processes catalyzed by oxygen and nitrogen radical-producing enzymes, including neuronal and endothelial NOS and XOR (Abu-Amara M 2011, Yuan HJ 2012), have been demonstrated in the action of IPC, and a number of additional data have also established the decisive roles of NOXs (Tejima K 2007, Wang Q 2007). NOXs are members of a family of ROSgenerating enzymes, producing superoxide via electron transfer from the reduced NADPH to molecular oxygen (Babior BM 2002, Lambeth JD 2004, Anilkumar N 2009). NOXs are particularly involved in redox signaling because, among many intracellular sources of superoxide, these are the only known enzymes whose primary function is ROS generation (Lambeth JD 2004). For a long time, NOX-linked superoxide generation was an oddity of phagocytic cells such as PMNs and macrophages (termed NOX2/gp91phox). With variation in the catalytic subunits, the NOXs comprise 7 family members (NOX1 to NOX5 and DUOX1 and DUOX2), which exhibit tissue-specific differences in their baseline expression (Bedard K 2007). In the case of the liver parenchyma, NOX2 and NOX 4 proteins have been found in the hepatocytes; NOX2 predominates in the Kuppfer cells, while NOX4 is more abundant in the microvessels (Bengtsson SH 2003, Ellmark SHM 2005). The expression of NOX4 is at least 20 -fold greater than that of NOX2 in the endothelial cells (Sorescu D 2002), while the expression of NOX2 cannot be detected in the vascular smooth muscle cells (Görlach A 2000, Lassègue B 2001).

NOXs are specifically activated by many stimuli known to cause an endothelial dysfunction (Anilkumar N 2009), and previous studies have provided evidence of elevated mRNA levels of both NOX2 and NOX4 in response to a liver IR injury (Marden JJ 2008). Moreover, the mortality rate due to hepatic ischemia was reduced in NOX2deficient mice (Harada H 2004) and the role of the phagocytic form of NOX in Kupffer cells has been demonstrated after preconditioning with a chemical agent that induces hypoxia (Tejima K 2007). Collectively, these data suggest that influencing NOX4 (derived from hepatocytes and/or vascular cells) and NOX2 (produced by phagocytic PMNs and/or Kuppfer cells) may contribute to the protective mechanism of remote IPC. It can additionally be hypothesized that the effects of rIPC linked to an alleviated inflammatory reaction in the postischemic hepatic microcirculation are associated with NOX2 and NOX4 activation. 


\subsection{Traumatological aspects of osteoporosis}

\subsubsection{Pathogenesis and clinical symptoms of osteoporosis. Possible role of the periosteum in the pathogenesis of osteoporosis}

Osteoporosis is regarded as the most common metabolic bone disease, affecting approximately 750 million people worldwide, with a further tendency to increase in the elderly in both developed and developing countries (Schuiling KD 2011). Every other woman and every fifth man aged 50 years or older will suffer an osteoporotic fracture during their remaining lifetime (Lippuner K 2012).

Osteoporosis originates from a disturbance of the normal bone turnover, where the bone resorption is increased or the bone formation is decreased (or both components are affected) (Raisz LG 2005). The process is characterized by a decrease in bone mineral density, a deterioration of the bone microarchitecture, and progressive weakening of the trabeculae. The gradual loss of bone density and strength results in an increased risk of fractures.

Osteoporosis is generally classified as either primary or secondary. Primary osteoporosis is associated with postmenopausal women and aging. In women, an estrogen deficiency causes several metabolic changes, among them the release of proinflammatory cytokines, such as TNF- $\alpha$, IL-1 and IL-6, leading to bone resorption (Kitazawa R 1994). The age-related osteoporotic changes stem from a low-level and impaired intake of calcium, the compensatory rise of parathyroid hormone, and a decrease in the absorption of vitamin D (Geusens P 2011, Ebeling PR 2014, Li GL 2014).

Secondary osteoporosis affects both women and men at any age. It may be a consequence of various diseases (e.g. leukemia, multiple myeloma or Gaucher's disease), endocrine disorders (e.g. hyperprolactinemia or thyroid diseases) or the association of these pathogenic conditions; different medications too may be related to osteoporosis, including heparin therapy, lithium and glucocorticoids (Gennari C 1998).

Several early studies provided convincing evidence that an imbalance between bone resorption and formation can be suppressed or even prevented by restitution of the premenopausal estrogen levels in females (Christiansen C 1982). The effector cells of these processes originate from mesenchymal osteoprogenitor cells found in the periosteum and endosteum, with the predominant role of the periosteum (Brighton CT 1992). Furthermore, the experimental and clinical evidence points to an important function for the periosteum not only in the pathogenesis of osteoporosis, but also in the effects of different anti-osteoporotic approaches (Allen MR 2004). Since the effector cells of bone 
remodeling originate mainly from the periosteum, this structure plays a decisive role not only in the pathogenesis of osteoporosis, but also during successful bone healing.

\subsubsection{Inflammatory complications related to estrogen loss and replacement}

The systemic and local consequences of an endogenous estrogen loss and exogenous replacement in the circulatory system are ambiguous. The incidence of septic and inflammatory complications is significantly lower in many trauma-hemorrhage conditions in females than in males (Choudhry MA 2005, Sperry JL 2008), and short-term estrogen pretreatment confers significant protection from IR injury and leukocyte activation in males (Burkhardt M 2008). However, other lines of evidence support the notion that estrogen supplementation may increase the risk of intravascular clotting complications in post-menopausal women (Cushman M 2002). Although the underlying mechanistic details are still unclear and the concept is debated (Seelig MS 2004, Canonico M 2008), it is obvious that the skeletal and anti-inflammatory benefits of hormone replacement therapies should be carefully weighed against the possible circulatory side-effects. Given this background, it is important to note that the consequences of chronic estrogen depletion and repletion on the human bone circulation are still unclear. Under compromised flow conditions, the periosteal microcirculation may be a good indicator of the perfusion changes of the whole bone (Kolodny A 1923), but the microcirculatory effects of osteoporosis in this tissue layer are also largely unknown. It has been shown that the patency of the periosteal microcirculation is of particular importance in models of tourniquet application and soft tissue trauma (Zhang L 2003, Varga R 2008). In these cases, both the bone and the periosteum undergo microvascular events reflected by perfusion insufficiencies and severe antigen-independent inflammatory reactions. These processes are mainly initiated by the increased adhesion of PMNs to the microvascular endothelium (rolling and then firm adhesion), followed by their migration to and accumulation in the perivascular tissues (Wolfárd A 2002).

As the prevalence of skeletal injuries increases after the menopause, our studies were designed to determine whether hormonal replacement therapy might be of microcirculatory benefit in this subset of the osteoporotic population. Ovariectomy (OVX) in the rat is a well-established animal model for osteoporosis research, as it shares many similarities with the human disease. These include an increased rate of bone turnover (Wronski TJ 1986), and an initial rapid phase of bone loss and similar skeletal responses to treatment with estrogen, calcitonin, bisphosphonates and many other agents (Fleisch H 1993, Allen MR 2004). 


\section{MAIN GOALS OF THE STUDIES}

The major aim of our study was to examine the local and remote microcirculatory effects of transient lower limb ischemia. We directly observed the periosteal and hepatic microcirculations by intravital microscopy in order to assess the responses to a local IR challenge elicited by tourniquet ischemia.

- In this context, our primary objective was to observe the effects of osteoporosis and the consequences of estrogen therapy in a clinically relevant time frame in rats. To this end, we first determined whether chronic treatment with estrogen influences the OVX-triggered local periosteal microcirculatory reactions. We additionally hypothesized that the periosteal microcirculation in osteoporotic rats would be more sensitive to the detrimental consequences of transient limb ischemia than that in estrogen-treated, age-matching controls. Further we wished to establish whether the microcirculatory protection provided by limb IPC is also effective in an osteopenic situation (elicited by OVX).

- IR injury of the liver has an increasing clinical impact, and remote limb IPC can be a modality through which to overcome a postischemic hepatic injury. Our aim was to investigate the effects of rIPC on the microcirculatory consequences and the underlying molecular mechanisms in the postischemic liver. In this respect, we hypothesized that the changes in NADPH-oxidase expression may contribute to the efficacy of limb IPC. 


\section{MATERIALS AND METHODS}

The experiments were performed in 3 major studies: (1) the microcirculatory effects of chronic estrogen deprivation (elicited by OVX) and estrogen supplementation were examined on the postischemic microcirculatory inflammatory changes in the tibial periosteum after tourniquet ischemia; (2) The effects of limb IPC on the local tibial periosteal microcirculatory consequences were examined in OVX rats; and (3) the effects of rIPC (evoked by limb ischemia) on the postischemic microcirculatory reactions of liver ischemia were assessed in male rats.

\subsection{Animals}

All studies were carried out on Sprague-Dawley rats housed in an environmentally controlled room with a 12-h light-dark cycle, and kept on commercial rat chow (Charles River, Wilmington, MA, USA) and tap water ad libitum. The experimental protocol was approved by the local animal rights protection authorities and followed EC Directive 86/609/EEC and the National Institutes of Health guidelines for the care and use of laboratory animals and was approved by the Animal Welfare Committee of the University of Szeged (\#CSI/01/144/2013).

\subsection{Experimental design and protocols}

\section{Study 1}

3-month-old female animals (weighing 200-210 g) were ovariectomized (Group 1, OVX, $n=12$ ), or sham-operated (Group 2, Sham, $n=6$ ). Five months later (at the age of 8 months), chronic estrogen therapy (Sims NA 1996) was initiated 5 days/week with 20 $\mu \mathrm{g} \mathrm{kg}^{-1}$ subcutaneous $17 \beta$-estradiol (E2, Sigma, St. Louis, MO, USA) in 6 animals of the OVX group (Group 1a). The E2 substitution was continued weekly until the end of the experiments (see time scheme in Figure 1). The remaining OVX (Group 1b) and Sham animals received the vehicle for E2 (100\% ethanol diluted in corn oil) in the same volume. Body weight changes and the development of osteoporosis were continuously followed in the proximal tibiae by means of ultrasonic densitometry (see later). Eleven months after OVX, the animals were subjected to a 60-min complete hindlimb ischemia followed by a 180-min reperfusion period. Limb ischemia was induced by applying a tourniquet around the thigh and a miniclip on the femoral artery. Control hindlimb IR was conducted on another group of 3-month-old female rats (Group 3, n =6). In this group the microcirculatory consequences of limb IR alone were investigated by intravital videomicroscopy (IVM). After a 30-min stabilization period, the baseline cardiovascular 
and microhemodynamic parameters were determined (baseline; $-60 \mathrm{~min}$ ). The periosteal microcirculation was observed every 60 min during the 180-min reperfusion period.

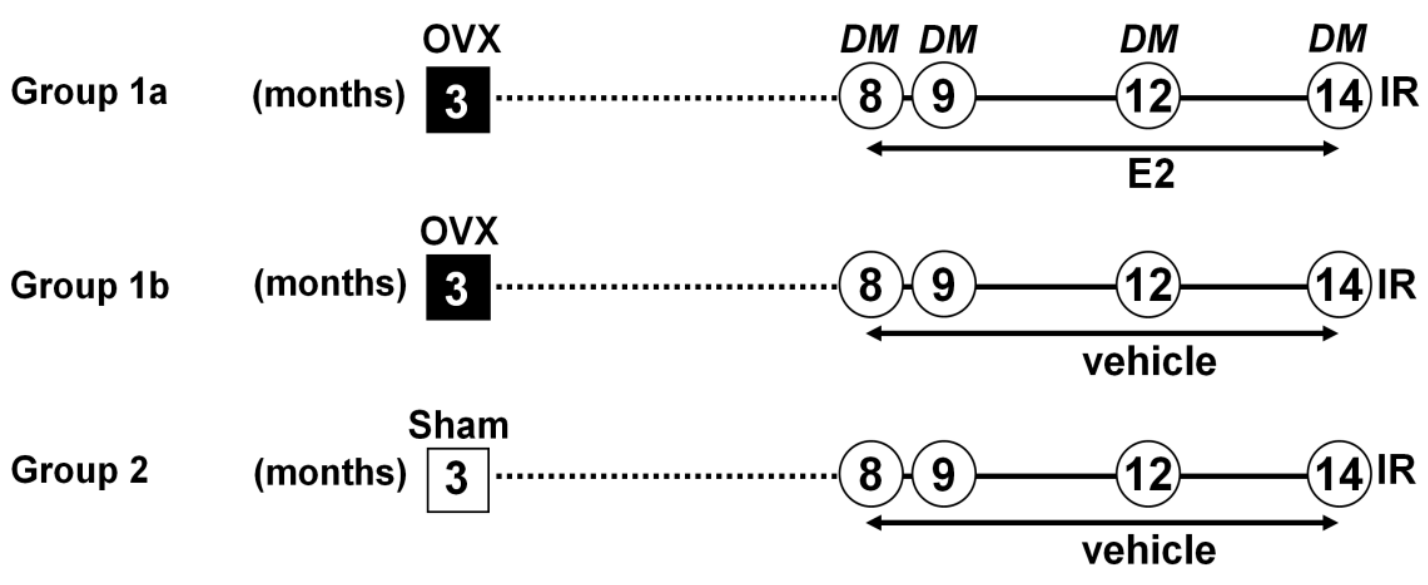

Group 3 (months) 3 IR

Figure 1. The time sequence of surgical interventions, treatments and measurements in Study 1. 3-month-old animals were ovariectomized (Group 1, OVX), or sham-operated (Group 2, Sham). Five months later (at the age of 8 months), chronic estrogen therapy was initiated 5 days/week with $20 \mu \mathrm{g} \mathrm{kg}^{-1} \mathrm{sc} 17 \beta$-estradiol (E2) in 6 animals of the OVX group (Group 1a). The remaining OVX (Group 1b) and Sham animals received vehicle. Densitometric analysis was performed at the marked months of age $(D M)$. At the end of the protocol, $60 \mathrm{~min}$ of tourniqet ischemia followed by $180 \mathrm{~min}$ of reperfusion (IR) was elicited and IVM recordings were performed.

In further groups, (Groups 4a, 4b, 5 and 6), identical protocols (OVX or Sham \pm IR, n $=7-10)$ were performed to detect changes in the proinflammatory cytokine TNF- $\alpha$ concentrations in the plasma and in the expressions of adhesion molecules known to play a role in the process of PMN adhesion to the endothelium. This was necessary because the fluorescent dyes used for IVM interfere with the flow-cytometry technique, and blood samples for the assessment of adhesion molecule expressions were therefore obtained separately. Blood samples from the carotid artery were taken at baseline and during the reperfusion period for the detection of changes in the plasma concentrations of TNF- $\alpha$ and in the expression of the adhesion molecule CD11b. TNF- $\alpha$ levels were determined on plasma samples taken at the 60th min of reperfusion. In a pilot study, the dynamics of the CD11b expression changes in response to limb IR were characterized; significant elevations were not found earlier than 120 or $180 \mathrm{~min}$ in the reperfusion period. Accordingly, this time frame was selected for flow cytometric evaluations of blood 
samples (see later). Tissue biopsies were also taken for the detection of tissue ICAM-1 changes by immunohistochemistry (see later).

\section{Study 2}

In this study, the effects of limb IPC on the local tibial periosteal microcirculatory consequences were examined in OVX rats. To this end, OVX was performed on 3-monthold (weighing 200-210 g) female rats (Group 1, $\mathrm{n}=16$ ) while others were sham-operated (Group 2, $\mathrm{n}=16$ ). Two months later, $60 \mathrm{~min}$ of tourniqet ischemia followed by $180 \mathrm{~min}$ of reperfusion was performed in 8 animals of the OVX group (Group 1a, OVX+IR) and 8 animals in the Sham group (Group 2a, Sham+IR). Two further groups were also subjected to 2 cycles of $10 \mathrm{~min}$ of limb IPC/10 min of reperfusion (Group 1b, OVX+IPC+IR, $\mathrm{n}=8$; Group 2b, Sham+IPC+IR, $n=8$ ) (see scheme in Figure 2).

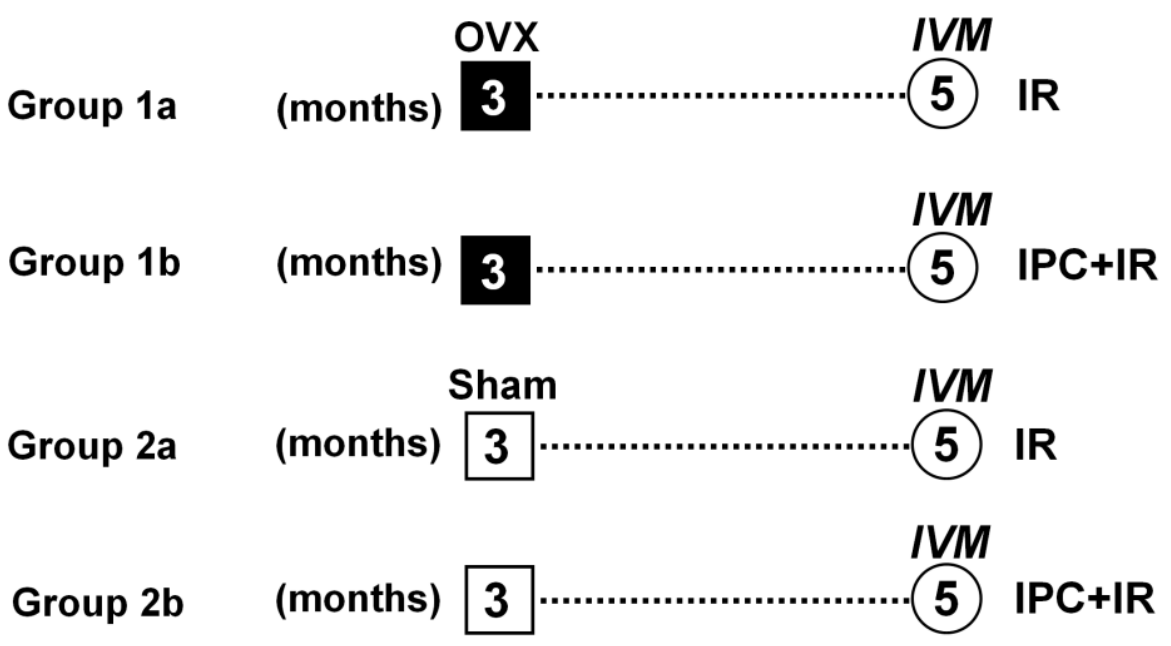

Figure 2. Experimental protocol in Study 2. 3-month-old animals were ovariectomized (Group 1, OVX), or sham-operated (Group 2, Sham). Two months later, $60 \mathrm{~min}$ of tourniqet ischemia followed by 180 min of reperfusion was performed in 8 animals of the OVX group (Group 1a, OVX+IR) and 8 animals in the sham-operated group (Group 2a, Sham+IR). Further two groups were also subjected to 2 cycles of $10 \mathrm{~min}$ of limb IPC / $10 \mathrm{~min}$ of reperfusion (Group 1b, OVX+IPC+IR; Group 2b, Sham+IPC+IR)

CD11b expression on the PMN leukocytes was determined in identical experimental groups, but in a separate experimental series, where blood samples were taken from the carotid artery at baseline and at 120 and 180 min of reperfusion $(n=6$ or 7$)$.

\section{Study 3}

In this study, the microcirculatory and biochemical effects of rIPC (evoked by limb ischemia) on the postischemic inflammatory reactions of liver ischemia were assessed in two major experimental series in male rats. 
In the first series, we evaluated the microcirculatory consequences of partial hepatic ischemia by using the noninvasive modified spectrometric $\mathrm{O} 2 \mathrm{C}$ method $(\mathrm{O} 2 \mathrm{C}$ system, see later). In one group, the hepatic microcirculatory responses to 60-min complete ischemia followed by a 180-min reperfusion period were examined (IR group, $n=6$ ). After recording of the baseline microcirculatory variables $(\mathrm{t}=-100 \mathrm{~min})$, ischemia was induced in the median and left hepatic lobes. The occlusions were then released ( $\mathrm{t}=0 \mathrm{~min})$, and the microcirculation in the affected lobes was observed via $\mathrm{O} 2 \mathrm{C}$ at $\mathrm{t}=60,120$ and 180 min in the reperfusion phase. In another group, two cycles of 10-min complete hindlimb ischemia and 10-min reperfusion were used as a preconditioning trigger before the induction of liver ischemia (rIPC+IR group, $n=6$ ). The animals in a third group were subjected to the same surgical procedures, except for the induction of liver or limb ischemia (Sham group, $\mathrm{n}=6$ ). Blood samples for biochemical determinations were taken at $\mathrm{t}=0,60,120$ and $180 \mathrm{~min}$ of the experiments. Tissue biopsies for enzyme activity and Western-blot analyses were taken at the end of the experiments. Tissue biopsies were stored at $-80{ }^{\circ} \mathrm{C}$, and plasma samples at $-20{ }^{\circ} \mathrm{C}$ until later analysis.

In the second series of experiments, the groups $(n=6$ each) and the protocols were identical with those in the first series, with the exception that the microcirculation in the affected liver lobes was investigated by means of IVM (see later) at $\mathrm{t}=60 \mathrm{~min}$ in the reperfusion phase.

\subsection{Quantitative ultrasound bone densitometry}

Animals were anesthetized with an intraperitoneal combination of ketamine and xylazine ( $25 \mathrm{mg} \mathrm{kg}^{-1}$ and $75 \mathrm{mg} \mathrm{kg}^{-1}$, respectively) and bone density measurements were performed at the tibia and the tail with a DBM-Sonic 1200 (IGEA, Carpi, Italy) ultrasonic bone densitometry device in Study 1 . The changes in the average of the amplitudedependent speed of sound (AD-SoS) were determined (Joly J 1999). After calibration, the $\mathrm{AD}-\mathrm{SoS}$ values of the soft tissues (the muscle and skin above the thigh) were determined, and the system deducted this value from the bone density. The AD-SoS values were calculated via a computer program and the average of 5 measurements was used at each time point. Twenty-one weeks after OVX, statistically significant density alterations were observed in the proximal tibia, and this location was therefore used for further quantitative ultrasound measurements at the ages of 8, 9, 12 and 14 months. 


\subsection{Surgical procedures}

\section{Surgical procedure of $O V X$}

Under ketamine-xylazine anesthesia (as discussed earlier), a median laparotomy was performed under sterile conditions. The connection of the Fallopian tubes was cut between hemostats, the ovaries were removed, and the stumps were then ligated. Thereafter, the abdomen was filled with warm sterile physiological saline and the abdominal wall was closed in two layers. Sham-operated animals underwent identical procedures except that the Fallopian tubes and ovaries remained intact.

\section{Preparation of animals before IVM}

IVM examinations of the tibial periosteum (Study 1 and 2) were performed under sodium pentobarbital (45 $\mathrm{mg} \mathrm{kg}^{-1}$ ip) anesthesia and sustained with small supplementary intravenous doses when necessary. In the case of liver examinations, however, anesthesia was induced with a combination of $25 \mathrm{mg} \mathrm{ml}^{-1}$ (S)-ketamine (Ketanest; Parke Davis, Berlin, Germany) and $20 \mathrm{mg} \mathrm{ml}^{-1}$ xylazine (Rompun; Bayer, Leverkursen, Germany) in a ratio of 8:1, injected ip and sustained with small supplementary iv doses every $30 \mathrm{~min}$. The right carotid artery and the jugular vein were cannulated for the measurement of mean arterial pressure and the administration of drugs and fluids, respectively. The animals were placed in a supine position on a heating pad to maintain the body temperature between 36 and $37^{\circ} \mathrm{C}$. Ringer's lactate was infused at a rate of $10 \mathrm{ml} \mathrm{kg}^{-1} \mathrm{~h}^{-1}$ during the experiments. The trachea was cannulated to facilitate respiration.

\section{Preparation of the tibial periosteum for IVM measurements in rats}

The medial/anterior surface of the left tibia was exposed by means of an atraumatic surgical technique where the skin above the anterior tibia was dissected, the anterior gracilis muscle was cut completely through with microscissors, and the connective tissue covering the tibial periosteum was carefully removed via an atraumatic microsurgical approach (under a Zeiss 6× magnification operating microscope) (Varga R 2008).

\section{Preparation of the liver for IVM measurements in rats}

After midline laparotomy and bilateral subcostal incisions, the liver was carefully freed from all ligamentous attachments and was exposed, and the left branches of the portal vein and the hepatic artery were mobilized. Complete ischemia of the median and left hepatic lobes was achieved by clamping the left lateral branches of the hepatic artery and the portal vein with a microsurgical clip for $60 \mathrm{~min}$ (Taniguchi M 2007). After the ischemic period, the clips were removed and the wound was temporarily covered with water-impermeable foil. 


\subsection{Microcirculatory measurements}

\section{IVM - technical setup}

The right hindlimb with the exposed tibial periosteum (in Studies 1 and 2) or the exteriorized posterior surface of the left liver lobe (Study 3) was positioned horizontally on an adjustable stage for examination of the microcirculation by IVM (Zeiss Axiotech Vario 100HD microscope, 100W HBO mercury lamp, Acroplan 20× water immersion objective, Carl Zeiss GmbH, Jena, Germany). Microcirculation was visualized with fluorescein isothiocyanate (Sigma, St. Louis, MO, USA)-labeled erythrocytes ( $0.2 \mathrm{ml}$ iv), whereas leukocytes were labeled with an iv injection of rhodamine 6G (Sigma, St. Louis, MO, USA, $0.2 \%, 0.1 \mathrm{ml} \mathrm{iv})$. The microscopic images were recorded with a chargecoupled device video camera (Teli CS8320Bi, Toshiba Teli Corporation, Osaka, Japan) attached to an S-VHS video recorder (Panasonic AG-MD 830, Matsushita Electric Industrial Co., Tokyo, Japan) and a personal computer.

IVM - video analysis

Quantitative assessment of the microcirculatory parameters was performed off-line by frame-to-frame analysis of the videotaped images, using image analysis software (IVM, Pictron Ltd., Budapest, Hungary). As for the periosteum, leukocyte-endothelial cell interactions were analyzed within 5 postcapillary venules (diameter between 11 and $20 \mu \mathrm{m})$ per animal. In case of the liver, leukocyte adherence was assessed in the postsinusoid venules (diameter between 20 and $40 \mu \mathrm{m}$ ). Adherent leukocytes (stickers) were defined in each vessel segment as cells that did not move or detach from the endothelial lining within an observation period of $30 \mathrm{~s}$, and are reported as the number of cells per $\mathrm{mm}^{2}$ of endothelial surface. Rolling leukocytes were defined as cells moving at a velocity less than $40 \%$ of that of the erythrocytes in the centerline of the microvessel, and given as the number of cells/vessel circumference in $\mathrm{mm}$.

Modified lightguide spectrophotometry $(\mathrm{O} 2 \mathrm{C})$

In Study 3, the O2C system (LEA Medizintechnik, Gießen, Germany) was used for noninvasive and online examinations of the microcirculation; this allows the simultaneous recording of tissue oxygen saturation ( $\mathrm{S}_{\mathrm{O} 2}$ percentage, absolute value), tissue hemoglobin (rHb, AU), capillary blood flow (AU) and capillary blood flow velocity (RBCV, AU). The $\mathrm{O} 2 \mathrm{C}$ device combines white light spectroscopy with laserDoppler measurement in one flat probe. To prevent the influence of regional heterogeneity and temporal blood flow variations, measurements were performed at three 
predetermined locations on the liver surface for $30 \mathrm{~s}$ each with an ambient light correction before measurement (Schreinemachers MC 2009).

\subsection{Immune labeling and flow cytometric analysis of adhesion molecule CD11b expression of PMNs}

The surface expression of CD11b on the peripheral blood PMNs was determined through flow-cytometric analysis of whole blood in duplicate (Varga R 2008). $100 \mu$ of whole blood was incubated with $20 \mu \mathrm{l}$ of $\left(50 \mu \mathrm{g} \mathrm{ml}^{-1}\right)$ mouse anti-rat monoclonal antibody (BD Pharmingen, San Jose, CA, USA) for $20 \mathrm{~min}$. Negative controls were obtained by omitting the monoclonal antibody. The cells were then washed twice in Hanks buffer and centrifuged at 13,000 rpm for $5 \mathrm{~min}$, and the resuspended pellet was incubated with fluorescein isothiocyanate-conjugated polyclonal rabbit anti-mouse immunoglobulin $\left(10 \mu \mathrm{g} \mathrm{ml}^{-1}\right.$; DAKO Cytomation, Glostrup, Denmark; 20- $\mu$ l aliquots of reagents to $180-\mu 1$ aliquots of blood cells). The cells were again washed twice, and the erythrocytes were lysed with a Lysing kit (Biodesign, Saco, ME, USA), after which the cells were washed twice again $(6000 \mathrm{rpm}, 5 \mathrm{~min})$ and resuspended in $200 \mu \mathrm{l}$ of Hanks buffer. Computer-assisted FACStar Plus Becton-Dickinson equipment was used for cytometry; the granulocytes were gated on the basis of their characteristic forward and sidescatter features. Generally 10,000 events per sample were collected and recorded; the percentages of labeled (activated) granulocytes (relative to the overall marker-bearing cells) and the mean fluorescence intensity (average marker density) were calculated.

\subsection{Determination of plasma TNF- $\alpha$ and high-mobility group protein B1 (HMGB1) levels}

Blood samples $(0.5 \mathrm{ml})$ were taken from the carotid artery into precooled EDTAcontaining polypropylene tubes, centrifuged at $1000 \mathrm{~g}$ for $30 \mathrm{~min}$ at $4{ }^{\circ} \mathrm{C}$, and then stored at $-70{ }^{\circ} \mathrm{C}$ until assay. Proinflammatory cytokine TNF- $\alpha$ and HMGB1 concentrations were determined in plasma samples with commercially available enzyme-linked immunosorbent assays (Quantikine Ultrasensitive ELISA kit for rat TNF- $\alpha$; Biomedica Hungaria Kft, Hungary and Shino-Test Corporation ELISA kit for HMGB1; Kanagawa, Japan).

\subsection{Liver transaminase release determined in plasma samples}

Blood samples withdrawn from the carotid artery were analyzed for aspartateaminotransferase (AST), alanine-aminotransferase (ALT) and lactate-dehydrogenase (LDH) by standard photometric procedures (Vitros 250 analyzer, Ortho-Clinical Diagnostics, Raritan, NJ, USA). 


\subsection{Liver XOR activity}

Tissue biopsies were homogenized in phosphate buffer ( $\mathrm{pH} 7.4$ ) containing $50 \mathrm{mM}$ Tris.HCl, $0.1 \mathrm{mM}$ EDTA, $0.5 \mathrm{mM}$ dithiotreitol, $1 \mathrm{mM}$ phenylmethylsulfonyl fluoride, 10 $\mu \mathrm{g} \mathrm{ml}{ }^{-1}$ soybean trypsin inhibitor and $10 \mu \mathrm{g} \mathrm{ml}^{-1}$ leupeptin. The homogenate was centrifuged at $4{ }^{\circ} \mathrm{C}$ for $20 \mathrm{~min}$ at $24,000 \mathrm{~g}$ and the supernatant was loaded into centrifugal concentrator tubes. The activity of XOR in the ultrafiltered supernatant was determined by fluorometric kinetic assay based on the conversion of pterine to isoxanthopterine in the presence (total XOR) or absence of the electron acceptor methylene blue (XOR activity) (Beckman JS 1989)

\subsection{Liver myeloperoxidase (MPO) activity}

Tissue MPO activity was measured in liver biopsies by the method of Kuebler WM (1996). Briefly, the tissue was homogenized with Tris.HCl buffer (0.1 M, pH 7.4) containing $0.1 \mathrm{M}$ polymethylsulfonyl fluoride to block tissue proteases, and then centrifuged at $4{ }^{\circ} \mathrm{C}$ for $20 \mathrm{~min}$ at $24,000 \mathrm{~g}$. The MPO activities of the samples were measured at $450 \mathrm{~nm}$ (UV-1601 spectrophotometer; Shimadzu, Japan), and the data were referred to the protein content.

\subsection{Western blot analysis of liver NOX2 and NOX4 protein expression}

Liver samples were homogenized and then lyzed with RIPA buffer (Santa Cruz Biotech). Protein extracts $\left(20 \mu \mathrm{g}\right.$ of total protein) were heated at $95{ }^{\circ} \mathrm{C}$ for $10 \mathrm{~min}$, then placed in ice to cool, electrophoresed in $4-15 \%$ gradient sodium dodecyl sulfatepolyacrylamide gels, and transferred onto nitrocellulose membranes. Membranes were blocked with TRIS-buffered saline (TBS) and 5\% skim milk at room temperature for $1 \mathrm{~h}$ prior to overnight incubation at $4{ }^{\circ} \mathrm{C}$ with primary antibodies against gp91phox (NOX2) (1:2000 dilution; Epitomics, Burlingame, CA, USA), and NOX4 (1:2000 dilution; Epitomics, Burlingame, CA, USA). After washing with TBS-Tween 20, membranes were incubated for $1 \mathrm{~h}$ at room temperature with horseradish peroxidase-conjugatecorresponding secondary antibodies (anti-rabbit, (1:2500 dilution; Promega, Madison, WI, USA). The membranes were then developed with the SuperSignal West Pico horseradish peroxidase substrate kit (Pierce, Rockford, IL, USA) and the intensities of protein bands were quantitated and photographed on a Lumi-Imiger ${ }^{\mathrm{TM}}$ (RocheDiagnostics, Boehringer Mannheim, Germany) image station. For the control of sample loading and protein transfer, the membranes were stripped and reprobed with $\beta$-actin antibody (1:1000 dilution; Sigma-Aldrich, St. Louis, MO, USA). 


\subsection{Detection of tissue ICAM-1 by immunohistochemistry}

At the end of the experiments, both the limb subjected to IR and the contralateral one were removed and the tibias and the surrounding muscles were fixed in $4 \%$ phosphatebuffered formalin for 2-3 days in Study 1. The tissues were then decalcified with an electrophoretic apparatus (for $2 \times 4 \mathrm{~h}$ ), using a special decalcifying solution (Sakura TDE30; Sakura Finetek Corp. Torrance, CA, USA). The samples were embedded in paraffin, and 4- $\mu \mathrm{m}$ sections were placed on silanized slides. After conventional methods of dewaxing and rehydration (initiated in xylene, followed by decreasing concentrations of ethanol and methanol), tissue endogenous peroxidase was blocked with a mixture of methanol and $1 \% \mathrm{H}_{2} \mathrm{O}_{2}$ for $5 \mathrm{~min}$, and the nonspecific tissue antigens with conventional $2.8 \%$ cow milk. For ICAM-1 immunohistochemistry, mouse monoclonal anti-rat ICAM-1 antibody (BD Pharmingen, BD Biosciences, San Jose, CA, USA) was used as primary antibody (1:200; $30 \mathrm{~min})$, this being followed by a biotinylated goat anti-mouse antibody conjugated to HRP polymer (Envision ${ }^{\circledR}$ System; Dako, Glostrup, Denmark) for $30 \mathrm{~min}$, which employs 3,3'-diaminobenzidine as chromogen. The sections were counterstained with hematoxylin (for $1 \mathrm{~min}$ ) and examined by two independent histologists by means of light microscopy at $200 \times$ magnification. During the semiquantitative analysis, periosteal and intramuscular vessels were evaluated separately and the percentage of ICAM-1positive vessels was calculated. The samples were allotted to one or other of the following semiquantitative categories (scores 1-8) (Table 1).

\begin{tabular}{|l|l|l|}
\hline Score & \% of ICAM-1-positive vessels & Staining \\
\cline { 1 - 1 } 1 & \multirow{2}{*}{$55 \%$} & local \\
\cline { 1 - 1 } 2 & \multirow{2}{*}{$5-25 \%$} & diffuse \\
\hline 3 & \multirow{2}{*}{$25-50 \%$} & local \\
\cline { 1 - 1 } & & diffuse \\
\hline 5 & \multirow{2}{*}{$>50 \%$} & local \\
\cline { 1 - 1 } 5 & & diffuse \\
\hline 7 & & local \\
\cline { 1 - 1 } & & diffuse \\
\hline 8 & & \\
\hline
\end{tabular}

Table 1. Semiquantitative scoring system for the analysis of ICAM-1-positive vessels from periosteal samples processed for immunohistochemistry 


\subsection{Statistical analyses}

All data are expressed as means \pm standard error of the mean (SEM). Data analysis was performed with the SigmaStat statistical software (Jandel Corporation, San Rafael, CA, USA). For microcirculatory variables and bone density data, differences within and between groups were analyzed by analysis of variance (ANOVA) followed by the Bonferroni test. Changes in microcirculatory parameters and liver enzyme activities between groups and within groups were analyzed by two-way ANOVA or two-way RM ANOVA, followed by the Bonferroni test. For the evaluation of biochemical assays and ELISA data, changes in variables between groups were analyzed by ANOVA on ranks, followed by the Holm-Sidak test. Western blot data were analyzed with non-normal distribution by the Mann-Whitney test. $P$ values $<0.05$ were regarded as significant. 


\section{RESULTS}

\subsection{Effects of $O V X$ and chronic estrogen therapy on bone density and postischemic}

tibial periosteal inflammatory reactions

As shown by bone densitometry on the proximal tibia (Study 1), osteoporosis had developed by 21 weeks after bilateral OVX. The AD-SoS was significantly lower than that for the Sham animals $\left(1674 \pm 33 \mathrm{~ms}^{-1}\right.$ vs $1850 \pm 101 \mathrm{~ms}^{-1}$, respectively). The OVXinduced osteopenia was completely restored by E2 therapy (Figure 3).

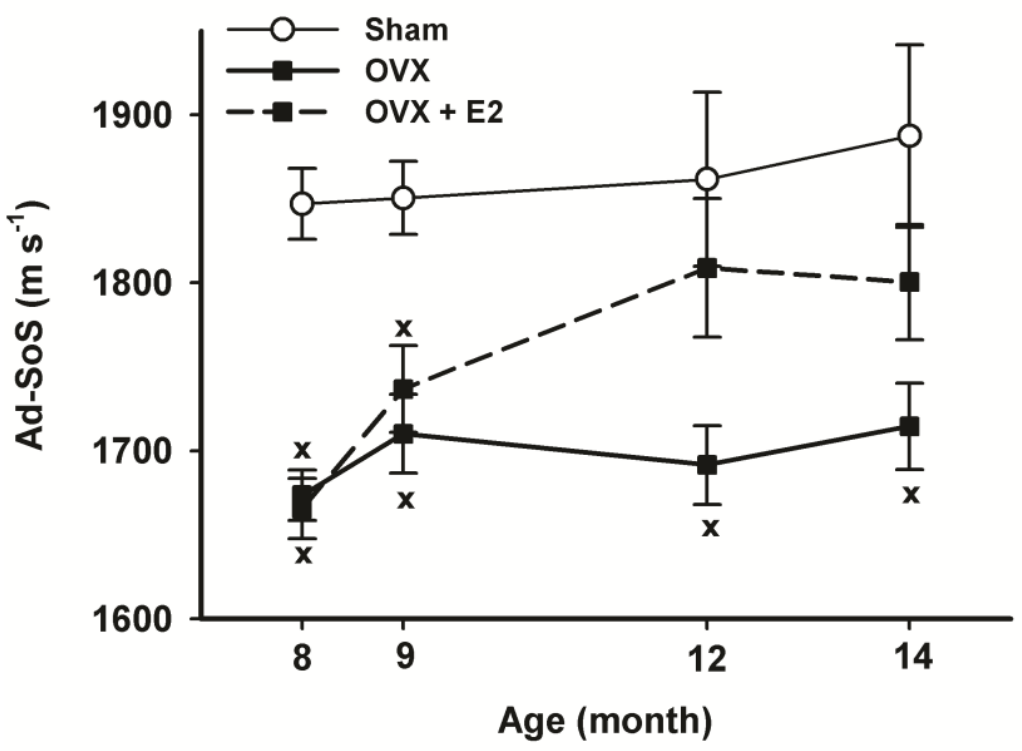

Figure 3. Bone density changes in the proximal part of the tibia in Sham animals or OVX animals treated with E2 $(\mathrm{OVX}+\mathrm{E} 2)$ or vehicle $(\mathrm{OVX})$. Data are expressed as Ad-SoS and presented as means \pm SEM ANOVA was followed by the Bonferroni test. ${ }^{\mathrm{X}} P<0.05$ vs Sham group.

The number of firmly adherent (sticking) leukocytes was significantly increased in the postcapillary venules of the tibial periosteum in the 3-month-old controls, the Sham rats and the OVX animals at the end of the reperfusion phase (120 and $180 \mathrm{~min}$ ). This phenomenon was nearly completely prevented by chronic E2 supplementation in the OVX animals (Figure 4). 


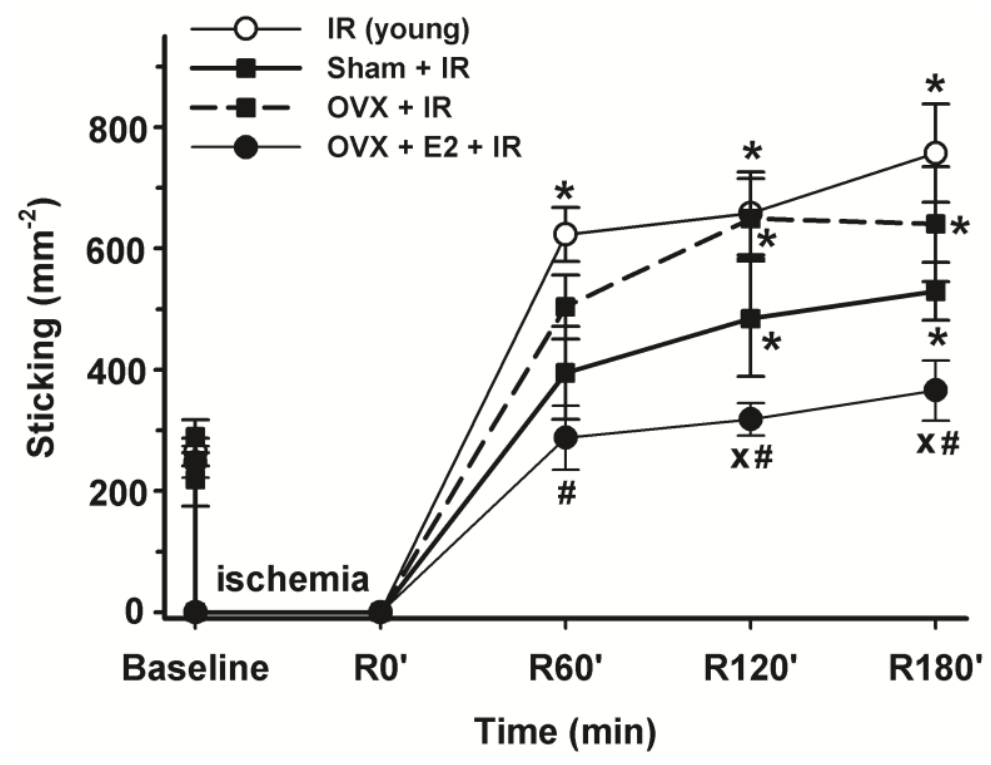

Figure 4. Secondary leukocyte-endothelial cell interactions (sticking) in the postcapillary venules of the tibial periosteum after $60 \mathrm{~min}$ of limb ischemia followed by $180 \mathrm{~min}$ of reperfusion (IR). Values in Sham+IR, OVX+E2+IR or OVX+IR animals were compared with those in 3-month-old (young) female rats (IR). Data are presented as means \pm SEM. ANOVA was followed by the Bonferroni test. ${ }^{*} P<0.05$ vs baseline, ${ }^{\mathrm{X}} P<0.05$ vs OVX+IR group, ${ }^{\#} P<0.05$ vs IR group.

An increased surface expression of adhesion molecule CD11b was observed after 120 and 180 min of reperfusion; no major differences could be detected between the findings for the OVX and the Sham or the 3-month-old rats (Figure 5). Chronic E2 administration did not influence this parameter.

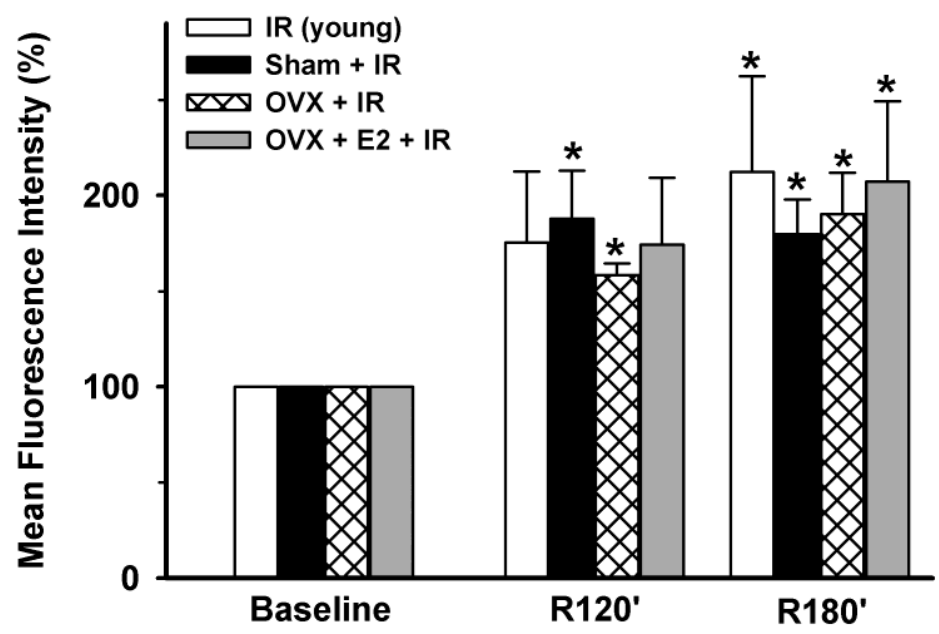

Figure 5. Changes in expression of the CD11b adhesion molecule on the surface of PMNs in response to $60 \mathrm{~min}$ of limb ischemia followed by $180 \mathrm{~min}$ of reperfusion. Values for Sham+IR, OVX+E2+IR or OVX+IR animals were compared with those for 3-month-old (young) female rats (IR). Data are presented as means \pm SEM. ${ }^{*} P<0.05$ vs baseline. 
The plasma TNF- $\alpha$ had reached similar concentrations (young animals: $21.24 \pm 3.30$ pg ml${ }^{-1}$; Sham: $22.16 \pm 5.79 \mathrm{pg} \mathrm{ml}^{-1}$; OVX: $19.84 \pm 1.35 \mathrm{pg} \mathrm{ml}^{-1}$ ) by the 60th min of reperfusion. E2 treatment, however, resulted in a significantly lower TNF- $\alpha$ value $\left(\mathrm{OVX}+\mathrm{E} 2: 11.14 \pm 1.19 \mathrm{pg} \mathrm{ml}^{-1}\right)$ as compared with that for the OVX-challenged rats $(P<$ 0.05). No TNF- $\alpha$ was detected in control samples taken before the ischemic insult.

As assessed by immunohistochemical analysis (Figure 6), the tissue ICAM-1 density in the vessels of the periosteum was significantly higher in the limbs subjected to IR (young animals: $1.67 \pm 0.67$; Sham: $1.83 \pm 0.60$; OVX: $2.17 \pm 0.48$; OVX+E2: $2.0 \pm$ 0.52) than in the intact contralateral limbs in all the experimental groups (young animals: $0.33 \pm 0.21$; Sham: $0.50 \pm 0.22$; OVX: $0.67 \pm 0.21, \mathrm{OVX}+\mathrm{E} 2: 0.50 \pm 0.22)$. The intensity of the IR-induced ICAM-1-positive reaction was only moderate in the muscle tissue, and the data for the 3-month-old controls, the Sham, the OVX and the OVX+E2 animals were also similar.
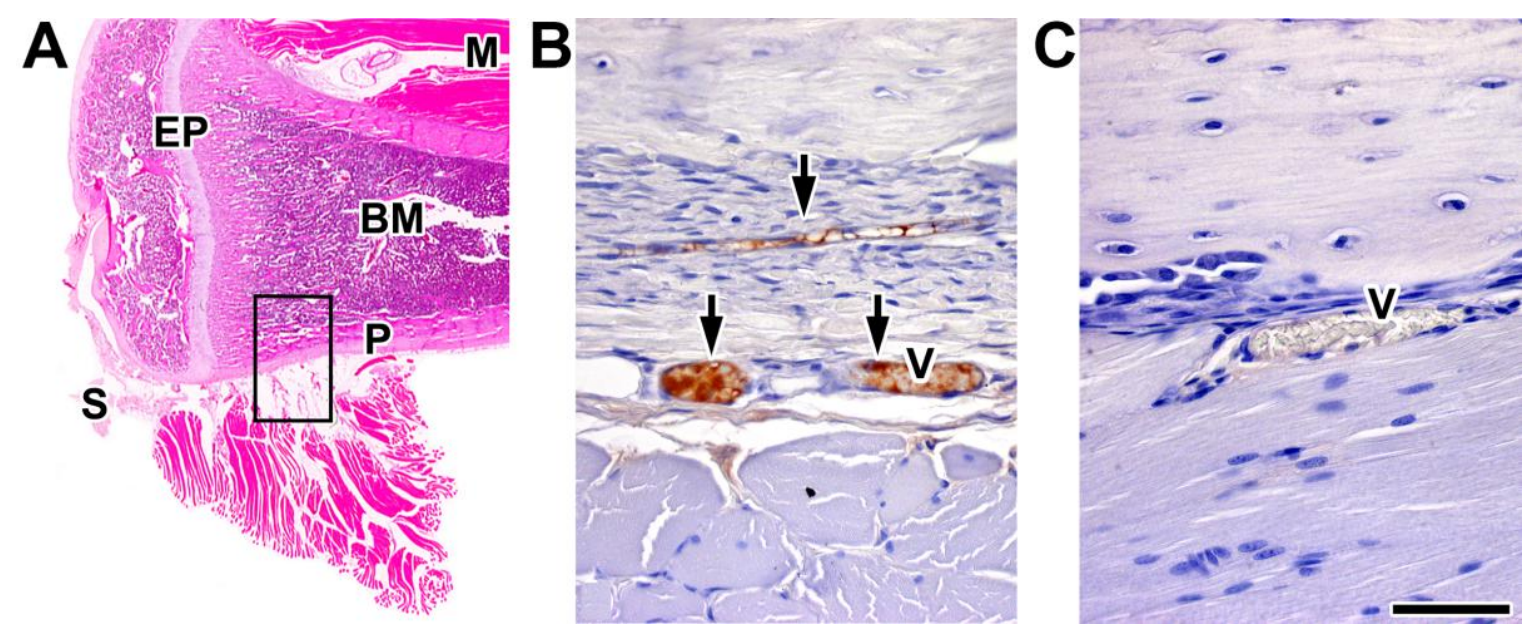

Figure 6. Representative longitudinal section of the rat tibia surrounded by soft tissues (stained with ICAM-1 antibody plus hematoxylin). Left panel (A): tibial epiphysis (EP), bone marrow (BM), knee-joint synovia (S), muscle (M) and tibial periosteum (P) are indicated. Middle panel: positive staining for ICAM-1 (arrows) was found in the periosteal venules (V) after IR (B), but not in the contralateral (non-IR) limbs $(\mathbf{C})$. Bar represents $50 \mu \mathrm{m}$.

\subsection{Effects of local IPC on the postischemic tibial periosteal microcirculatory inflammatory reactions in the presence of estrogen depletion}

As compared with the baseline values, the numbers of primary PMN-endothelial interactions (termed rolling) were increased at all examined timepoints (120 and $180 \mathrm{~min}$ ) of reperfusion after limb IR in all groups in the postcapillary venules of the tibial periosteum (Figure 7A). When limb IR was combined with local IPC in the 
Sham+IPC+IR group, significantly lower rolling values were observed than when only limb IR was induced (Sham+IR group). In the OVX animals, however, the reduction caused by IPC was significantly lower (OVX+IPC+IR group). Secondary leukocyteendothelial cell interactions (sticking) were similar to those seen at rolling; no effect of IPC was evidenced in the OVX+IPC+IR group (Figure 7B).
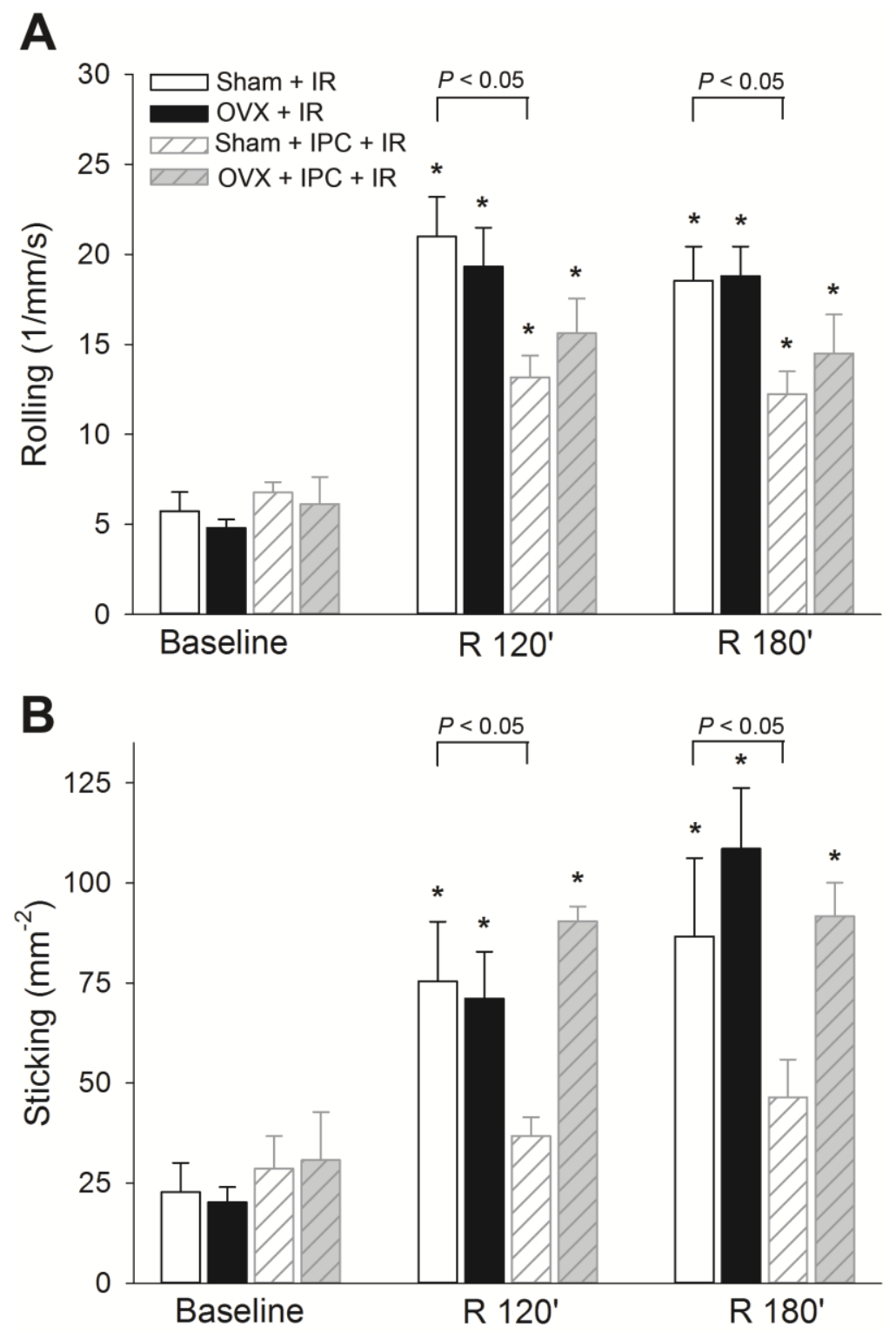

Figure 7. Primary (rolling) and secondary (sticking) leukocyte-endothelial cell interactions in the postcapillary venules of the tibial periosteum after $60 \mathrm{~min}$ of limb ischemia. Values for the Sham+IR and OVX+IR rats were compared with those for the Sham+IPC+IR and OVX+IPC+IR animals. Data are presented as means \pm SEM. Two-way RM ANOVA was followed by the Bonferroni test. ${ }^{*} P<0.05$ vs baseline.

CD11b expression changes used as measures of PMN activation showed markedly enhanced values during reperfusion (120 and $180 \mathrm{~min}$ ) in response to the limb IR insult in 
both groups (Figure 8). Neither OVX+IR nor OVX+IPC caused attenuation of this parameter.

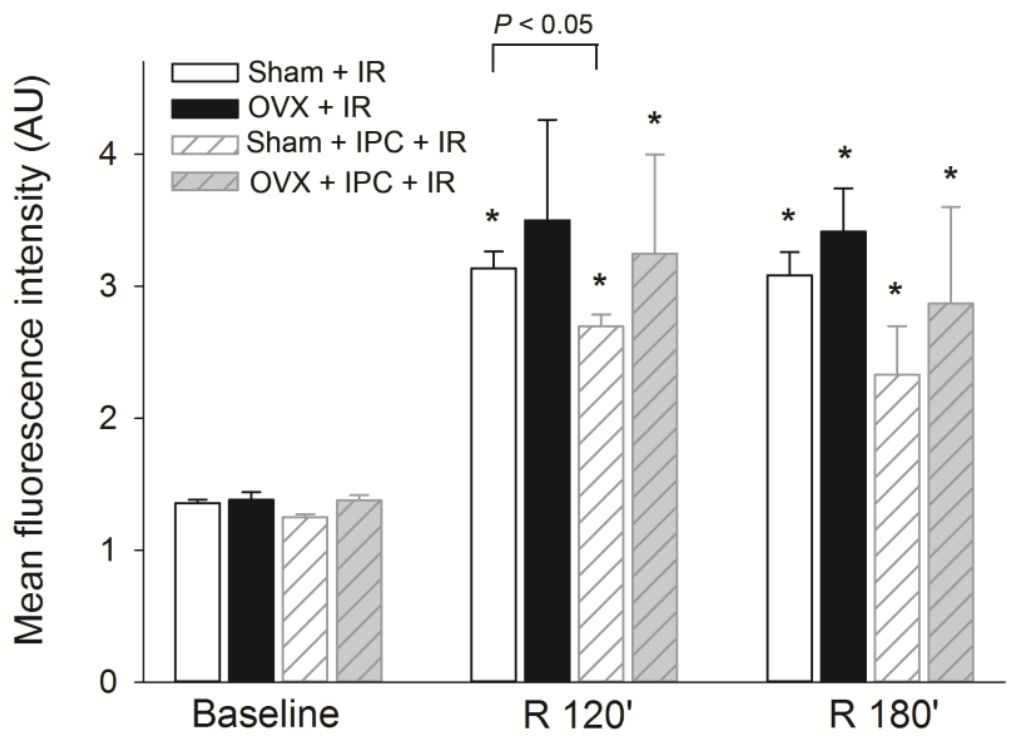

Figure 8. Expression changes of the CD11b adhesion molecule on the surface of PMNs after $60 \mathrm{~min}$ of limb ischemia, followed by $180 \mathrm{~min}$ of reperfusion. Values for Sham+IR and OVX+IR rats were compared with those for Sham+IPC+IR and OVX+IPC+IR animals. Data are presented as means \pm SEM. Two-way RM ANOVA was followed by the Bonferroni test. ${ }^{*} P<0.05$ vs baseline.

\subsection{Effects of rIPC on inflammatory consequences of partial liver IR}

\section{Hepatic microcirculatory dysfunction}

The microhemodynamic parameters, capillary blood flow, $\mathrm{RBCV}, \mathrm{S}_{\mathrm{O} 2}$ and $\mathrm{rHb}$ were assessed simultaneously and on-line in the left liver lobes (Figure 9). Reperfusion after 60-min ischemia was not associated with significant changes in intrahepatic blood flow (Figure 9A) as compared with the Sham group. When IR was preceded by rIPC, however, the postischemic hepatic blood flow was significantly higher than the pre-ischemic values throughout the examination period. The RBCV in the IR group was significantly lower during reperfusion in comparison with the pre-ischemic values, and no recovery was observed during the examination period (Figure 9B). rIPC, however, reversed the RBCV changes to the level measured in the Sham group. Taken together, the flow and velocity changes caused by the 60-min partial ischemia were manifested in deteriorated levels of tissue $\mathrm{S}_{\mathrm{O} 2}$ and $\mathrm{rHb}$, which were restored by the rIPC protocol (Figure 9C,D). 

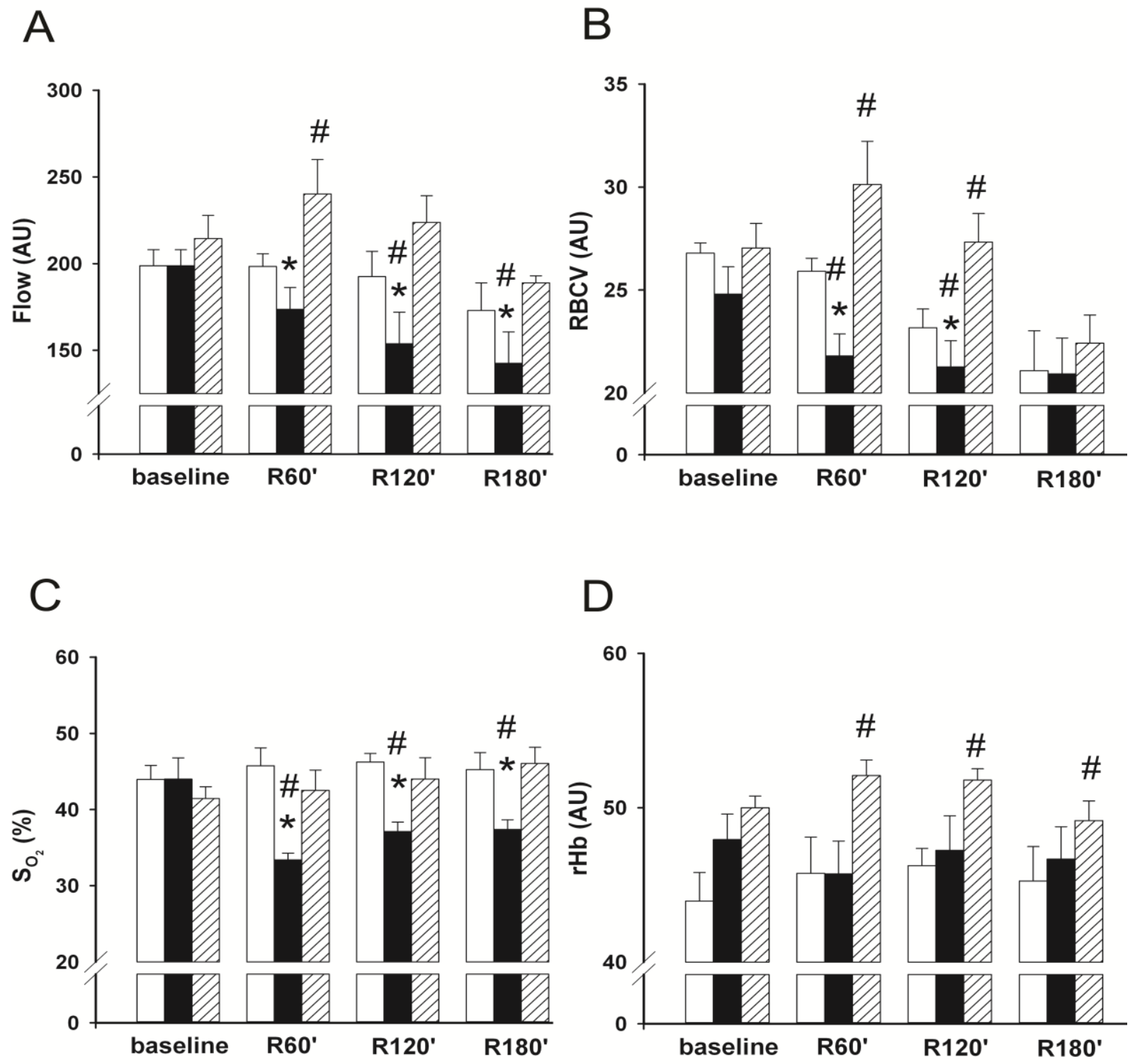

Figure 9. The animals were sham-operated (Sham group, white columns) or subjected to $60 \mathrm{~min}$ partial hepatic ischemia followed by $180 \mathrm{~min}$ of reperfusion (IR group, black columns), or two cycles of 10-min complete hindlimb ischemia followed by a 10-min reperfusion period were applied as a preconditioning trigger before liver ischemia (rIPC+IR group, striated columns). Capillary blood flow, $\mathrm{RBCV}$ and $\mathrm{rHb}$ are given in arbitrary units (AU) (Figure 9A,B,D), and $\mathrm{S}_{\mathrm{O} 2}$ in percentage (\%) (Figure 9C). Data are presented as means \pm SEM. Two-way RM ANOVA was followed by the Bonferroni test. ${ }^{*} P<0.05$ vs baseline; ${ }^{\#} P<0.05$ vs Sham group.

Due to the lack of selectin molecules in the post-sinusoidal endothelium, "classical rolling" could not be observed, but the number of PMNs exhibiting the rolling phenomenon could nevertheless be determined in the central venules. Liver IR was accompanied by an approximately 4-fold increase in the number of rolling leukocytes relative to that of the Sham animals (Figure 10A). In accordance with this, the number of sticking cells also displayed a significant increase in response to liver IR (Figure 10B). rIPC resulted in significant improvements in both forms of cell-to-cell interactions. 

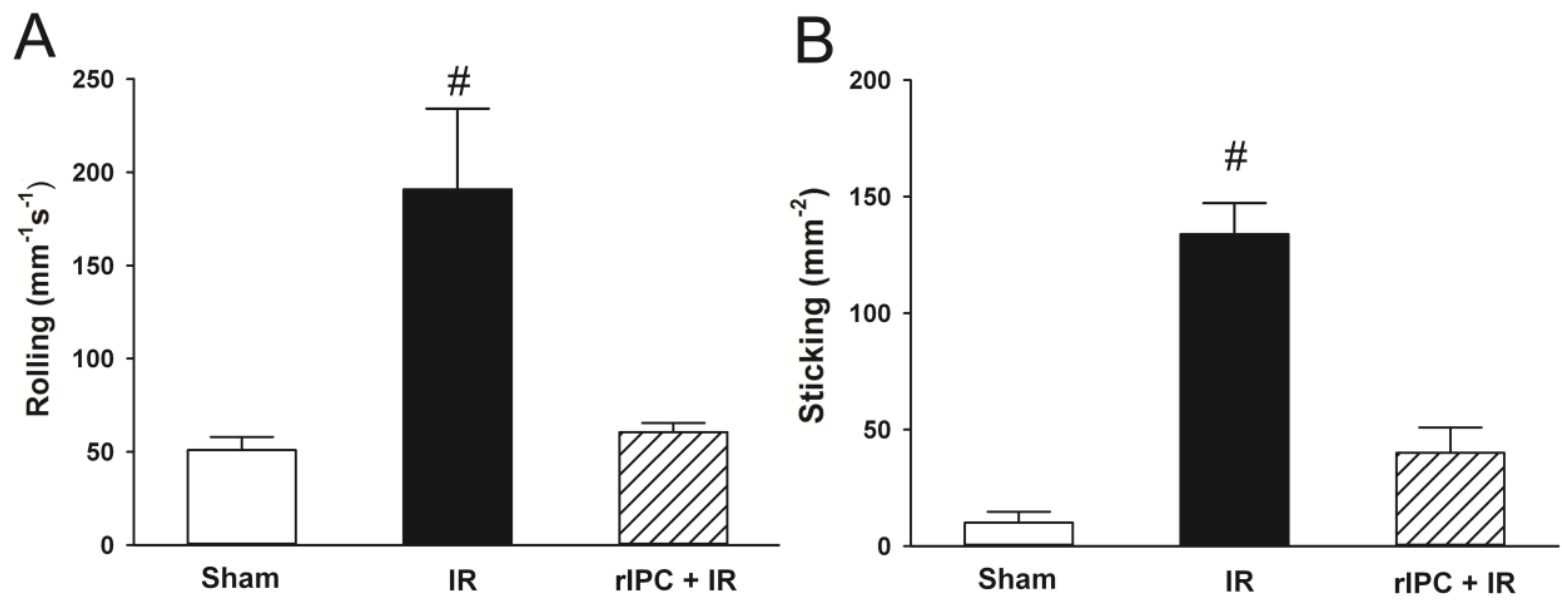

Figure 10. Changes in PMN-endothelial interactions at $60 \mathrm{~min}$ of reperfusion. Numbers of rolling (A) and sticking (B) leukocytes in Sham, IR and rIPC+IR groups. Data are presented as means \pm SEM. ANOVA was followed by the Holm-Sidak test. ${ }^{\#} P<0.05$ vs Sham group.

\section{Systemic inflammatory changes}

Following 60-min partial liver ischemia, significantly increased HMGB1 and TNF- $\alpha$ levels were observed at $180 \mathrm{~min}$ of the reperfusion period (Figure $11 \mathrm{~A}, \mathrm{~B}$ ). The IRinduced elevations of the plasma HMGB1 and TNF- $\alpha$ were effectively attenuated by rIPC (Figure 11A,B).
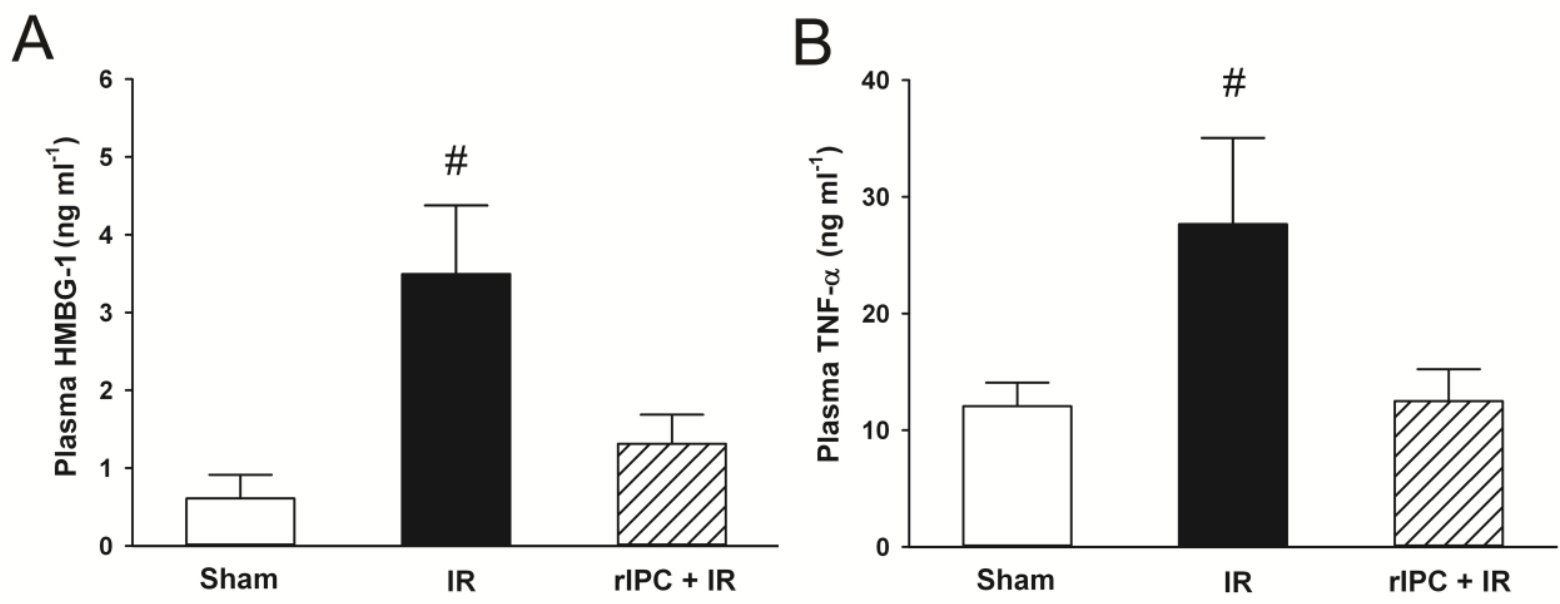

Figure 11. Plasma HMGB1 (A) and TNF- $\alpha$ (B) levels at the end of reperfusion (180 min) in the Sham, IR and rIPC+IR groups. Data are presented as means \pm SEM. ANOVA was followed by the Holm-Sidak test. ${ }^{\#} P<0.05$ vs Sham group.

\section{Inflammatory enzyme (MPO and XOR) levels}

The PMN deposition analyzed via the MPO activity was increased significantly 180 min after the ischemia, together with the XOR activity, which was elevated approximately 2-fold as compared with the Sham group. rIPC applied prior to the partial 
liver IR insult reduced the MPO and XOR activities almost to the Sham levels (Figure 12A,B).
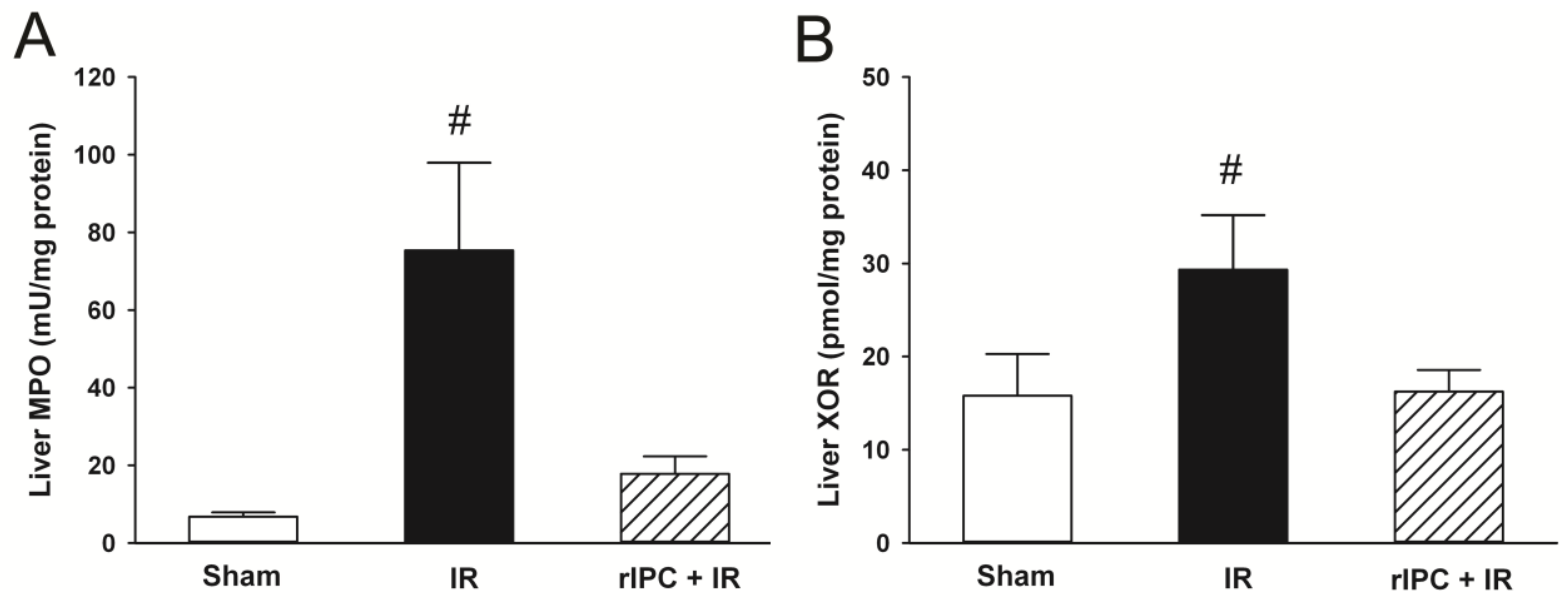

Figure 12. Hepatic MPO (A) and XOR (B) activities 180 min after ischemia in the Sham, partial liver IR and rIPC+IR groups. Data are presented as means \pm SEM. ANOVA was followed by the Holm-Sidak test. ${ }^{\#} P<0.05$ vs Sham group.

\section{NOX2 and NOX4 protein expression}

Western blot analysis of the NOX2 and NOX4 proteins revealed significant increases after partial liver IR in comparison with the Sham animals. The application of rIPC before IR decreased the expression of NOX2 significantly (Figure 13A), but did not affect the level of NOX4 expression (Figure 13B).

A
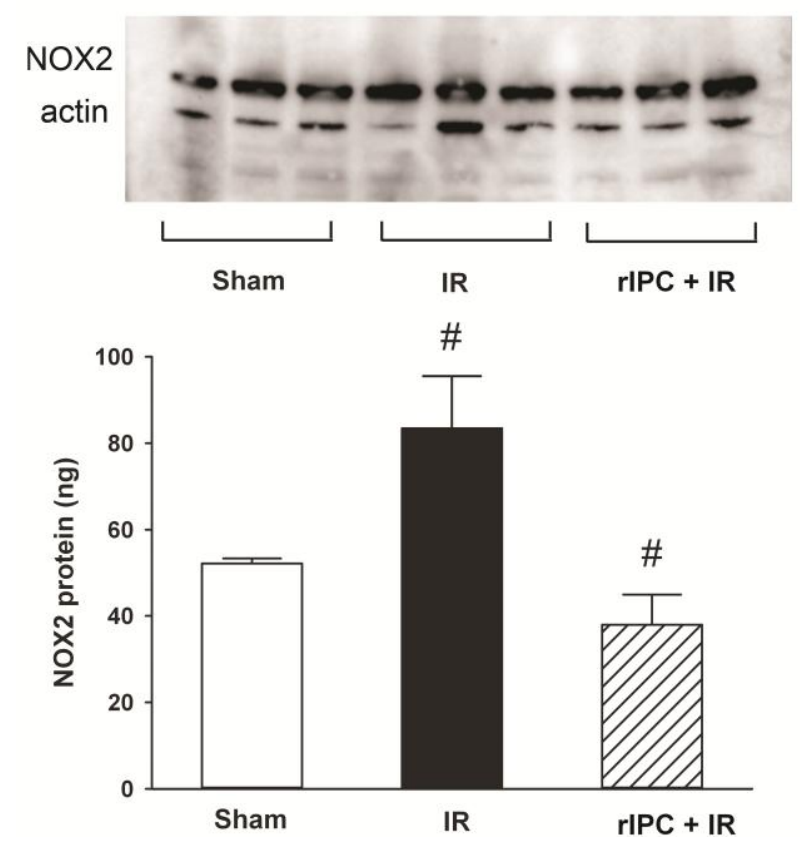

B
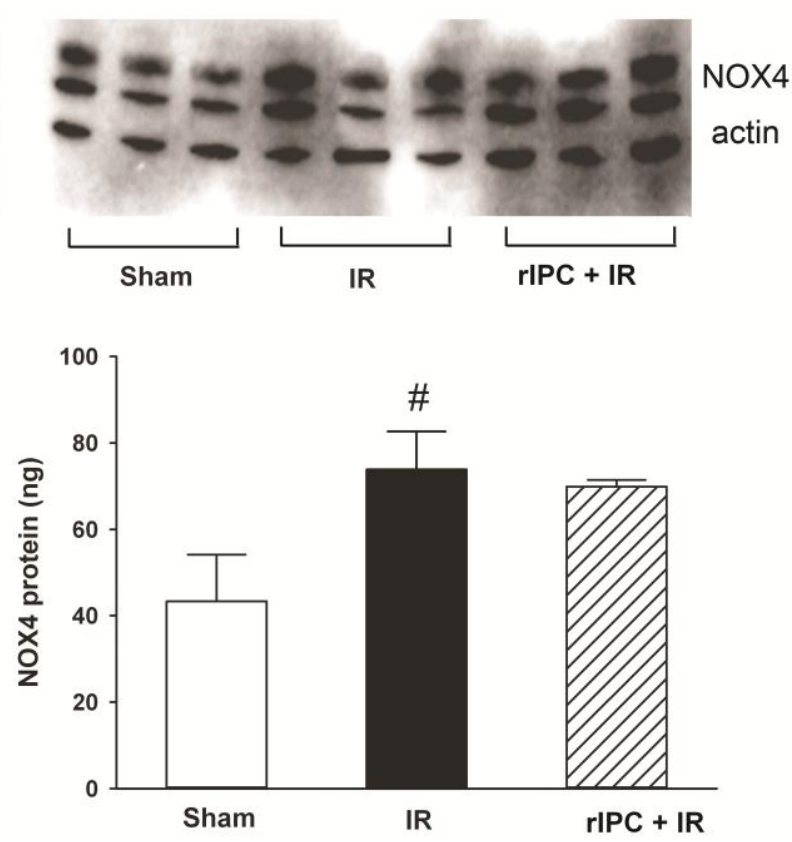

Figure 13. Hepatic expressions of NOX2 (A) and NOX4 (B) proteins at $180 \mathrm{~min}$ of reperfusion in the Sham, IR and rIPC+IR animals. Data are presented as medians \pm SD, analyzed with nonnormal distribution by the Mann-Whitney test. ${ }^{\#} P<0.05$ vs Sham group. 


\section{Functional hepatic changes}

The animals in the Sham group displayed minimally increased necroenzyme levels throughout the experimental protocol as compared with the baseline values. In comparison, the IR group exhibited significantly higher AST, ALT and LDH activities during the reperfusion period, indicating significant functional damage. When the rIPC protocol preceded liver IR (rIPC group), the plasma levels of the necroenzymes were significantly reduced in comparison with the IR group (Figure 14).

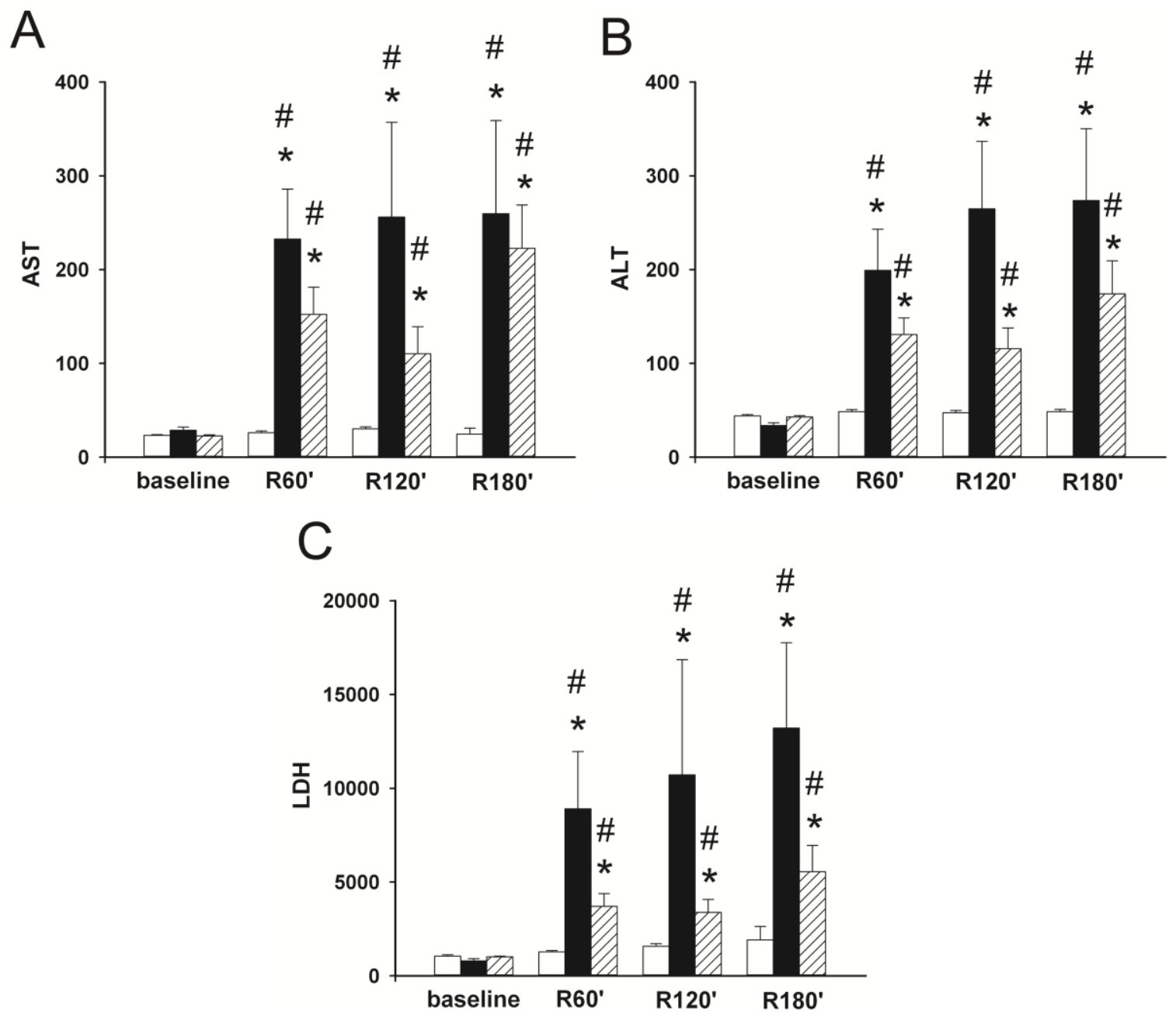

Figure 14. Time courses of plasma AST (A), ALT (B) and LDH (C) changes. Values are given in $\mathrm{UL}^{-1}$. The animals were sham-operated (Sham group, white columns) or subjected to 60-min partial hepatic ischemia followed by 180-min reperfusion (IR group, black columns), or two cycles of 10-min complete hindlimb ischemia followed by a 10-min reperfusion applied as a preconditioning trigger before liver ischemia (rIPC+IR group, striated columns). Data are presented as means \pm SEM. Two-way RM ANOVA was followed by the Bonferroni test. ${ }^{*} P<$ 0.05 vs baseline; ${ }^{\#} P<0.05$ vs Sham group. 


\section{DISCUSSION}

\subsection{Effects of $\mathrm{OVX}$ and estrogen supplementation on local postischemic periosteal microcirculatory injury}

Females are more resistant to circulatory shock and inflammation than males, but this gender-related anti-inflammatory protection is lost during the menopause or after OVX (Angele MK 2000, Wichmann MW 2000). As the incidence of traumas and osteoporotic fractures steadily rises in the elderly population (Gullberg B 1997), the question arises of whether osteoporotic women are more susceptible to postoperative or post-traumatic inflammatory bone complications than postmenopausal women receiving estrogen replacement therapy. In our first study, we set out to answer this question by employing a chronic rat model of osteoporosis where the consequences of a long-term female hormone deficiency can be adequately estimated (Tan $Z$ 2003). The results revealed that osteoporosis reproducibly evolved after OVX, and the reversing efficacy of E2 therapy on osteopenia, together with the periosteal microcirculatory status of the tibia, could subsequently be evaluated in the long term. The data also showed, however, that the postischemic periosteal microcirculatory PMN recruitment and the expressions of the adhesion molecules CD11b and ICAM-1 undergo similar changes in this condition, irrespective of the age or the endogenous estrogen status of the animals. Thus, the primary message of our study is that a chronic estrogen deficit does not change the magnitude of the PMN-associated microcirculatory menace in the event of transient ischemia of the osteoporotic limb.

IVM allows direct observation and quantitative analysis of the microcirculation of the exposed tissues. With this technique, the consequences of an estrogen deficit and estrogen replacement have already been demonstrated in certain organs (Santizo RA 2000, Watanabe Y 2001), but never in the periosteum, though the protecting and feeding functions of the periosteum are hallmarked by the fact that restoration of the periosteal microcirculation guarantees bone survival even in an environment with a limited blood supply (Berggren A 1982). Additionally, osteoporosis has been found to develop on the basis of an imbalance between bone resorption and formation, the effector cells being derived from mesenchymal osteoprogenitor cells located in the periosteum and endosteum, the former displaying predominance in this respect (Brighton CT 1992). Furthermore, the experimental and clinical evidence suggests an important role of the periosteum not only in the pathogenesis of osteoporosis itself, but also in the effects of 
different anti-osteoporotic approaches (Allen MR 2004). The periosteal region of the cortical bones exhibits a better anti-fracture efficacy than that of the endosteal region and it is proposed that the major target of different bone-reinforcing therapies is the periosteal site (Ferretti JL 1995). The periosteum also undergoes structural changes during the course of the development of osteoporosis (Fan W 2010). Together with the nutritive functions of the periosteum, these observations underline the importance of the periosteum in the pathogenesis of different disorders that affect the bone metabolism.

In our experimental protocol IR induced considerable increases in the periosteal leukocyte-endothelial interactions during the reperfusion phase, but these changes were similar in the aged OVX, the Sham-OVX, and the young animals. This observation adds a new aspect to the previous finding of enhanced PMN adhesion in the venules of the femur in the short run, i.e. 2 weeks after OVX in unstressed animals (Kasiyaphat A 2008). Similarly, an early enhancement of PMN infiltration has been demonstrated in the muscle of OVX rats after IR (Stupka N 2001). In fact, there is currently no consensus on the magnitude or pathologic role of leukocyte adhesion in non-skeletal tissues after OVX. OVX has been reported to enhance PMN accumulation in the brain of resting animals (Santizo RA 2000), but other data indicated that OVX does not influence the PMN adherence in the brain tissue after transient ischemia (Xu HL 2004). We suggest that these differences in baseline leukocyte adhesion might be explained by the different timelines. Use of a standardized experimental setup with matching sex, age and bone density conditions would solve this question.

The microcirculatory patency is influenced by functional and morphological changes in the microvasculature. As concerns the structural aspects, it has been shown that OVX leads to a reduced blood flow in the bone (Kapitola J 1995) and a lower total capillary density in the heart (Jesmin S 2002) and brain (Jesmin S 2003), a phenomenon probably related to the well-known effects of estrogen on angiogenesis. In our chronic OVX rat model, the periosteal vessel density was not affected by OVX or E2 replacement therapy. It is important to note that these changes were followed in the proximal tibial periosteum, where venules are the predominant vessel type. The postcapillary venules are predilectory sites for PMN-endothelial interactions, and thus a higher density may predispose to local inflammatory complications. The particularly high venular density of the periosteal microarchitecture may account, at least in part, for a tissue-specific response.

Although relatively little information is available on the effects of chronic OVX itself, there have been numerous experimental studies on the microcirculatory changes of 
hormone substitution (e.g. E2). Since estradiol is protective in many forms of injury, it is possible that E2 is protective independently of the presence of OVX. This view is supported by findings where a single dose of E2 given hours or even minutes before reperfusion ameliorates PMN-related processes in different organs (e.g. the heart, liver and retina) (Nonaka A 2000, Booth EA 2003, Burkhardt M 2008). It can be assumed that acute E2 administration could also be beneficial in reducing leukocyte trafficking in our model. Nonetheless, E2 has been shown to reduce leukocyte accumulation, infarct size (Jeanes HL 2006) and ROS production (Florian M 2004) in OVX rats; PMN adherence and infiltration, for instance, can be effectively prevented by estrogen supplementation after OVX (Stupka N 2001).

The mechanism of action by which E2 influences PMN-endothelial interactions is not known in detail. It has been suggested that E2 reduces the expression of endotheliumderived adhesion factors such as P-selectin, VCAM-1 and ICAM-1 (Miller AP 2004). Interestingly, some of these molecules also have a role in bone development, since the CD11/CD18a complex and ICAM-1 have been shown to influence the osteoclast function (Kurachi T 1993). It is hypothesized that an estrogen deficiency results in increased ICAM-1 expression on osteoclast precursors, which may contribute to the bone loss following the menopause or OVX (Gao Y 2000). The smaller diameter of the medullary resistance arterioles in OVX rats further suggests that endogenous estrogen exerts a significant dilator influence within the bone circulation (Soukhova-O'Hare G 2005). We investigated the changes in expression of CD11b, a key determinant of PMN-mediated injuries (Hentzen ER 2000). Upon activation, CD11b (the $\alpha \mathrm{M}$ part of the CD11b-CD18 complex) is transferred to the cell surface from preformed intracellular pools (Jones DH 1988) and, as opposed to the constitutive CD11a, its expression is increased several-fold in response to IR stimuli. The considerably increased CD11b expression implies that complete limb ischemia leads to severe systemic inflammatory consequences in this model. The local expression of ICAM-1, the endothelial counterpart of CD11b, was also enhanced in the postischemic periosteum, where the PMN-endothelial interactions were simultaneously and visibly increased. These reactions were not influenced by E2 repletion, which suggests that E2 exerts its anti-adhesive effect independently of CD11b or ICAM-1. The mechanism of how estrogen can modulate in vivo PMN reactions demands further attention, but our results are in agreement with those of in vitro studies, where OVX did not influence the CD11b expression of the PMNs (Deitch EA 2006). There is evidence of a cellular sexual dimorphism in the activation of PMNs, implying 
that PMNs from females respond to trauma and humoral stimuli to a lower extent than do those from males (Deitch EA 2006). Further, estrogen directly modulates the expression of the neuronal isoform of NOS in PMNs (García-Durán M 1999). In our study, E2 treatment clearly reduced the IR-induced secondary PMN-endothelial interactions (i.e. sticking), but this potentially protective effect was not mediated by a mechanism involving tissue ICAM-1 expression changes. Although an increased PMN-derived NO production might reduce PMN adhesion, this reaction is ICAM-1-dependent (Dal Secco $D$ 2006). Overall, the above findings may implicate that chronic estrogen supplementation modulates PMN activation directly, through a novel, specific, estrogensensitive pathway.

In our rat model, OVX was followed by definite diagnostic signs of osteoporosis 21 weeks later. In this condition, the postischemic periosteal microcirculatory complications were not aggravated further relative to the non-OVX age-matched controls. Similar changes were observed in TNF- $\alpha$ release, providing further evidence that OVX itself does not modify the inflammatory complications, but E2 supplementation greatly reduces this reaction. It has also been demonstrated that $\mathrm{E} 2$ inhibits TNF- $\alpha$ gene transcription via the beta estrogen receptors (Srivastava S 1999) and via the TNF- $\alpha$-mediated increases in the expressions of adhesion molecules and chemoattractants (Xing D 2007). A downregulation of NO synthesis by TNF- $\alpha$ may also contribute to the mechanisms of these microcirculatory reactions (Yoshizumi M 1993). Our data indicating the positive effect of prolonged E2 substitution on the PMN reactions and TNF- $\alpha$ release, however, point to another clinical implication of our findings: ovarial hormone deprivation supplemented with estrogen therapy (apart from the well-known positive effect in reducing the risk of osteoporotic fractures) affords marked protection against inflammatory mediator release.

\subsection{Influence of local IPC on limb IR injury in intact and $O V X$ female rats}

In the second study, we examined a somewhat shorter term of OVX, which is sufficient to evoke a chronic estrogen deficit (Iwaniec UT 2001, Xu HL 2001), but does not cause osteopenia in rats. Simarly to our previous results with male rats, the enhanced periosteal primary PMN-endothelial interactions evoked by the 60 -min IR insult of the lower extremity could be ameliorated effectively by local IPC. This protection, however, was only incomplete in the OVX animals, as some attenuation could be evidenced in the case of leukocyte rolling, but firm adhesion was not affected. Similarly, the CD11b expression of PMNs did not change after IPC. Accordingly, the protection against 
postischemic inflammatory complications in the periosteum is lost in an estrogendepleted situation. It is therefore reasonable to assume that endogenous estrogen is involved in anti-inflammatory mechanisms provided by IPC in the periosteum.

As concerns the role of endogenous estrogen in the mechanism of IPC, only relatively few studies have been performed and rather conflicting data are available. Shinmura et al. (2008) demonstrated that cardiac ischemia has similar detrimental effects in OVX and control mice, showing that endogenous estrogen in itself is not cardioprotective. The positive effects of IPC were shown to be lost in postischemic hearts harvested from OVX rats, but this reaction could be reversed by E2 (Shinmura K 2008). Interestingly, the protection by IPC was present in OVX rabbit hearts (Sbarouni E 2006). No cardiac protection was afforded by IPC in OVX mice in another study and this could be reversed by E2 substitution (Song X 2003). Others showed that IPC in OVX animals could evoke only a partial postischemic recovery in contractile functions and blood flow, but E2 administration caused a significant improvement (Kolodgie FD 1997). Long- and short-term estrogen administration was shown to have different effects (Peng WJ 2004). The controversy behind these findings remains to be elucidated, but the potential role of differences between species and even organs can not be excluded. It is also a matter of debate why the actions of endogenous and exogenous estrogen are different (Cohen MV 2008). As regards the heart, OVX causes a marked decrease in the phosphorylation of protein kinase $\mathrm{C}$ epsilon- and phosphoinositide-dependent kinases, emphasizing the importance of estrogen as a transcription factor (Shinmura K 2008). The present study design did not permit an examination of the underlying mechanisms at a molecular level behind the missing anti-inflammatory protection in OVX animals. Further studies are also needed to clarify the impact of long-term E2 treatment in the postischemic injury of the periosteum in the presence of IPC.

\subsection{Remote effects of limb IPC. Beneficial microcirculatory and biochemical effects on the consequences of partial liver IR}

The liver plays a complex role in the metabolism of the body as it neutralizes and excretes toxins and drugs, synthesizes enzymes, proteins and glycogen and stores iron and vitamins. For an appropriate function, the liver requires a continuous blood supply to carry out the above processes with their high oxygen demand. Although the liver has good blood perfusion, the ischemic tolerance is low (González-Flecha B 1993). Thanks to the improvements in surgical techniques, complete exclusion of the hepatic blood supply (complete hepatic ischemia) during surgical interventions can be fully avoided, usually 
being restricted to hardly manageable cases of bleeding or traumatological situations. To some degree, however, hepatic IR injury is inevitable in clinical practice during hepatic resection and liver transplantation (Huguet C 1992, Hunt CM 1998, Jaeschke H 1998, Teoh NC 2003, Datta G 2013). Along with the increasing need for and improving feasibility of transplantation, novel strategies targeting the attenuation of liver IR injuries may crucially affect the postoperative outcome and graft survival (Dulkanchainun TS 1998).

Extensive or prolonged hepatic ischemia could result in severe inflammation, which begins with Kupffer cell activation, inflammatory cytokine release and ROS production, and then, as a consequence of the oxidative burst, leads to microcirculatory failure (Schauer RJ 2001). Locally rising proinflammatory cytokine and chemokine concentrations recruit circulating PMNs. Adhesion and the following transmigration of PMNs into the perisinusoidal tissues further propagate inflammation (Hasegawa T 2005). In critical cases, postischemic tissue damage leads to hepatocellular apoptosis or necrosis (Gujral JS 2001). Moreover, this local inflammatory cascade can become generalized by leukocytes, causing a systemic inflammatory response syndrome (Lentsch AB 1999, Nastos C 2014) or even a multiorgan dysfunction syndrome (Işeri SO 2005).

Several studies have been performed to augment the tolerance of the liver and to attenuate the harmful effects of IR. Although numerous approaches have been used in experimental settings such as hypothermia (Kim YI 1996), gene therapy (Contreras JL 2004), pharmacological treatment and machine perfusion (Abu-Amara M 2009, Monbaliu D 2010) with various preservation fluids of the graft (Kotulski M 2003, Li L 2007) and surgically-induced pre- and postconditioning (Zhao ZQ 2003, Gurusamy KS 2008), only a few methods have been tested clinically. A reduction in postischemic liver injury was demonstrated after direct hepatic IPC elicited by intermittent portal inflow occlusion during liver resection in patients (Clavien PA 2000), but the potential drawbacks include an increased operating time and greater blood loss during reperfusion (Belghiti J 1999). Hence, rIPC may be a novel and simple method of protecting the liver without inflicting direct stress. One of the most reasonable approaches is when rIPC is elicited by limb ischemia. In such a study, many positive effects of rIPC were identified, including ameliorations in aminotransferase levels, improvements in hepatic blood flow and peripheral oxygen saturation and hepatic venous nitrate/nitrite levels (Kanoria S 2006). The role of heme oxygenase-1 has also been demonstrated (Lai IR 2006). 
In our study, the complex microcirculatory and biochemical effects of rIPC by limb IR were examined with particular emphasis on the role of endogenous NOXs. The partial hepatic ischemia model was chosen in order to evaluate effects that are solely related to IR, excluding poorly tolerated mesenteric congestion with the concomitant mediator release and deterioration of the systemic hemodynamics (Vollmar B 1994). We earlier demonstrated the microcirculatory effects of IPC achieved by using two cycles of complete hindlimb ischemia on IR-induced periosteal microcirculatory derangement and systemic inflammatory responses (Szabó A 2009). For a direct continuation of these studies, we first explored the consequences of warm hepatic IR affecting the left liver lobe. Changes in microcirculatory inflammatory reactions and in the efficacy of microcirculation were examined with fluorescence IVM and laser Doppler flowmetry supplemented with modified light spectrometry. Functional parameters and the expression of oxidant-generating intrahepatic enzymes were also assessed. Similarly to the beneficial local effects of local IPC, our study clearly demonstrated the microcirculatory benefits of remote limb IPC on IR-induced inflammatory responses in the liver. These microcirculatory changes were manifested in improvements in postischemic hepatic perfusion and oxygenation and reductions in PMN-endothelial interactions. The IR-related increases in the levels of necroenzymes and inflammatory cytokines were also ameliorated.

A major aim was to investigate the effects of rIPC on liver enzymes that generate ROS. The scope of this project was narrowed down to the most likely ROS-producing sources (i.e. XOR, MPO and NOXs) and we focused on the most relevant NOX isoforms, NOX2 and NOX4, whose roles in the mechanisms of IR damage or IPC have already been implicated. In our model, the expression of NOX2 was reduced by rIPC, but the enhanced NOX4 expression was not affected. Our findings are consistent with those of other research, which revealed that IPC inhibits the effects of mediators involved in the microcirculatory dysfunction, including ROS (Cutrn JC 2002, Jabs A 2010). The main cellular sources of ROS generation in the blood vessels are the NOXs in the smooth muscle cells (Griendling KK 2000), endothelial cells (Bayraktutan U 2000) and adventitial fibroblasts (Pagano PJ 1998). Among the NOX homologs, NOX4 has been reported to be the main isoform in the vascular cells (Bengtsson SH 2003, Ellmark SHM 2005), although the expression of NOX2 or even NOX1 has also been demonstrated. Enhanced NOX4 activity has been implicated in the development of various cardiovascular pathologies, because NOX-derived superoxide rapidly reduces the 
bioavailability of endothelium-derived NO, thereby promoting vasoconstriction and enhancing the vascular resistance (Dusting GJ 1998, Zicha J 2001). Nevertheless, NOX4 within the vessel wall generates a low level of ROS continuously, even in the absence of extrinsic stimulation, and, unlike phagocytic NOXs, is involved in physiological vascular processes such as maintenance of the vascular tone, regulation of the endotheliumdependent vasodilator function, oxygen sensing and modulation of the redox-sensitive signaling pathways (Cave AC 2006, Dworakowski R 2008). Moreover, endothelial NOX4 acts as a constitutive endothelial generator of $\mathrm{H}_{2} \mathrm{O}_{2}$, which positively affects the vascular function, linked to signaling events that promote vasodilatation and cell protection (Dikalov SI 2008, Takac I 2011). The exact factors determining the action of NOX4 in producing superoxides or $\mathrm{H}_{2} \mathrm{O}_{2}$ are unclear, but in overexpression systems NOX4 releases predominantly $\mathrm{H}_{2} \mathrm{O}_{2}$ (Ray R 2011). Additionally, molecular mechanisms implicated in NOX4 vasoprotection includes the activation of endothelial NOS and the increased production of NO, and the increased expression of antioxidant systems such as nuclear factor erythroid 2-related factor 2 (Schröder K 2012). Indeed, a significant decrease in myocardial infarct size was recently observed in NOX2- and NOX1/NOX2-, but not in NOX4-deficient mice (Braunersreuther V 2013). Thus, data are accumulating concerning a Janus-faced mechanism by which NOX4 can protect or cause harm to the circulatory system (Schmidt HH 2012) and, if a defensive action of NOX4 activity is possible, it could be hypothesized that the potentially vasoprotective characteristics of NOX4 may, at least in part, explain the ineffectiveness of rIPC in reducing the IR-related NOX4 expression.

Another possibility is that the influence of IPC is not universally effective, in consequence of the different sensitivities of the various target genes and enzymes. rIPC provided significant, but incomplete protection, and the residual damage and IR-induced inflammatory activation could therefore well be linked to the unchanging NOX4 activity. In this sense, the effect of IPC does not extend to all homologs (at least not to NOX4). Recent findings suggest that, unlike other ROS-generating NOXs, the tightly-assembled active conformation of NOX4 cannot be disrupted by conventional means, because the membrane-bound subunit does not require interaction with the cytosolic subunits (Csányi G 2013).

Previous studies demonstrated that the beneficial effect of IPC extends to reducing the adherence of PMNs to the ischemic-reperfused sinusoidal endothelium, attenuating the PMN-mediated endothelial dysfunction, and limiting leukocyte accumulation in the 
postischemic liver tissue (Yuan GJ 2005). In accordance with these observations, the influx of activated PMNs into the postsinusoidal venules was observed in the present model, and, as a result of rIPC, the extent of rolling and sticking of the leukocytes was significantly reduced in the central venules. The mechanisms underlying PMN trafficking after IR and rIPC can be explained in terms of several pathways leading to a modified adhesion molecule expression. The characteristic of the hepatic sinusoidal endothelium may contribute to leukocyte trapping: non-classical rolling and mainly VCAM-1mediated strong adhesion occur in response to inflammation (Lee YS 2004). NOXs have been shown to be particularly involved in regulating VCAM-1 expression through TNF- $\alpha$ release (Cayatte AJ 2001). When applied in vitro, S17834, a flavonoid NOX inhibitor, directly repressed the vascular NOX activity, and it reduced TNF- $\alpha$-stimulated VCAM, ICAM-1 and E-selectin expression in vivo (Cayatte AJ 2001). Further, the lower degree of ROS formation after rIPC partially produced by NOXs can also be linked to reduced adhesion molecule expression. Via mineral corticoid receptor activation, the aldosteroneinduced adhesion molecule expression also involves activation of the NOXs (Hashikabe Y 2006). Moreover, LPS induces the expression of surface adhesion molecules through the activation of toll-like receptor 4 , which has been shown to be involved in the NOXdependent activation of NF-кB (Park HS 2006).

The detection of MPO activity, the commonly used index of PMN priming and activation (Yuan GJ 2005), further strengthened our IVM observations. In Study 3, the MPO activity correlated significantly with the number of PMNs visualized. This observation is in agreement with a previous report that accumulated PMNs correlated positively with the development of hepatocellular damage after IR (Yuan GJ 2005). Upon activation, the prototypic isoform NOX2 has been proven to be responsible for the superoxide generation of PMNs (Babior BM 1999). This isoform, also referred to as "respiratory burst oxidase", was first described in PMNs as the starting point of ROS production (Babior BM 1999). The effects of NOX2-derived ROS and proteases released from activated PMNs in promoting cell death in the liver have been widely documented (Yuan GJ 2005, De Minicis S 2010). In the present study, rIPC attenuated both arms of the PMN-related injury: it lowered the PMN priming/MPO activity and reduced the expression of NOX2. This is in accordance with previous observations where preconditioning was induced via NOX2 in the ischemic brain, myocardium and endothelial cells (Kawano T 2007, Milovanova T 2008, Thirunavukkarasu M 2012). 
Cellular ROS (superoxide and $\mathrm{H}_{2} \mathrm{O}_{2}$ ) are now well recognized as playing an integral role in several growth factors and cytokine signal transduction pathways (Lander HM 1997) and serve as second messengers for cellular tyrosine kinase signaling (Goldstein BJ 2005). NOXs appear to be especially involved in redox signaling because they are the only enzymes (among the many intracellular sources of superoxide formation) whose primary function is to generate ROS (Lambeth JD 2004). The tissue specificity and difference in catalytic subunits offers an opportunity for the development of NOX inhibitors that do not compromise the essential physiological signaling and phagocytic functions carried out by ROS.

rIPC significantly attenuated systemic cytokine release. It has previously been shown that NOX-mediated ROS production has a major role in the ischemia-induced inflammatory responses involving activation of the NF- $\mathrm{B}$ (Dworakowski R 2008). TNF$\alpha$ and HMGB1 have a common NF- $\mathrm{BB}$-dependent transcription; both are involved in inflammatory responses (Dworakowski R 2008, Kamo N 2013). Moreover, hepatocytes have been demonstrated to produce TNF- $\alpha$ in a NOX-dependent manner following hypoxia-reoxygenation and liver IR (Spencer NY 2013). The relationship between TNF- $\alpha$ and HMGB1 expression and ROS production is bidirectional: TNF- $\alpha$ and HMGB1 are involved in regulating the expression of cytokines and other mediators that participate in acute inflammatory responses, many of which are associated with the increased generation of ROS (Kamo N 2013). On the other hand, oxidative stress has been reported to upregulate the expression of cytokines that promote inflammatory responses during reperfusion. These antigen-independent responses interact and amplify each other, finally leading to impaired microhemodynamics, functional and structural cell damage, and remote or systemic inflammatory complications. 


\section{SUMMARY OF NEW FINDINGS}

1. The periosteal microcirculatory consequences of tourniquet-induced ischemia were first quantified by IVM in an adequately long-term follow-up of osteoporosis. OVX does not predispose the periosteal microcirculation to enhanced IR-induced inflammatory complications such as local leukocyte activation and inflammatory cytokine release. The ameliorating effect of E2 therapy on the systemic and PMNdriven local periosteal inflammatory reactions is independent of its anti-osteoporotic effects.

2. Beneficial periosteal microcirculatory effects of local limb IPC are lost after OVX, suggesting that endogenous estrogen plays a potential role in the protection provided by IPC.

3. rIPC (elicited by limb ischemia) reverses the postischemic hepatic microcirculatory perfusion deficit and inflammatory reactions, restores tissue oxygenation and reduces proinflammatory cytokine and necroenzyme levels. These beneficial effects are associated with a reduced NOX2 expression, suggesting a potential role of NOX2 in the mechanism of protection provided by rIPC. 


\section{ACKNOWLEDGMENTS}

I am grateful to Professor Mihály Boros for providing me with the opportunity to carry out my scientific work and for initiating my scientific career in the Institute of Surgical Research under his valuable scientific guidance.

I am indebted to Dr. Andrea Szabó, who helped me acquire the basic experimental skills, and I am especially grateful for her patience and daily assistance in my performing the studies, preparing for conferences, writing publications and my thesis.

I am also grateful to Dr. Petra Hartmann for the help and support in my carrying out the experiments and making my publication as a first author.

I would like to thank all my immediate co-workers and collaborators for their contributions in the daily work and in performing the studies.

I also thank all the technicians at the Institute of Surgical Research for providing a stable background for the experiments and the biochemical assays.

I wish to thank my close and distant friends for supporting me during the years, helping me to get through challenging times.

Lastly, I am very grateful to and wish to thank my family and the family of my aunt and my grandmother for their love and care encouraging me to achieve my goals.

The thesis was supported by TÁMOP-4.2.2.A-11/1/KONV-2012-0035 and TÁMOP4.2.2.A-11/1/KONV-2012-0073. 


\section{REFERENCES}

1. Abu-Amara M, Yang SY, Quaglia A, Rowley P, Fuller B, Seifalian A, Davidson B. Role of endothelial nitric oxide synthase in remote ischemic preconditioning of the mouse liver. Liver Transpl 2011; 17:610-619

2. Abu-Amara M, Gurusamy KS, Glantzounis G, Fuller B, Davidson BR. Pharmacological interventions for ischaemia reperfusion injury in liver resection surgery performed under vascular control. Cochrane Database Syst Rev. 2009; (4):CD008154

3. Allen MR, Hock JM, Burr DB. Periosteum: biology, regulation, and response to osteoporosis therapies. Bone 2004; 35,1003-1012

4. Angele MK, Schwacha MG, Ayala A, Chaudry IH. Effect of gender and sex hormones on immune responses following shock. Shock 2000; 14,81-90

5. Anilkumar N, Sirker A, Shah AM. Redox sensitive signaling pathways in cardiac remodeling, hypertrophy and failure. Front Biosci (Landmark Ed) 2009; 14:31683187

6. Arai M, Thurman RG, Lemasters JJ. Contribution of adenosine A(2) receptors and cyclic adenosine monophosphate to protectiveischemic preconditioning of sinusoidal endothelial cells against Storage/Reperfusion injury in rat livers. Hepatology 2000; 32(2):297-302

7. Babior BM, Lambeth JD, Nauseef W. The neutrophil NADPH oxidase. Arch Biochem Biophys 2002; 397:342-344

8. Babior BM. NADPH oxidase: an update. Blood 1999; 93:1464-1476

9. Bayraktutan U, Blayney L, Shah AM. Molecular characterization and localization of the $\mathrm{NAD}(\mathrm{P}) \mathrm{H}$ oxidase components gp91-phox and p22-phox in endothelial cells. Arterioscler Thromb Vasc Biol. 2000; 20:1903-1911

10. Beckman JS, Koppenol WH. Nitric oxide, superoxide, and peroxynitrite: the good, the bad, and ugly. Am J Physiol. 1996; 271(5 Pt 1):C1424-1437

11. Beckman JS, Parks DA, Pearson JD, Marshall PA, Freeman BA. A sensitive fluorometric assay for measuring xanthine dehydrogenase and oxidase in tissues. Free Radic Biol Med. 1989; 6:607

12. Bedard K, Krause KH. The NOX family of ROS-generating NADPH oxidases: physiology and pathophysiology. Physiol Rev. 2007; 87:245-313 
13. Belghiti J, Noun R, Malafosse R, Jagot P, Sauvanet A, Pierangeli F, Marty J, Farges O. Continuous versus intermittent portal triad clamping for liver resection: a controlled study. Ann Surg. 1999; 229(3):369-375

14. Bengtsson SH, Gulluyan LM, Dusting GJ, Drummond GR. Novel isoforms of NADPH oxidase in vascular physiology and pathophysiology. Clin Exp Pharmacol Physiol. 2003; 30:849-854

15. Berggren A, Weiland AJ, Ostrup LT, Dorfman H. Microvascular free bone transfer with revascularization of the medullary and periosteal circulation or the periosteal circulation alone. A comparative experimental study. J Bone Joint Surg Am. 1982; 64(1):73-87

16. Björk J, Arfors KE. Oxygen free radicals and leukotriene B4 induced increase in vascular leakage is mediated by polymorphonuclear leukocytes. Agents Actions Suppl. 1982;11:63-72

17. Booth EA, Marchesi M, Kilbourne EJ, Lucchesi BR. 17Beta-estradiol as a receptormediated cardioprotective agent. Journal of Pharmacology and Experimental Therapeutics 2003; 307,395-401

18. Braunersreuther V, Montecucco F, Ashri M, Pelli G, Galan K, Frias M, Burger F, Quinderé AL, Montessuit C, Krause KH, Mach F, Jaquet V. Role of NADPH oxidase isoforms NOX1, NOX2 and NOX4 in myocardial ischemia/reperfusion injury. $\mathrm{J} \mathrm{Mol}$ Cell Cardiol. 2013; 64:99-107

19. Brighton CT, Lorich DG, Kupcha R, Reilly TM, Jones AR, Woodbury RA $2^{\text {nd }}$. The pericyte as a possible osteoblast progenitor cell. Clinical Orthopaedics and Related Research 1992; 275,287-299

20. Brzozowski T, Konturek PC, Konturek SJ, Pajdo R, Kwiecien S, Pawlik M, Drozdowicz D, Sliwowski Z, Pawlik WW. Ischemic preconditioning of remote organs attenuates gastric ischemia-reperfusion injury through involvement of prostaglandins and sensory nerves. Eur J Pharmacol. 2004; 499(1-2):201-213

21. Burkhardt M, Slotta JE, Garcia P Seekamp A, Menger MD, Pohlemann T. The effect of estrogen on hepatic microcirculation after ischemia/reperfusion. International Journal of Colorectal Disease 2008; 23,113-119

22. Canonico M, Plu-Bureau G, Lowe GD, Scarabin PY. Hormone replacement therapy and risk of venous thromboembolism in postmenopausal women: systematic review and meta-analysis. British Medical Journal 2008; 10,1227-1231 
23. Cao Y, Zhang SZ, Zhao SQ, Bruce IC. The mitochondrial Ca(2+)-activated K(+) channel contributes to cardioprotection by limb remoteischemic preconditioning in rat. Life Sci. 2011; 88(23-24):1026-1030

24. Carden DL, Granger DN. Pathophysiology of ischaemia-reperfusion injury. $J$ Pathol. 2000; 190(3):255-266

25. Cave AC, Brewer AC, Narayanapanicker A, Ray R, Grieve DJ, Walker S, Shah AM. NADPH oxidases in cardiovascular health and disease. Antioxid Redox Signal 2006; 8:691-728

26. Cayatte AJ, Rupin A, Oliver-Krasinski J, Maitland K, Sansilvestri-Morel P, Boussard MF, Wierzbicki M, Verbeuren TJ, Cohen RA. S17834, a new inhibitor of cell adhesion and atherosclerosis that targets nadph oxidase. Arterioscler Thromb Vasc Biol. 2001; 21:1577-1584

27. Chai W, Mehrotra S, Jan Danser AH, Schoemaker RG. The role of calcitonin generelated peptide (CGRP) in ischemic preconditioning in isolated rat hearts. Eur $J$ Pharmacol. 2006; 531(1-3):246-253

28. Chamoun F, Burne M, O’Donnell M, Rabb H. Pathophysiologic role of selectins and their ligands in ischemia reperfusion injury. Front. Biosci. 2000; 5:103-109

29. Cheung MM, Kharbanda RK, Konstantinov IE, Shimizu M, Frndova H, Li J, Holtby HM, Cox PN, Smallhorn JF, Van Arsdell GS, Redington AN. Randomized controlled trial of the effects of remote ischaemic preconditioning on children undergoing cardiac surgery: first clinical application in humans. J Am Coll Cardiol. 2006; 47:2277-2282

30. Choudhry MA, Schwacha MG, Hubbard WJ, Kerby JD, Rue LW, Bland KI, Chaudry IH. Gender differences in acute response to trauma-hemorrhage. Shock $2005 ; 24,101-106$

31. Christiansen C, Christensen MS, Larsen NE, Transbøl IB. Pathophysiological mechanisms of estrogen effect on bone metabolism. Dose-response relationships in early postmenopausal women. J Clin Endocrinol Metab. 1982; 55(6):1124-1130

32. Clavien PA, Yadav S, Sindram D, Bentley RC. Protective effects of ischemic preconditioning for liver resection performed under inflow occlusion in humans. Ann Surg. 2000; 232(2):155-162

33. Cohen MV, Downey JM. Oestrogen plays a permissive role in cardioprotection. Cardiovasc Res. 2008; 79(3):353-354 
34. Contreras JL, Vilatoba M, Eckstein C, Bilbao G, Anthony Thompson J, Eckhoff DE. Caspase-8 and caspase-3 small interfering RNA decreases ischemia/reperfusion injury to the liver in mice. Surgery 2004; 136(2):390-400

35. Csányi G, Pagano PJ. Strategies Aimed at Nox4 Oxidase Inhibition Employing Peptides from Nox4 B-Loop and C-Terminus and p22 (phox) N-Terminus: An Elusive Target. Int J Hypertens 2013; 2013:842827

36. Cushman M. Effects of hormone replace therapy and estrogen receptor modulators on markers of inflammation and coagulation. American Journal of Cardiology 2002; 90(Suppl 1), F7-10

37. Cutrn JC, Perrelli MG, Cavalieri B, Peralta C, Rosell Catafau J, Poli G. Microvascular dysfunction induced by reperfusion injury and protective effect of ischemic preconditioning. Free Radic Biol Med. 2002; 33:1200-1208

38. Dal Secco D, Moreira AP, Freitas A, Silva JS, Rossi MA, Ferreira SH, Cunha FQ. Nitric oxide inhibits neutrophil migration by a mechanism dependent on ICAM-1: role of soluble guanylate cyclase. Nitric Oxide. 2006; 15(1):77-86

39. Datta G, Fuller BJ, Davidson BR. Molecular mechanisms of liver ischemia reperfusion injury: insights from transgenic knockout models. World J Gastroenterol. 2013; 19(11):1683-1698

40. De Minicis S, Seki E, Paik YH, Osterreicher CH, Kodama Y, Kluwe J, Torozzi L, Miyai K, Benedetti A, Schwabe RF, Brenner DA. Role and cellular source of nicotinamide adenine dinucleotide phosphate oxidase in hepatic fibrosis. Hepatology 2010; 52:1420-1430

41. Deitch EA, Ananthakrishnan P, Cohen DB, Xu da Z, Feketeova E, Hauser CJ. Neutrophil activation is modulated by sex hormones after trauma-hemorrhagic shock and burn injuries. American Journal of Physiology 2006; 291,H1456-1465

42. Diamond MS, Staunton DE, de Fougerolles AR, Stacker SA, Garcia-Aguilar J, Hibbs ML, Springer TA. ICAM-1 (CD54): a counter-receptor for Mac-1 (CD11b/CD18). J Cell Biol. 1990; 111(6 Pt 2):3129-3139

43. Dikalov SI, Dikalova AE, Bikineyeva AT, Schmidt HH, Harrison DG, Griendling KK. Distinct roles of Nox1 and Nox4 in basal and angiotensin II-stimulated superoxide and hydrogen peroxide production. Free Radic Biol Med. 2008; 45:13401351

44. Dong HL, Zhang Y, Su BX, Zhu ZH, Gu QH, Sang HF, Xiong L. Limb remote ischemic preconditioning protects the spinal cord from ischemia- 
reperfusion injury: a newly identified nonneuronal but reactive oxygen speciesdependent pathway. Anesthesiology 2010; 112(4):881-891

45. Duda M, Czarnowska E, Kurzelewski M, Konior A, Beresewicz A. Ischemic preconditioning prevents endothelial dysfunction, P-selectin expression, and neutrophiladhesion by preventing endothelin and $\mathrm{O} 2$ - generation in the postischemic guinea-pig heart. J Physiol Pharmacol. 2006; 57(4):553-569

46. Dulkanchainun TS, Goss JA, Imagawa DK, Shaw GD, Anselmo DM, Kaldas F, Wang T, Zhao D, Busuttil AA, Kato H, Murray NG, Kupiec-Weglinski JW, Busuttil RW. Reduction of hepatic ischemia/reperfusion injury by a soluble P-selectin glycoprotein ligand-1. Ann Surg. 1998; 227(6):832-840

47. Dusting GJ, Fennessy P, Yin ZL, Gurevich V. Nitric oxide in atherosclerosis: vascular protector or villain? Clin Exp Pharmacol Physiol Suppl. 1998; 25:S34-41

48. Dworakowski R, Alom-Ruiz SP, Shah AM. NADPH oxidase-derived reactive oxygen species in the regulation of endothelial phenotype. Pharmacol Rep. 2008; 60:21-28

49. Ebeling PR. Vitamin D and bone health: Epidemiologic studies. Bonekey Rep. 2014; $3: 511$

50. Ellmark SHM, Dusting GJ, Ng TangFui M, Guzzo-Pernell N, Drummond GR. The contribution of Nox4 to NADPH oxidase activity in mouse vascular smooth muscle. Cardiov Res. 2005; 65:495-504

51. Esterhai JL, Queenan J. Management of soft tissue wounds associated with type III open fractures. Orthop Clin North Am. 1991; 22:427-432

52. Fan W, Bouwense SA, Crawford R, Xiao Y. Structural and cellular features in metaphyseal and diaphyseal periosteum of osteoporotic rats. Journal of Molecular Histology 2010; 41,51-60

53. Ferretti JL, Frost HM, Gasser JA, High WB, Jee WS, Jerome C, Mosekilde L, Thompson DD. Perspectives on osteoporosis research: its focus and some insights from a new paradigm. Calcified Tissue International 1995; 57,399-404

54. Fleisch H. New bisphosphonates in osteoporosis. Osteoporosis International 1993; $3, \mathrm{~S} 15-22$

55. Fleming SD, Mastellos D, Karpel-Massler G, Shea-Donohue T, Lambris JD, Tsokos GC.C5a causes limited, polymorphonuclear cell-independent, mesenteric ischemia/reperfusion-induced injury. Clin Immunol. 2003; 108(3):263-273 
56. Florian M, Freiman A, Magder S. Treatment with 17-beta-estradiol reduces superoxide production in aorta of ovariectomized rats. Steroids 2004; 69,779-787

57. Freeman BA, Crapo JD. Biology of disease: free radicals and tissue injury. Lab Invest. $1982 ; 47: 412-426$

58. Gaboury J, Woodman RC, Granger DN, Reinhardt P, Kubes P. Nitric oxide prevents leukocyte adherence: role of superoxide. Am J Physiol. 1993; 265(3 Pt 2):H862-867

59. Gaboury JP, Johnston B, Niu XF, Kubes P. Mechanisms underlying acute mast cellinduced leukocyte rolling and adhesion in vivo. J Immunol. 1995;154(2):804-813.

60. Gao Y, Morita I, Kubota T, Murota S, Aso T. Expression of adhesion molecules LFA-I and ICAM-I on osteoclast precursors during osteoclast differentiation and involvement of estrogen deficiency. Climacteric 2000; 3,278-287

61. García-Durán M, de Frutos T, Díaz-Recasens J, García-Gálvez G, Jiménez A, Montón M, Farré J, Sánchez de Miguel L, González-Fernández F, Arriero MD, Rico L, García R, Casado S, López-Farré A. Estrogen stimulates neuronal nitric oxide synthase protein expression in human neutrophils. Circulation Research 1999; $85,1020-1026$

62. Gennari C, Martini G, Nuti R. Secondary osteoporosis. Aging (Milano) 1998; $10(3): 214-224$

63. Geusens P, Lems WF. Osteoimmunology and osteoporosis. Arthritis Res Ther. 2011; 13(5):242

64. Gho BC, Schoemaker RG, van den Doel MA, Duncker DJ, Verdouw PD. Myocardial protection by brief ischemia in noncardiac tissue. Circulation 1996; 94:2193-2200

65. Ginzberg HH, Cherapanov V, Dong Q, Cantin A, McCulloch CA, Shannon PT, Downey GP. Neutrophil-mediated epithelial injury during transmigration: role of elastase. Am J Physiol Gastrointest Liver Physiol. 2001; 281(3):G705-717

66. Goldman G, Welbourn R, Klausner JM, Paterson IS, Kobzik L, Valeri CR, Shepro D, Hechtman HB. Ischemia activates neutrophils but inhibits their local and remote diapedesis. Ann Surg. 1990; 211(2):196-201

67. Goldstein BJ, Mahadev K, Wu X. Redox paradox: insulin action is facilitated by insulin-stimulated reactive oxygen species with multiple potential signaling targets. Diabetes 2005; 54:311-321 
68. González-Flecha B, Cutrin JC, Boveris A. Time course and mechanism of oxidative stress and tissue damage in rat liver subjected to in vivo ischemia-reperfusion. $J$ Clin Invest. 1993; 91(2):456-464

69. Görlach A, Brandes RP, Nguyen K, Amidi M, Dehghani F, Busse R. A gp91phox containing NADPH oxidase selectively expressed in endothelial cells is a major source of oxygen radical generation in the arterial wall. Circ Res. 2000; 87:26-32

70. Griendling KK, Sorescu D, Lassègue B, Ushio-Fukai M. Modulation of protein kinase activity and gene expression by reactive oxygen species and their role in vascular physiology and pathophysiology. Arterioscler Thromb Vasc Biol. 2000; $20: 2175-2183$

71. Grisham MB, Hernandez LA, Granger DN. Xanthine oxidase and neutrophil infiltration in intestinal ischemia. Am J Physiol. 1986; 251(4 Pt 1):G567-574

72. Groves RW, Ross E, Barker JN, Ross JS, Camp RD, MacDonald DM. Effect of in vivo interleukin-1 on adhesion molecule expression in normal human skin. J Invest Dermatol. 1992; 98(3):384-387

73. Gujral JS, Bucci TJ, Farhood A, Jaeschke H. Mechanism of cell death during warm hepatic ischemia-reperfusion in rats: apoptosis or necrosis? Hepatology 2001; 33(2):397-405

74. Gullberg B, Johnell O, Kanis JA. World-wide projections for hip fracture. Osteoporosis International 1997; 7,407-413

75. Gurusamy KS, Kumar Y, Sharma D, Davidson BR. Ischaemic preconditioning for liver transplantation. Cochrane Database Syst Rev. 2008; (1):CD006315

76. Gustilo RB, Merkow RL, Templeman D. The management of open fractures. J Bone Joint Surg Am. 1990; 72:299-304

77. Gute DC, Ishida T, Yarimizu K, Korthuis RJ. Inflammatory responses to ischemia and reperfusion in skeletal muscle. Mol Cell Biochem. 1998; 179(1-2):169-187

78. Harada H, Hines IN, Flores S, Gao B, McCord J, Scheerens H, Grisham MB. Role of NADPH oxidase-derived superoxide in reduced size liver ischemia and reperfusion injury. Arch Biochem Biophys. 2004; 423:103-108

79. Harkin DW, Barros D'Sa AA, McCallion K, Hoper M, Campbell FC. Ischemic preconditioning before lower limb ischemia--reperfusion protects against acute lung injury. J Vasc Surg. 2002; 35(6):1264-1273 
80. Harris AG, Leiderer R, Peer F, Messmer K. Skeletal muscle microvascular and tissue injury after varying durations of ischemia. Am J Physiol. 1996; 271(6 Pt 2):H2388-2398

81. Hartmann P, Varga R, Zobolyák Z, Héger J, Csősz B, Németh I, Rázga Z, Vízler C, Garab D, Sántha P, Jancsó G, Boros M, Szabó A. Anti-inflammatory effects of limb ischaemic preconditioning are mediated by sensory nerve activation in rats. Naunyn Schmiedebergs Arch Pharmacol. 2011; 383(2):179-189

82. Hasegawa T, Malle E, Farhood A, Jaeschke H. Generation of hypochlorite-modified proteins by neutrophils during ischemia-reperfusion injury in rat liver: attenuation by ischemic preconditioning. Am J Physiol Gastrointest Liver Physiol. 2005; 289(4):G760-767

83. Hashikabe Y, Suzuki K, Jojima T, Uchida K, Hattori Y. Aldosterone impairs vascular endothelial cell function. J Cardiovasc Pharmacol. 2006; 47:609-613

84. Hentzen ER, Neelamegham S, Kansas GS, Benanti JA, McIntire LV, Smith CW, Simon SI. Sequential binding of CD11a/CD18 and CD11b/CD18 defines neutrophil capture and stable adhesion to intercellular adhesion molecule-1. Blood 2000; 95,911-920

85. Hu S, Dong H, Zhang H, Wang S, Hou L, Chen S, Zhang J, Xiong L. Noninvasive limb remote ischemic preconditioning contributes neuroprotective effects via activation of adenosine A1 receptor and redox status after transient focal cerebral ischemia in rats. Brain Res. 2012; 1459:81-90

86. Huguet C, Gavelli A, Chieco PA, Bona S, Harb J, Joseph JM, Jobard J, Gramaglia M, Lasserre M. Liver ischemia for hepatic resection: where is the limit? Surgery 1992; 111(3):251-259

87. Hunt CM, Camargo CA Jr, Dominitz JA, Bute BP, Clavien PM. Effect of postoperative complications on health and employment following liver transplantation. Clin Transplant. 1998; 12(2):99-103

88. Işeri SO, Sener G, Saglam B, Gedik N, Ercan F, Yegen BC. Oxytocin protects against sepsis-induced multiple organ damage: role of neutrophils. J Surg Res. 2005; 126(1):73-81

89. Iuliano L, Pedersen JZ, Praticò D, Rotilio G, Violi F. Role of hydroxyl radicals in the activation of human platelets. Eur J Biochem. 1994; 221(2):695-704 
90. Iwaniec UT, Samnegård E, Cullen DM, Kimmel DB. Maintenance of cancellous bone in ovariectomized, human parathyroid hormone [hPTH(1-84)]-treated rats by estrogen, risedronate, or reduced hPTH. Bone 2001; 29(4):352-360

91. Jabs A, Fasola F, Muxel S, Münzel T, Gori T. Ischemic and non-ischemic preconditioning: Endothelium-focused translation into clinical practice. Clin Hemorheol Microcirc. 2010; 45:185-191

92. Jaeschke H. Mechanisms of reperfusion injury after warm ischemia of the liver. $J$ Hepatobiliary Pancreat Surg. 1998; 5(4):402-408

93. Jeanes HL, Wanikiat P, Sharif I, Gray GA. Medroxyprogesterone acetate inhibits the cardioprotective effect of estrogen in experimental ischemia-reperfusion injury. Menopause 2006; 13,80-86

94. Jesmin S, Hattori Y, Sakuma I, Liu MY, Mowa CN, Kitabatake A. Estrogen deprivation and replacement modulate cerebral capillary density with vascular expression of angiogenic molecules in middle-aged female rats. Journal of Cerebral Blood Flow \& Metabolism 2003; 23,181-189

95. Jesmin S, Sakuma I, Hattori Y, Kitabatake A. In vivo estrogen manipulations on coronary capillary network and angiogenic molecule expression in middle-aged female rats. Arteriosclerosis, Thrombosis, and Vascular Biology 2002; 22,1591-1597

96. Joly J, Westhovens R, Borghs H, Peeters H, Tirry J, Nijs J, Dequeker J. Reference curve and diagnostic sensitivity for a new ultrasound device for the phalanges, the DBMsonic 1200, in Belgian women. Osteoporos Int. 1999; 9(4):284-289

97. Jones DH, Anderson DC, Burr BL, Rudloff HE, Smith CW, Krater SS, Schmalstieg FC. Quantitation of intracellular Mac-1 (CD11b/CD18) pools in human neutrophils. Journal of Leukocyte Biology 1988; 44,535-544

98. Kamo N, Ke B, Ghaffari AA, Shen XD, Busuttil RW, Cheng G, Kupiec-Weglinski JW. ASC/caspase-1/IL-1 $\beta$ signaling triggers inflammatory responses by promoting HMGB1 induction in liver ischemia/reperfusion injury. Hepatology 2013; 58:351362

99. Kanoria S, Jalan R, Davies NA, Seifalian AM, Williams R, Davidson BR. Remote ischaemic preconditioning of the hind limb reduces experimental liver warm ischaemia-reperfusion injury. Br J Surg. 2006; 93(6):762-768

100.Kapitola J, Kubícková J, Andrle J. Blood flow and mineral content of the tibia of female and male rats: changes following castration and/or administration of estradiol or testosterone. Bone 1995; 16,69-72 
101.Kasiyaphat A, Siriviriyakul P, Patumraj S. Preventive effects of genistein on leukocyte adhesion in femur venules and on bone-loss induced in ovariectomized female rats. Clinical Hemorheology and Microcirculation 2008; 38,235-243

102.Kawano T, Kunz A, Abe T, Girouard H, Anrather J, Zhou P, Iadecola C. iNOSderived NO and nox2-derived superoxide confer tolerance to excitotoxic brain injury through peroxynitrite. J Cereb Blood Flow Metab. 2007; 27:1453-1462

103.Kharbanda RK, Mortensen UM, White PA, Kristiansen SB, Schmidt MR, Hoschtitzky JA, Vogel M, Sorensen K, Redington AN, MacAllister R. Transient limb ischemia induces remote ischemic preconditioning in vivo. Circulation 2002; 106(23):2881-2883

104.Kim YI, Hiratsuka K, Kitano S, Joo DH, Kamada N, Sugimachi K. Simple in situ hypothermia reduced ischaemic injury to human liver during hepatectomy. Eur $J$ Surg. 1996; 162(9):717-721

105.Kitazawa R, Kimble RB, Vannice JL, Kung VT, Pacifici R. Interleukin-1 receptor antagonist and tumor necrosis factor binding protein decrease osteoclast formation and bone resorption in ovariectomized mice. J Clin Invest. 1994; 94(6):2397-2406

106.Koike K, Moore EE, Moore FA, Carl VS, Pitman JM, Banerjee A. Phospholipase A2 inhibition decouples lung injury from gut ischemia-reperfusion. Surgery 1992; 112(2):173-180

107.Koike K, Moore FA, Moore EE, Read RA, Carl VS, Banerjee A. Gut ischemia mediates lung injury by a xanthine oxidase-dependent neutrophil mechanism. J Surg Res. 1993; 54(5):469-473

108.Koike K, Moore EE, Moore FA, Franciose RJ, Fontes B, Kim FJ. CD11b blockade prevents lung injury despite neutrophil priming after gut ischemia/reperfusion. $J$ Trauma. 1995; 39(1):23-27

109.Kolodgie FD, Farb A, Litovsky SH, Narula J, Jeffers LA, Lee SJ, Virmani R. Myocardial protection of contractile function after global ischemia by physiologic estrogen replacement in the ovariectomized rat. J Mol Cell Cardiol. 1997; 29(9):2403-2414

110.Kolodny A. The periosteal blood supply and healing of fractures: an experimental study. Journal of Bone and Joint Surgery American Edition 1923; 5:698-711

111.Koti RS, Yang W, Dashwood MR, Davidson BR, Seifalian AM. Effect of ischemic preconditioning on hepatic microcirculation and function in a rat model of ischemia reperfusion injury. Liver Transpl. 2002; 8:1182-1191 
112.Kotulski M, Pawlak J, Hevelke P, Krawczyk M. Assessment of early graft function in relation to different preservation fluids--preliminary results. Ann Transplant. 2003; $8(4): 31-35$

113.Kubes P, Kanwar S, Niu XF, Gaboury JP. Nitric oxide synthesis inhibition induces leukocyte adhesion via superoxide and mast cells. FASEB J. 1993; 7:1293-1299

114.Kubes P, Suzuki M, Granger DN. Nitric oxide: an endogenous modulator of leukocyte adhesion. Proc Natl Acad Sci U S A. 1991; 88:4651-4655

115.Kuebler WM, Abels C, Schuerer L, Goetz AE. Measurement of neutrophil content in brain and lung tissue by a modified myeloperoxidase assay. Int J Microcirc Clin Exp. 1996; 16:89

116.Küntscher MV, Kastell T, Altmann J, Menke H, Gebhard MM, Germann G. Acute remote ischemic preconditioning II: the role of nitric oxide. Microsurgery 2002; 22(6):227-231

117.Kurachi T, Morita I, Murota S. Involvement of adhesion molecules LFA-1 and ICAM-1 in osteoclast development. Biochimica et Biophysica Acta 1993; 1178, 259266

118.Kurose I, Anderson DC, Miyasaka M, Tamatani T, Paulson JC, Todd RF, Rusche JR, Granger DN. Molecular determinants of reperfusion-induced leukocyte adhesion and vascular protein leakage. Circ Res. 1994b; 74(2):336-343

119.Kurose I, Granger DN. Evidence implicating xanthine oxidase and neutrophils in reperfusion-induced microvascular dysfunction. Ann N Y Acad Sci. 1994a; 723:158179

120.Lai IR, Chang KJ, Chen CF, Tsai HW. Transient limb ischemia induces remote preconditioning in liver among rats: the protective role of heme oxygenase-1. Transplantation 2006; 81(9):1311-1317

121.Lambeth JD. NOX enzymes and the biology of reactive oxygen. Nat Rev Immunol. 2004; 4:181-189

122.Lander HM. An essential role for free radicals and derived species in signal transduction. FASEB J. 1997; 11:118-124

123.Lassègue B, Sorescu D, Szöcs K, Yin Q, Akers M, Zhang Y, Grant SL, Lambeth JD, Griendling KK. Novel gp91(phox) homologues in vascular smooth muscle cells : nox 1 mediates angiotensin II-induced superoxide formation and redox-sensitive signaling pathways. Circ Res. 2001; 88:888-894 
124.Lawlor DK, Brock RW, Harris KA, Potter RF. Cytokines contribute to early hepatic parenchymal injury and microvascular dysfunction after bilateral hindlimb ischemia. J Vasc Surg. 1999; 30(3):533-541

125.Lee WY, Lee SM. Ischemic preconditioning protects post-ischemic oxidative damage to mitochondria in rat liver. Shock 2005; 24(4):370-375

126.Lee YS, Kang YS, Lee JS, Nicolova S, Kim JA. Involvement of NADPH oxidasemediated generation of reactive oxygen species in the apototic cell death by capsaicin in HepG2 human hepatoma cells. Free Radic Res. 2004; 38:405-412

127.Lentsch AB, Yoshidome H, Warner RL, Ward PA, Edwards MJ. Secretory leukocyte protease inhibitor in mice regulates local and remote organ inflammatory injury induced by hepatic ischemia/reperfusion. Gastroenterology 1999; 117(4):953961

128.Leo R, Praticò D, Iuliano L, Pulcinelli FM, Ghiselli A, Pignatelli P, Colavita AR, FitzGerald GA, Violi F. Platelet activation by superoxide anion and hydroxyl radicals intrinsically generated by platelets that had undergone anoxia and then reoxygenated. Circulation 1997; 95(4):885-891

129.Li GL, Xu XH, Wang BA, Yao YM, Qin Y, Bai SR, Rong J, Deng T, Hu YH. Analysis of protein-protein interaction network and functional modules on primary osteoporosis. Eur J Med Res. 2014; 19:15

130.Li L, Li CM, Zhang BY, Hu MD, Li XY, Ran JH, Huang M. Apoptosis of rat liver in cold preservation with custom-designed KYL solution. Hepatobiliary Pancreat Dis Int. 2007; 6(5):497-503

131.Li X, Steeber DA, Tang ML, Farrar MA, Perlmutter RM, Tedder TF. Regulation of L-selectin-mediated rolling through receptor dimerization. J Exp Med. 1998; 188(7):1385-1390

132.Lippuner K. Epidemiology and burden of osteoporosis in Switzerland. Ther Umsch. 2012; 69(3):137-144

133.Lorant DE, Patel KD, McIntyre TM, McEver RP, Prescott SM, Zimmerman GA. Coexpression of GMP-140 and PAF by endothelium stimulated by histamine or thrombin: a juxtacrine system for adhesion and activation of neutrophils. J Cell Biol. $1991 ; 115(1): 223-234$

134.Mallick IH, Yang W, Winslet MC, Seifalian AM. Ischaemic preconditioning improves microvascular perfusion and oxygenation following reperfusion injury of the intestine. Br J Surg. 2005; 92:1169-1176 
135.Mansour Z, Bouitbir J, Charles AL, Talha S, Kindo M, Pottecher J, Zoll J, Geny B. Remote and local ischemic preconditioning equivalently protects rat skeletal muscle mitochondrial function during experimental aortic cross-clamping. J Vasc Surg. 2012; 55(2):497-505

136.Marden JJ, Zhang Y, Oakley FD, Zhou W, Luo M, Jia HP, McCray PB Jr, Yaniv M, Weitzman JB, Engelhardt JF. JunD protects the liver from ischemia/reperfusion injury by dampening AP-1 transcriptional activation. J Biol Chem. 2008; 283:66876695

137.Mazzoni MC, Borgström $\mathrm{P}$, Intaglietta $\mathrm{M}$, Arfors KE. Lumenal narrowing and endothelial cell swelling in skeletal muscle capillaries during hemorrhagic shock. Circ Shock. 1989; 29(1):27-39

138.McClanahan TB, Nao BS, Wolke LJ, Martin BJ, Metz TE, Gallagher KP. Brief renal occlusion and reperfusion reduces myocardial infarct size in rabbits FASEB $J$. $1993 ; 7$

139.McCord JM, Roy RS. The pathophysiology of superoxide: roles in inflammation and ischemia. Can J Physiol Pharmacol. 1982; 60(11):1346-1352

140.Menger MD, Laschke MW, Amon M, Schramm R, Thorlacius H, Rucker M, Vollmar B. Experimental models to study microcirculatory dysfunction in muscle ischemia-reperfusion and osteomyocutaneous flap transfer. Langenbecks Arch Surg. 2003; 388(5):281-290

141.Menger MD, Rücker M, Vollmar B. Capillary dysfunction in striated muscle ischemia/reperfusion: on the mechanisms of capillary "no-reflow". Shock 1997; $8(1): 2-7$

142.Menger MD, Steiner D, Messmer K. Microvascular ischemia-reperfusion injury in striated muscle: significance of "no reflow". Am J Physiol. 1992; 263(6 Pt 2):H18921900

143.Miller AP, Feng W, Xing D, Weathington NM, Blalock JE, Chen YF, Oparil S. Estrogen modulates inflammatory mediator expression and neutrophil chemotaxis in injured arteries. Circulation 2004; 110,1664-1669

144.Milovanova T, Chatterjee S, Hawkins BJ, Hong N, Sorokina EM, Debolt K, Moore JS, Madesh M, Fisher AB. Caveolae are an essential component of the pathway for endothelial cell signaling associated with abrupt reduction of shear stress. Biochim Biophys Acta 2008; 1783: 1866-1875 
145.Mitchell MB, Meng X, Ao L, Brown JM, Harken AH, Banerjee A. Preconditioning of isolated rat heart is mediated by protein kinase C. Circ Res. 1995; 76(1):73-81

146. Monbaliu D, Brassil J. Machine perfusion of the liver: past, present and future. Curr Opin Organ Transplant. 2010; 15(2):160-166

147.Murry CE, Jennings RB, Reimer KA. Preconditioning with ischemia: a delay of lethal cell injury in ischemic myocardium. Circulation 1986; 74:1124-1136

148.Nakano A, Baines CP, Kim SO, Pelech SL, Downey JM, Cohen MV, Critz SD. Ischemic preconditioning activates MAPKAPK2 in the isolated rabbit heart: evidence for involvement of p38 MAPK. Circ Res. 2000; 86(2):144-151

149.Nastos C, Kalimeris K, Papoutsidakis N, Tasoulis MK, Lykoudis PM, Theodoraki K, Nastou D, Smyrniotis V, Arkadopoulos N. Global consequences of liver ischemia/reperfusion injury. Oxid Med Cell Longev. 2014; 2014:906965

150.Nishida T, Shibata H, Koseki M, Nakao K, Kawashima Y, Yoshida Y, Tagawa K. Peroxidative injury of the mitochondrial respiratory chain during reperfusion of hypothermic rat liver. Biochim Biophys Acta. 1987; 890(1):82-88

151.Nonaka A, Kiryu J, Tsujikawa A, Yamashiro K, Miyamoto K, Nishiwaki H, Mandai M, Honda Y, Ogura Y. Administration of 17beta-estradiol attenuates retinal ischemia-reperfusion injury in rats. Investigative Ophthalmology \& Visual Science $2000 ; 41,2689-2696$

152.Pagano PJ, Chanock SJ, Siwik DA, Colucci WS, Clark JK. Angiotensin II induces p67phox mRNA expression and NADPH oxidase superoxide generation in rabbit aortic adventitial fibroblasts. Hypertension 1998; 32:331-337

153.Park HS, Chun JN, Jung HY, Choi C, Bae YS. Role of NADPH oxidase 4 in lipopolysaccharide-induced proinflammatory responses by human aortic endothelial cells. Cardiovasc Res. 2006; 72:447-455

154.Park KM, Chen A, Bonventre JV. Prevention of kidney ischemia/reperfusioninduced functional injury and JNK, p38, and MAPK kinase activation by remote ischemic pretreatment. J Biol Chem. 2001; 276(15):11870-11876

155.Parks DA, Bulkley GB, Granger DN. Role of oxygen free radicals in shock, ischemia, and organ preservation. Surgery 1983; 94(3):428-432

156.Peng WJ, Yu J, Deng S, Jiang JL, Deng HW, Li YJ. Effect of estrogen replacement treatment on ischemic preconditioning in isolated rat hearts. Can $J$ Physiol Pharmacol. 2004; 82(5):339-344 
157.Peralta C, Hotter G, Closa D, Gelpí E, Bulbena O, Roselló-Catafau J. Protective effect of preconditioning on the injury associated to hepatic ischemia-reperfusion in the rat: role of nitric oxide and adenosine. Hepatology 1997; 25(4):934-937

158.Pohlman TH, Stanness KA, Beatty PG, Ochs HD, Harlan JM. An endothelial cell surface factor(s) induced in vitro by lipopolysaccharide, interleukin 1, and tumor necrosis factor-alpha increases neutrophil adherence by a CDw18-dependent mechanism. J Immunol. 1986; 136(12):4548-4553

159.Powell SR, Tortolani AJ. Recent advances in the role of reactive oxygen intermediates in ischemic injury. I. Evidence demonstrating presence of reactive oxygen intermediates; II. Role of metals in site-specific formation of radicals. J Surg Res. 1992; 53:417-429

160.Przyklenk K, Bauer B, Ovize M, Kloner RA, Whittaker P. Regional ischemic 'preconditioning' protects remote virgin myocardium from subsequent sustained coronary occlusion. Circulation 1993; 87(3):893-899

161.Quarrie R, Lee DS, Steinbaugh G, Cramer B, Erdahl W, Pfeiffer DR, Zweier JL, Crestanello JA. Ischemic preconditioning preserves mitochondrial membrane potential and limits reactive oxygen species production. J Surg Res. 2012; 178(1):817

162.Raisz LG. Pathogenesis of osteoporosis: concepts, conflicts, and prospects. J Clin Invest. 2005; 115(12):3318-3325

163. Ray R, Murdoch CE, Wang M, Santos CX, Zhang M, Alom-Ruiz S, Anilkumar N, Ouattara A, Cave AC, Walker SJ, Grieve DJ, Charles RL, Eaton P, Brewer AC, Shah AM. Endothelial Nox4 NADPH oxidase enhances vasodilatation and reduces blood pressure in vivo. Arterioscler Thromb Vasc Biol. 2011; 31:1368-1376

164.Reynolds JM, McDonagh PF. Early in reperfusion, leukocytes alter perfused coronary capillarity and vascular resistance. Am J Physiol. 1989; 256(4 Pt 2):H982989

165.Rolo AP, Teodoro JS, Peralta C, Rosello-Catafau J, Palmeira CM. Prevention of I/R injury in fatty livers by ischemic preconditioning is associated with increased mitochondrial tolerance: the key role of ATPsynthase and mitochondrial permeability transition. Transpl Int. 2009; 22(11):1081-1090

166.Rucker M, Schafer T, Roesken F, Spitzer WJ, Bauer M, Menger MD. Reduction of inflammatory response in composite flap transfer by local stress conditioninginduced heat-shock protein 32. Surgery 2001; 129(3):292-301 
167.Rybicka JM, Balce DR, Khan MF, Krohn RM, Yates RM. NADPH oxidase activity controls phagosomal proteolysis in macrophages through modulation of the lumenal redox environment of phagosomes. Proc Natl Acad Sci U S A. 2010; 107(23):1049610501

168.Santizo RA, Anderson S, Ye S, Koenig HM, Pelligrino DA. Effects of estrogen on leukocyte adhesion after transient forebrain ischemia. Stroke 2000; 31,2231-2235

169.Sbarouni E, Iliodromitis EK, Zoga A, Vlachou G, Andreadou I, Kremastinos DT. The effect of the phytoestrogen genistein on myocardial protection, preconditioning and oxidative stress. Cardiovasc Drugs Ther. 2006; 20(4):253-258

170.Schaser KD, Zhang L, Haas NP, Mittlmeier T, Duda G, Bail HJ. Temporal profile of microvascular disturbances in rat tibial periosteum following closed soft tissue trauma. Langenbecks Arch Surg. 2003; 388:323-330

171.Schauer RJ, Bilzer M, Kalmuk S, Gerbes AL, Leiderer R, Schildberg FW, Messmer K. Microcirculatory failure after rat liver transplantation is related to Kupffer cellderived oxidant stress but not involved in early graft dysfunction. Transplantation 2001; 72(10):1692-1699

172.Schmidt HH, Wingler K, Kleinschnitz C, Dusting G. NOX4 is a Janus-faced reactive oxygen species generating NADPH oxidase. Circ Res. 2012; 111:e15-16

173.Schreinemachers MC, Doorschodt BM, Florquin S, van den Bergh Weerman MA, Reitsma JB, Lai W, Sitzia M, Minor TM, Tolba RH, van Gulik TM. Improved preservation and microcirculation with POLYSOL after transplantation in a porcine kidney autotransplantation model. Nephrol Dial Transplant 2009; 24:816

174.Schröder K, Zhang M, Benkhoff S, Mieth A, Pliquett R, Kosowski J, Kruse C, Luedike P, Michaelis UR, Weissmann N, Dimmeler S, Shah AM, Brandes RP. Nox4 is a protective reactive oxygen species generating vascular NADPH oxidase. Circ Res 2012; 110:1217-1225

175.Schuiling KD, Robinia K, Nye R. Osteoporosis update. J Midwifery Womens Health. $2011 ; 56(6): 615-627$

176.Seekamp A, Warren JS, Remick DG, Till GO, Ward PA. Requirements for tumor necrosis factor-alpha and interleukin-1 in limb ischemia/reperfusion injury and associated lung injury. Am J Pathol. 1993; 143(2):453-463

177.Seelig MS, Altura BM, Altura BT. Benefits and risks of sex hormone replacement in postmenopausal women. Journal of the American College of Nutrition 2004; 23,S482-496 
178.Serafín A, Roselló-Catafau J, Prats N, Xaus C, Gelpí E, Peralta C. Ischemic preconditioning increases the tolerance of Fatty liver to hepatic ischemia-reperfusion injury in the rat. Am J Pathol. 2002; 161(2):587-601

179.Sharma JP, Salhotra R. Tourniquets in orthopedic surgery. Indian J Orthop. 2012; 46(4):377-383

180.Shinmura K, Nagai M, Tamaki K, Bolli R. Loss of ischaemic preconditioning in ovariectomized rat hearts: possible involvement of impaired protein kinase $\mathrm{C}$ epsilon phosphorylation. Cardiovasc Res. 2008; 79(3):387-394

181.Sims NA, Morris HA, Moore RJ, Durbridge TC. Estradiol treatment transiently increases trabecular bone volume in ovariectomized rats. Bone 1996; 19(5):455-461

182.Song X, Li G, Vaage J, Valen G. Effects of sex, gonadectomy, and oestrogen substitution on ischaemic preconditioning and ischaemia-reperfusion injury in mice. Acta Physiol Scand. 2003; 177(4):459-466

183.Sorescu D, Griendling KK. Reactive oxygen species, mitochondria, and NAD(P)H oxidases in the development and progression of heart failure. Congest Heart Fail. 2002; 8:132-140

184.Soukhova-O'Hare G, Lei Z, Falcone JC Barati MT, Feitelson JB, Rao ChV, Fleming JT. Bone medullary arterioles from ovariectomized rats have smaller baseline diameters but normal eNOS expression and NO-mediated dilation. Life Sciences 2005; 77,1799-1812

185.Spencer NY, Zhou W, Li Q, Zhang Y, Luo M, Yan Z, Lynch TJ, Abbott D, Banfi B, Engelhardt JF. Hepatocytes produce TNF- $\alpha$ following hypoxia-reoxygenation and liver ischemia-reperfusion in a NADPH oxidase- and c-Src-dependent manner. Am J Physiol Gastrointest Liver Physiol. 2013; 305:G84-94

186.Sperry JL, Nathens AB, Frankel HL Vanek SL, Moore EE, Maier RV, Minei JP. Characterization of the gender dimorphism after injury and hemorrhagic shock: are hormonal differences responsible? Critical Care Medicine 2008; 36,1838-1845

187.Springer TA. Adhesion receptors of the immune system. Nature 1990; 346(6283):425-434

188.Srivastava S, Weitzmann MN, Cenci S, Ross FP, Adler S, Pacifici R. Estrogen decreases TNF gene expression by blocking JNK activity and the resulting production of c-Jun and JunD. Journal of Clinical Investigation 1999; 104,503-513 
189.Starr A, Graepel R, Keeble J, Schmidhuber S, Clark N, Grant A, Shah AM, Brain SD. A reactive oxygen species-mediated component in neurogenic vasodilatation. Cardiovasc Res. 2008; 78:139-147

190.Stupka N, Tiidus PM. Effects of ovariectomy and estrogen on ischemia-reperfusion injury in hindlimbs of female rats. Journal of Applied Physiology 2001; 91,18281835

191.Sugama Y, Tiruppathi C, offakidevi K, Andersen TT, Fenton JW 2nd, Malik AB. Thrombin-induced expression of endothelial P-selectin and intercellular adhesion molecule-1: a mechanism for stabilizing neutrophil adhesion. J Cell Biol. 1992; 119(4):935-944

192.Suzuki M, Grisham MB, Granger DN: Leukocyte-endothelial cell adhesive interactions: role of xanthine oxidase-derived oxidants. J Leukoc Biol. 1991; 50:488494

193.Suzuki M, Inauen W, Kvietys PR, Grisham MB, Meininger C, Schelling ME, Granger HJ, Granger DN: Superoxide mediates reperfusion-induced leukocyteendothelial cell interactions. Am J Physiol 1989; 257:H1740-1745

194.Szabó A, Varga R, Keresztes M, Vízler C, Németh I, Rázga Z, Boros M. Ischemic limb preconditioning downregulates systemic inflammatory activation. J Orthop Res. 2009; 27:897-902

195.Takac I, Schröder K, Zhang L, Lardy B, Anilkumar N, Lambeth JD, Shah AM, Morel F, Brandes RP. The E-loop is involved in hydrogen peroxide formation by the NADPH oxidase Nox4. J Biol Chem. 2011; 286:13304-13313

196.Takaoka A, Nakae I, Mitsunami K, Yabe T, Morikawa S, Inubushi T, Kinoshita M. Renal ischemia/reperfusion remotely improves myocardial energy metabolism during myocardialischemia via adenosine receptors in rabbits: effects of "remote preconditioning". J Am Coll Cardiol. 1999; 33(2):556-564

197.Tan Z, Wang TH, Yang D, Fu XD, Pan JY. Mechanisms of 17beta-estradiol on the production of ET-1 in ovariectomized rats. Life Sciences 2003; 73,2665-2674

198.Taniguchi M, Uchinami M, Doi K, Yoshida M, Sasaki H, Tamagawa K, Horiuchi T, Tanaka K. Edaravone reduces ischemia-reperfusion injury mediators in rat liver. $J$ Surg Res. 2007; 137: 69

199. Tapuria N, Kumar Y, Habib MM, Abu Amara M, Seifalian AM, Davidson BR. Remote ischaemic preconditioning: a novel protective method from ischemia reperfusion injury - a review. J Surg Res. 2008; 150:304-330 
200.Tejima K, Arai M, Ikeda H, Tomiya T, Yanase M, Inoue Y, Nagashima K, Nishikawa T, Watanabe N, Omata M, Fujiwara K. Ischemic preconditioning protects hepatocytes via reactive oxygen species derived from Kupffer cells in rats. Gastroenterology 2004; 127(5):1488-1496

201.Tejima K, Arai M, Ikeda H, Tomiya T, Yanase M, Inoue Y, Nishikawa T, Watanabe N, Ohtomo N, Omata M, Fujiwara K. Induction of ischemic tolerance in rat liver via reduced nicotinamide adenine dinucleotide phosphate oxidase in Kupffer cells. World J Gastroenterol. 2007; 13(38):5071-5078

202.Teoh NC, Farrell GC. Hepatic ischemia reperfusion injury: pathogenic mechanisms and basis for hepatoprotection. J Gastroenterol Hepatol. 2003; 18(8):891-902

203. Thirunavukkarasu M, Adluri RS, Juhasz B, Samuel SM, Zhan L, Kaur A, Maulik G, Sanchez JA, Hager J, Maulik N. Novel role of NADPH oxidase in ischemic myocardium: a study with Nox2 knockout mice. Funct Integr Genomics. 2012; $12: 501-514$

204.Tsang A, Hausenloy DJ, Mocanu MM, Yellon DM. Postconditioning: a form of "modified reperfusion" protects the myocardium by activating the phosphatidylinositol 3-kinase-Akt pathway. Circ Res 2004; 95:230-232

205.Utvag SE, Grundnes O, Reikeras O. Effects of lesion between bone, periosteum and muscle on fracture healing in rats. Acta Orthop Scand. 1998; 69:177-180

206. Varga R, Török L, Szabó A, Kovács F, Keresztes M, Varga G, Kaszaki J, Boros M. Effects of colloid solutions on ischemia-reperfusion-induced periosteal microcirculatory and inflammatory reactions: comparison of dextran, gelatin, and hydroxyethyl starch. Critical Care Medicine 2008; 36,2828-2837

207. Vega VL, Maldonado M, Mardones L, Schulz B, Manrïquez V, Vivaldi E, Roa J, Ward PH. Role of Küpffer cells and PMN leukocytes in hepatic and systemic oxidative stress in rats subjected to tourniquet shock. Shock 1999; 11(6):403-410

208. Vollmar B, Glasz J, Leiderer R, Post S, and Menger M.D. Hepatic microcirculatory perfusion failure is a determinant of liver dysfunction in warm ischemia-reperfusion. Am J Pathol. 1994; 145:1421-1431

209. Walsch SR, Tang T, Sadat U, Dutka DP, Gaunt ME. Cardioprotection by remote ischaemic preconditioning. Br J Anaesth. 2007; 99:611-616

210.Wang Q, Sun AY, Simonyi A, Kalogeris TJ, Miller DK, Sun GY, Korthuis RJ. Ethanol preconditioning protects against ischemia/reperfusion-induced brain damage: role of NADPH oxidase-derived ROS. Free Radic Biol Med. 2007; 43:1048-1060 
211.Wang YP, Maeta H, Mizoguchi K, Suzuki T, Yamashita Y, Oe M. Intestinal ischemia preconditions myocardium: role of protein kinase $\mathrm{C}$ and mitochondrial $\mathrm{K}$ channel. Cardiovav Res. 2002; 55:576-582

212.Wankowicz Z, Megyeri P, Issekutz A. Synergy between tumour necrosis factor alpha and interleukin-1 in the induction of polymorphonuclear leukocyte migration during inflammation. J Leukoc Biol. 1988; 43(4):349-356

213.Wanner GA, Ertel W, Müller P, Höfer Y, Leiderer R, Menger MD, Messmer K. Liver ischemia and reperfusion induces a systemic inflammatory response through Kupffer cell activation. Shock 1996; 5(1):34-40

214. Watanabe Y, Littleton-Kearney MT, Traystman RJ, Hurn PD. Estrogen restores postischemic pial microvascular dilation. American Journal of Physiology 2001; 281,H155-160

215. Wei D, Ren C, Chen X, Zhao H. The chronic protective effects of limb remote preconditioning and the underlying mechanisms involved in inflammatory factors in rat stroke. PLoS One. 2012; 7(2):e30892

216. Wichmann MW, Inthorn D, Andress HJ, Schildberg FW. Incidence and mortality of severe sepsis in surgical intensive care patients: the influence of patient gender on disease process and outcome. Intensive Care Medicine 2000; 26,167-172

217. Williams AF, Barclay AN. The immunoglobulin superfamily-domains for cell surface recognition. Annu Rev Immunol. 1988; 6:381-405

218. Wolfárd A, Császár J, Gera L, Petri A, Simonka JA, Balogh A, Boros M. Endothelin-a receptor antagonist treatment improves the periosteal microcirculation after hindlimb ischemia and reperfusion in the rat. Microcirculation 2002; 9,471-476

219. Wronski TJ, Walsh CC, Ignaszewski LA. Histologic evidence for osteopenia and increased bone turnover in ovariectomized rats. Bone 1986; 7,119-123

220.Xing D, Feng W, Miller AP, Weathington NM, Chen YF, Novak L, Blalock JE, Oparil S. Estrogen modulates TNF-alpha-induced inflammatory responses in rat aortic smooth muscle cells through estrogen receptor-beta activation. American Journal of Physiology 2007; 292,H2607-2612

221.Xu HL, Baughman VL, Pelligrino DA. Estrogen replacement treatment in diabetic ovariectomized female rats potentiates postischemic leukocyte adhesion in cerebral venules. Stroke 2004; 35,1974-1978 
222.Xu HL, Santizo RA, Koenig HM, Pelligrino DA. Chronic estrogen depletion alters adenosine diphosphate-induced pial arteriolar dilation in femalerats. Am J Physiol Heart Circ Physiol. 2001; 281(5):H2105-2112

223. Yellon DM, Downey JM. Preconditioning the myocardium: from cellular physiology to clinical cardiology. Physiol Rev. 2003; 83(4):1113-1151

224. Yoshizumi M, Perrella MA, Burnett JC Jr, Lee ME. Tumor necrosis factor downregulates an endothelial nitric oxide synthase mRNA by shortening its half-life. Circulation Research 1993; 73, 205-209

225. Yuan GJ, Ma JC, Gong ZJ, Sun XM, Zheng SH, Li X. Modulation of liver oxidantantioxidant system by ischemic preconditioning during ischemia/reperfusion injury in rats. World J Gastroenterol. 2005; 11:1825-1828

226. Yuan HJ, Zhu XH, Luo Q, Wu YN, Kang Y, Jiao JJ, Gao WZ, Liu YX, Lou JS. Noninvasive delayed limb ischemic preconditioning in rats increases antioxidant activities in cerebral tissue during severe ischemia-reperfusion injury. J Surg Res. 2012; 174:176-183

227.Zhang L, Bail H, Mittlmeier T, Haas NP, Schaser K. Immediate microcirculatory derangements in skeletal muscle and periosteum after closed tibial fracture. Journal of Trauma 2003; 54,979-985

228.Zhao ZQ, Corvera JS, Halkos ME, Kerendi F, Wang NP, Guyton RA, VintenJohansen J. Inhibition of myocardial injury by ischemic postconditioning during reperfusion: comparison with ischemic preconditioning. Am J Physiol Heart Circ Physiol. 2003; 285(2):H579-588

229.Zicha J, Dobesová Z, Kunes J. Relative deficiency of nitric oxide-dependent vasodilation in salt-hypertensive Dahl rats: the possible role of superoxide anions. $J$ Hypertens. 2001; 19:247-254

230.Zitta K, Meybohm P, Bein B, Gruenewald M, Lauer F, Steinfath M, Cremer J, Zacharowski K, Albrecht M. Activities of cardiac tissue matrix metalloproteinases 2 and 9 are reduced by remote ischemic preconditioning in cardiosurgical patients with cardiopulmonary bypass. J Transl Med. 2014; 12:94 
9. ANNEX 
I. 


\title{
MICROCIRCULATORY CONSEQUENCES OF OSTEOPOROSIS
}

\author{
Petra Hartmann ${ }^{1}$, Ferenc Greksa ${ }^{2}$, Dénes Garab ${ }^{1}$, Renáta Varga ${ }^{3}$, \\ Márta Széll ${ }^{4}$, Margit Keresztes ${ }^{5}$, Mihály Boros ${ }^{1}$, Andrea Szabó ${ }^{1}$
}

\begin{abstract}
REZUMAT
Introducere. Etiologia sindromului de osteoporoza senila este plurifactorial, dar nivelul scazut de estrogeni la femeile aflate in perimenopauza este clar asociat cu o pierdere accelerata de material osos. In cadrul studiului nostru experimental, au fost investigate consecintele osteoporozei si a terapiei cronice cu estrogeni asupra reactiilor inflamatorii de la nivelul microcirculatiei periostale si a expresiei receptorilor de estrogeni. Material si metoda. Dupa sase luni de la initierea terapiei de substitutie cu estrogeni cu $17 \beta$-estradiol $\left(E 2,20 \mathrm{\mu g}^{-1} \mathrm{~kg}^{-1} \mathrm{zl}^{-1}\right)$ la sobolani Sprague-Dawley ovarectomizati (OVX), au fost examinate consecintele inflamatorii la nivel de microcirculatie la 60-min de ischemie totala a membrului posterior si dupa reperfuzie la 180-min. Modificarea expresiei receptorului de estrogen de la nivel leucocitar a fost de asemenea evaluata la o luna de la OVX sub tratament cu E2. Rezultate: In afara de inversarea efectelor osteopenice ale OVX, tratamentul amelioreaza semnificativ cresterea aderentei leucocitelor neutrofile indusa de reperfuzarea zonei ischemice la nivelul venulelor postcapilare de la nivelul periostului (vizualizat prin microscopie cu fluorescenta). Acest efect nu a fost asociat cu reducerea expresiei CD11b de la nivelul leucocitelor neutrofile (analiza FACS). OVX a determinat o scadere moderata a expresiei proteinei ER-beta de la nivelul receptorului de estrogen leucocitar, care tinde sa fie inversata de E2. Nivelele mRNA ER-alpha si ER-beta (RT-PCR) a leucocitelor si expresia proteinei ER-alpha (Western blotting) au fost sub limita de detectie. Concluzii: Suplimentarea cronica de estrogeni amelioreaza eficient osteoporoza si consecintele microcirculatorii inflamatorii ale ischemiei tranzitorii de la nivelul membrului. Se pare ca acest efect nu este mediat de leucocite CD11b sau de modificari ale expresiei receptorilor de estrogeni.
\end{abstract}

Cuvinte cheie: ovarectomie, ischemie-reperfuzie, neutrofil, microscopie in vivo, recptor de estrogen

\begin{abstract}
Introduction. The etiology of senile osteoporosis syndrome is multifactorial, but the reduced estrogen levels in peri-menopausal women are clearly associated with an accelerated bone loss. In our experimental studies, the consequences of osteoporosis and chronic estrogen supplementation were investigated on the periosteal microcirculatory inflammatory reactions and estrogen receptor expressions. Material and method. Six months after the initiation of estrogen replacement therapy with $17 \beta$-estradiol $\left(E 2,20 \mu^{-1} \mathrm{~kg}^{-1} \mathrm{day}^{-1}\right)$ in ovariectomized (OVX) Sprague-Dawley rats, the microcirculatory inflammatory consequences of 60 -min total hindlimb ischemia followed by 180 -min reperfusion were examined. Leukocyte estrogen receptor expression changes were also assessed 1 month after OVX plus E2 treatment. Results. Apart from reversing the osteopenic effects of OVX, E2 treatment significantly ameliorated the ischemia-reperfusion-induced elevation of neutrophil leukocyte adherence to the postcapillary venules of the periosteum (visualized by means of intravital fluorescence microscopy). This effect was not associated with a reduction of CD11b expression of the neutrophil leukocytes (FACS analysis). OVX caused a moderate decrease in leukocyte estrogen receptor (ER)-beta protein expression which tended to be reversed by E2. Leukocyte ER-alpha and ER-beta mRNA levels (RT-PCR) and the ER-alpha protein expression (Western blotting) were below the detection limit. Conclusions. Chronic estrogen supplementation efficiently ameliorates osteoporosis and the inflammatory microcirculatory consequences of transient limb ischemia. It appears that this effect is not mediated by leukocyte CD11b, or estrogen receptor expression changes.
\end{abstract}

Key words: ovariectomy, ischemia-reperfusion, neutrophil, intravital microscopy, estrogen receptor

${ }^{1}$ Institute of Surgical Research, University of Szeged, Hungary

2Department of Orthopaedics, University of Szeged, Hungary

${ }^{3}$ Department of Oral and Maxillofacial Surgery, University of Szeged, Hungary

${ }^{4}$ Department of Dermatology and Allergology, University of Szeged, Hungary

${ }^{5}$ Institute of Biochemistry, University of Szeged, Hungary

Correspondence to:

Andrea Szabó

Institute of Surgical Research, University of Szeged, H-6720 Szeged,

Pécsi u. 6, Hungary,

Phone: + 3662545103 , Fax: +3662545743

E-mail: sza@expsur.szote.u-szeged.hu

Received for publication: Nov. 26, 2010. Revised: Dec. 03, 2010.

\section{INTRODUCTION}

Osteoporosis is the most common disease in the elderly population which progressively weakens bones and often leads to painful accidental fractures. The primary causative therapy is chronic estrogen supplementation which prevents or reverses osteopenic bone loss, and also exerts protection against different inflammatory processes ${ }^{1}$. Apart from their pivotal role in sexual development and reproduction, estrogens (in particular 17ß-estradiol, E2) play a remarkable role in the modulation of the cardiovascular system. Some of circulatory effects of $\mathrm{E} 2$ are mediated by the

100 TMJ 2010, Vol. 60 Supplement 2 
influencing of endothelial production of nitric oxide and prostacyclin ${ }^{2}$. Besides, E2 also promotes endothelial healing and angiogenesis. ${ }^{3}$ Both acetylcholine-induced and flow-dependent vasodilation are preserved or potentiated by estrogen treatment. ${ }^{4}$

The role of estrogen receptors in the mediation of microcirculatory reactions is yet largely unknown. Estrogen actions are essentially mediated by two molecular targets: estrogen receptor-alpha (ERalpha) and ER-beta. The impact of ER-beta has been addressed in vitro only, but a prominent role has been attributed to these receptors in the vascular biology ${ }^{5}$ (for review see at Arnal JF et al. ${ }^{\circ}$ ). E2 causes vasodilation via ER-alpha receptors which effect is lost in ovariectomized (OVX) rats. ${ }^{7}$ Besides, it has been shown that OVX leads to the down-regulation of ER-alpha expression in the vasculature. ${ }^{8}$

As the prevalence of skeletal injuries increase after menopause, our studies were designed to determine the potential microcirculatory benefit of $\mathrm{E} 2$ in a limb ischemia-reperfusion model of osteoporosis. An ovariectomized rat model with clinically relevant time frame was used which shares many similarities with the human disease?. Our aims were (1) to examine the consequences of osteoporosis on the postischemic periosteal microcirculatory reactions, (2) to evaluate the effects and the consequences of chronic estrogen on these microcirculatory reactions, and (3) to clarify whether the mechanisms of microcirculatory reactions provided by $\mathrm{E} 2$ are mediated by expression changes of ER-alpha or ER-beta.

\section{MATERIALS AND METHODS}

\section{Animals and experimental design}

The experiments were carried out on female Sprague-Dawley rats housed in an environmentally controlled room with a 12-h light-dark cycle, and kept on commercial rat chow (Charles River, Wilmington, MA, USA) and tap water ad libitum. The experimental protocol was approved by the local animal rights protection authorities and followed the EC Directive 86/609/EEC and the National Institutes of Health guidelines for the care and use of laboratory animals.

The experiments were performed in two series. In the first experimental series, 3-months-old animals (weighting 200-210 g) were ovariectomized (Group 1, OVX, $n=12$ ), or sham-operation was performed (Group 2, SH-OVX, $\mathrm{n}=12$; see methods at Szabó et $a l^{9}{ }^{9}$. Five months later (at the age of 8 months), chronic estrogen therapy ${ }^{10}$ was initiated 5 days per week with $20 \mu \mathrm{g} \mathrm{kg}^{-1}$ sc 17B-estradiol (E2, (Sigma,
St. Louis, MO, USA) in 6 animals of the OVX group (Group 1a, OVX+E2). The E2 substitution was continued weekly until the end of the experiments (see time scheme in Fig. 1).

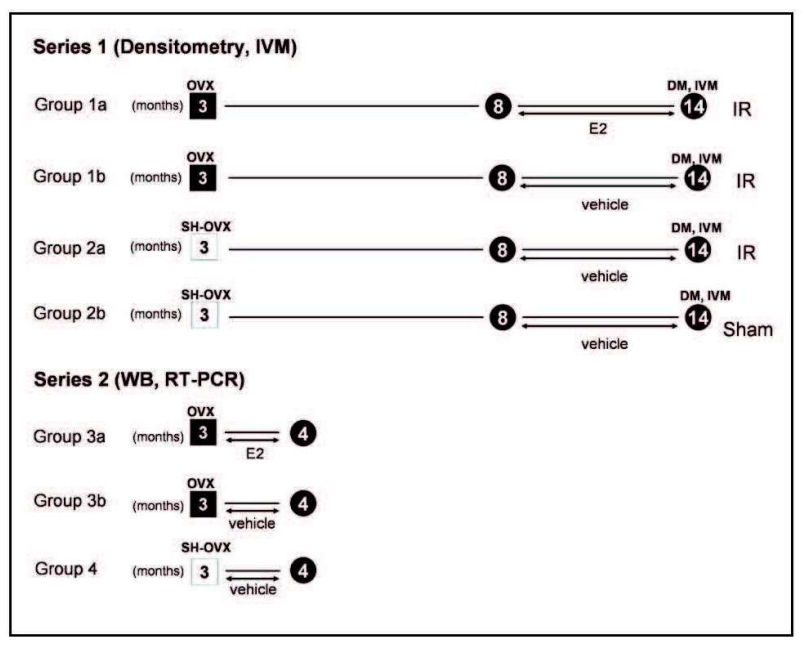

Figure 1. Experimental protocol. The time sequence of surgical interventions, treatments and measurements in Series 1 and Series 2. $\mathrm{OVX}=$ ovariectomy; $S H-O V X=$ sham operation for ovariectomy; $\mathrm{DM}=$ densitometry; $\quad \mathbb{R}=$ =ischemia-reperfusion; $\quad$ Sham=non-ischemic control; IVM=intravital microscopy, E2=17ß-estradiol treatment; WB=Western blotting; RT-PCR=real-time PCR.

The development of osteoporosis was detected by means of ultrasonic densitometry eleven months after OVX, and then microcirculatory consequences of a 60-min complete hindlimb ischemia followed by a 180-min reperfusion period (IR) were investigated using intravital video microscopy (IVM, in groups OVX+IR, OVX+E2+IR and SH-OVX+IR). Total limb ischemia was induced by applying a tourniquet around the thigh and placing a miniclip on the femoral artery. Six animals in the SH-OVX group served as non-ischemic controls SH-OVX+SH. Recordings of the tibial periosteal microcirculation were performed before ischemia and at the end of the 180-min reperfusion period.

A second series of experiments was performed to detect changes in expression of ER-alpha and beta in polymorphonuclear leukocytes (PMNs, by western blotting and real time-PCR). OVX was induced in 8 rats, 4 of which received $20 \mu \mathrm{g} \mathrm{kg}-1 \mathrm{E} 2$ supplementation (Group 3a) (in the former dose), starting 2 days after the OVX, while the remaining 4 rats were injected with vehicle (Group 3b). Vehicletreated sham-operated animals served as controls (Group $4 ; n=5$ ). 28 days after the OVX, PMNs were isolated from these animals for the determination of ER-alpha and ER-beta protein contents with Western blot analysis and mRNA expressions. 


\section{Intravital video microscopy}

At the age of 14 months of the animals, the periosteum of the medial surface of the right tibia was exposed under a Zeiss $6 \mathrm{x}$ magnification operating microscope, using an atraumatic surgical technique ${ }^{19}$ using pentobarbital anesthesia ( $45 \mathrm{mg} \mathrm{kg}^{-1}$ ip). The right hindlimb with the exposed tibial periosteum was positioned horizontally on an adjustable stage, and the microcirculation of the proximal tibia was visualized by IVM (Zeiss Axiotech Vario 100HD microscope, $100 \mathrm{~W}$ HBO mercury lamp, Acroplan 20x water immersion objective, Carl Zeiss GmbH, Jena, Germany), using fluorescein isothiocyanate (Sigma, St. Louis, MO, USA)-labeled erythrocytes (0.2 $\mathrm{ml}$ iv) for red blood cell staining, and rhodamine $6 \mathrm{G}$ (Sigma, St. Louis, MO, USA, 0.2\%, $0.1 \mathrm{ml}$ iv) for PMN staining. The microscopic images were recorded with a charge-coupled device video camera (AVT HORNBC 12, Aalen, Germany) attached to an S-VHS video recorder (Panasonic AG-MD 830, Matsushita Electric Industrial Co., Tokyo, Japan) and a personal computer.

\section{Video analysis}

Quantitative assessment of the microcirculatory parameters was performed off-line by frame-to-frame analysis of the videotaped images, using image analysis software (IVM, Pictron Ltd., Budapest, Hungary). Leukocyte-endothelial cell interactions were analyzed within 5 postcapillary venules (diameter between 11 and $20 \mu \mathrm{m}$ ) per animal. Adherent leukocytes (stickers) were defined in each vessel segment as cells that did not move or detach from the endothelial lining within an observation period of $30 \mathrm{~s}$, and are reported as the number of cells per $\mathrm{mm}^{2}$ of endothelial surface. Rolling leukocytes were defined as cells moving at a velocity less than $40 \%$ of that of the erythrocytes in the centerline of the microvessel, and given as the number of cells/vessel circumference in $\mathrm{mm}$.

\section{Flow cytometric analysis of CD11b expression on leukocytes}

The surface expression of CD11b on peripheral blood granulocytes was determined by whole blood flow-cytometric analysis (a modification of a literature

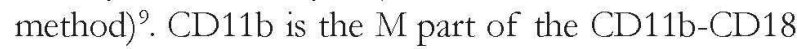
complex which binds to its endothelial counterpart ICAM-1 resulting in leukocyte adhesion to the venular endothelium (a process which can directly be observed with IVM.

\section{Isolation of PMN leukocytes from the blood}

PMN leukocytes were isolated by a method described by Russo-Racolante EMS et al.. ${ }^{12}$ The viability of the PMNs was found to be $80-95 \%$ (by the trypan blue exclusion test) and the purity of the suspension was $>80 \%$ (with the May-Grünwald/ Giemsa staining on cell smears). The cell number in $0.1 \mathrm{ml}$ of suspension was in the range $3.5-5.8 \times 10^{6}$.

The suspension was divided into two portions. Fifty $\mu \mathrm{l}$ of suspension was frozen and later used for the detection of ER-alpha and ER-beta protein by Western blot analysis. The remaining suspension was dissolved in TRIzol buffer and frozen for the later evaluation of ER-alpha and ER-beta mRNA expression by real-time PCR.

\section{Western blotting procedure}

SDS-polyacrylamide gel electrophoresis was performed on $10 \%$ gels; samples were applied without prior heating. Membrane proteins were transferred onto nitrocellulose membrane (Amersham Hybond-C Extra). After quenching with 5\% Blotto/Tween (5\% milk powder in Tris-buffered saline containing $0.2 \%$ Tween 20 ) for $1.5 \mathrm{~h}$, blots were incubated with the primary antibody overnight. The anti-estrogen receptor alpha rabbit polyclonal antibody (Thermo Fischer Scientific, Fremont, CA, USA) was used in a dilution of 1:150, while the dilution factor for the antiestrogen receptor beta mouse monoclonal antibody (Leica Biosystems Newcastle Ltd, Newcastle, UK) was 1:50. As secondary antibodies, either HRP-conjugated goat anti-rabbit immunoglobulins (DAKO Glostrup, Denmark) or HRP-conjugated anti-mouse IgG (R\&D Systems, Minneapolis, MN, USA) were employed at a dilution of 1:1000 for $1 \mathrm{~h}$. All the antibodies were diluted in 1\% Blotto/Tween (containing 1\% milk powder), and the washing steps were performed with Tris-buffered saline containing $0.2 \%$ Tween 20 . Labeled membrane proteins were visualized through a chemiluminescence reaction (Immobilon Western HRP substrate, Millipore, Billerica, MA, USA).

\section{Real-time PCR}

Total RNA was isolated from cell lysates with TRIzol $^{\text {TM }}$ reagent (Gibco, Invitrogen, Carlsbad, CA, USA) following the manufacturer's instructions. RNA concentration was determined by measuring the A260 values. First-strand cDNA was synthetized from $1 \mathrm{mg}$ of total RNA, using the iScriptTM cDNA Synthesis Kit from Bio-Rad (Hercules, CA, USA). Real-time RT-PCR experiments were performed to quantify the relative abundance of each mRNA by using the iCycler IQ Real-Time PCR machine of Bio-Rad. The Universal Probe Library (UPL) system (Roche, Basel, Switzerland) was used to design primers and probes (see Table 1). Real-time RT-PCR reactions were performed in the FastStart TaqMan Probe Master mix (Roche, Basel, Switzerland), following the 
Table 1. Probes and primers used in the study

\begin{tabular}{llll}
\hline & Probe no. & Left primer & Right primer \\
\hline 18S & 77, Cat. no. 04689003001 & ctcaacacgggaaacctcac & cgctccaccaactaagaacg \\
ER-alpha & 130, Cat. no. 04693663001 & ttcttaagagaagcattcaaggac & tcttatcgatggtgcattgg \\
ER-beta & 111, Cat. no. 04693442001 & ggctgggccaagaaaatc & tctaagagccggacttggtc \\
\hline
\end{tabular}

manufacturer's instructions.

\section{Statistical analysis}

All data are expressed as means \pm standard error of the mean (SEM). Data analysis was performed with the SigmaStat statistical software (Jandel Corporation, San Rafael, CA, USA). Changes in variables within and between groups were analyzed by one-way ANOVA followed by the Bonferroni test. $P$ values $<0.05$ were considered statistically significant.

\section{RESULTS}

\section{Bone mineral density changes}

A decrease in bone density in the proximal portion of the tibias was observed 11 months after the ovariectomy (proving the development of osteopenia). This reaction could be reversed by the chronic E2 supplementation (Figure 2).

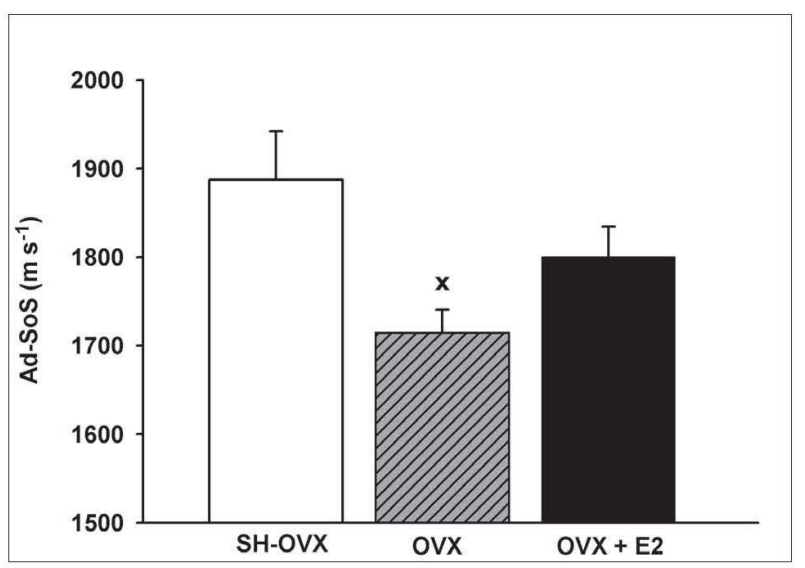

Figure 2. Bone density. Bone density changes in the proximal part of the tibia in sham-operated (SH-OVX), ovariectomized (OVX) or 17B-estradioltreated ovariectomized animals (OVX+E2) animals. Data are expressed as $\mathrm{Ad}-\mathrm{SOS}$ and presented as means \pm SEM. ANOVA was followed by the Bonferroni test. $X \mathrm{P}<0.05$ vs $\mathrm{SH}+\mathrm{OVX}$ group.

\section{Leukocyte-endothelial interactions}

Using intravital microscopy, a significant increase in the number of firmly adherent leukocytes (as compared to the baseline values or data of the sham-operated SH-OVX animals) was observed in the OVX+IR group by the $180^{\text {th }}$ min of reperfusion (Figure 3). No major differences, however, between the OVX+IR and OVX+SH+IR animals could be observed. These leukocyte-endothelial interactions were significantly ameliorated by $\mathrm{E} 2$ (see OVX+E2+IR group).

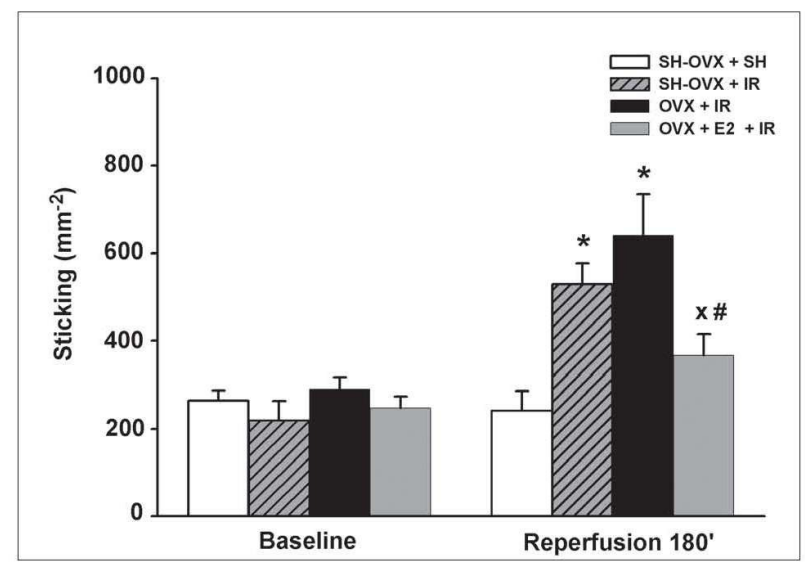

Figure 3. Leukocyte adherence. Firm adhesion (sticking) of neutrophil leukocytes in the postcapillary venules of the tibial periosteum in response to IR injury in sham-operated (SH-OVX+IR), ovariectomized (OVX+IR) or 17B-estradiol-treated ovariectomized animals (OVX+E2+lR) animals in comparison with sham-operated animals without IR $(\mathrm{SH}-\mathrm{OVX}+\mathrm{SH})$. Data are presented as means \pm SEM. ANOVA was followed by the Bonferroni test. ${ }^{*} P<0.05$ vs baseline, $X P<0.05$ vs $0 \mathrm{~V} X+\mathrm{IR}$ group, \# $P<0.05$ vs $\mathrm{SH}-\mathrm{OVX}+\mathrm{IR}$ group.

\section{CD11b expression changes}

The surface expression of adhesion molecule CD11b did not change significantly after sham operation, but the activation of the PMNs was increased approx. 1.8-fold in the OVX group subjected to IR (Figure 4). Similar increases were observed when SH-OVX animals or E2-treated OVX animals were subjected to IR.

Changes in ER-alpha and beta protein expression in the PMNs

On the basis of the available literature, a very low extent of ER expression was expected on the PMNs, hence relatively high amount of protein ( $75 \mu \mathrm{g} / \mathrm{lane})$ was loaded during the Western blotting procedures. 
Nevertheless, only low ER-alpha and ER-beta signals were detected, and we did not find statistically significant differences in ER-alpha expression within the different experimental groups (data no shown). ER-beta also afforded a very weak signal, which was weaker in the OVX animals in comparison with the Sham or OVX+E2 animals (Figure 5).

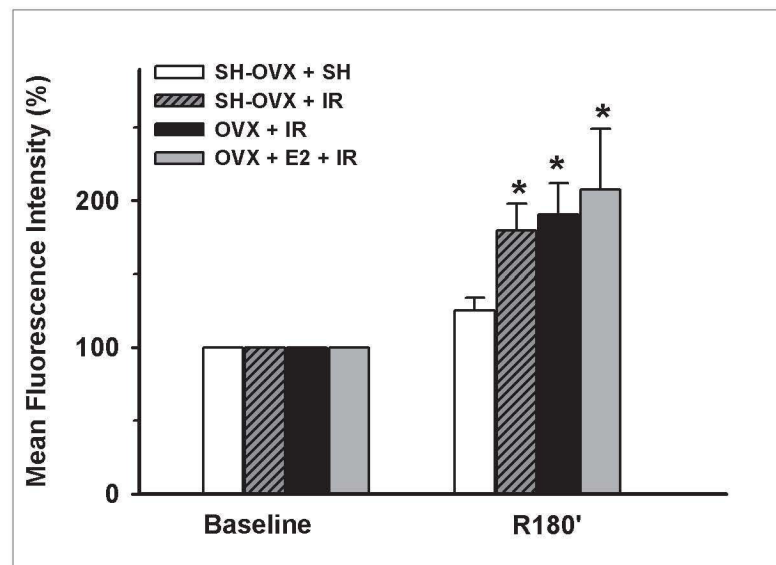

Figure 4. CD 11b expression. Changes in expression of the CD11b adhesion molecule on the surface appearance of PMN leukocytes in response to $60 \mathrm{~min}$ of ischemia followed by $180 \mathrm{~min}$ of reperfusion in sham-operated (SH-OVX+IR), ovariectomized (OVX+IR) or 17B-estradioltreated ovariectomized animals $(\mathrm{OVX}+\mathrm{E} 2+\mathrm{IR})$ animals in comparison with sham-operated animals without IR (SH-OVX+SH). Data are presented as means \pm SEM. ${ }^{*} \mathrm{P}<0.05$ vs baseline.

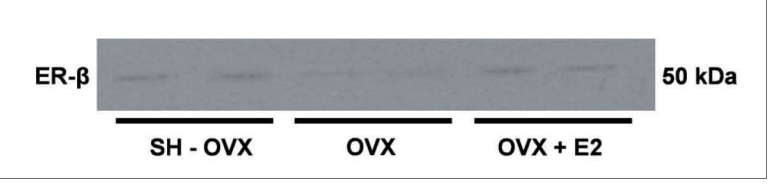

Figure 5. Estrogen receptor-beta protein expression. Representative Western blot demonstrating the expression of estrogen receptor beta $(E R \beta)$ in neutrophil leukocytes obtained from sham-operated (SH-OVX) or ovariectomized (OVX) or ovariectomized plus $17 B$-estradiol treated (OVX+E2) animals.

\section{Changes in ER-alpha and beta mRNA in the PMNs}

The ER-alpha mRNA content of the samples did not reach the limit of detection (Figure 6A). The ER-beta mRNA was detected in most of samples of the Sham group, but never in the OVX groups, while in the OVX+E2 group the data were inconclusive (Figure 6B).

The possibility of technical failure could be excluded, since the expression of $18 \mathrm{~S}$ RNA was very high and even in each cases, indicating that the amount and quality of the total RNA isolated from the cell lysates and the cDNA samples were satisfactorily high (Figure 6C).

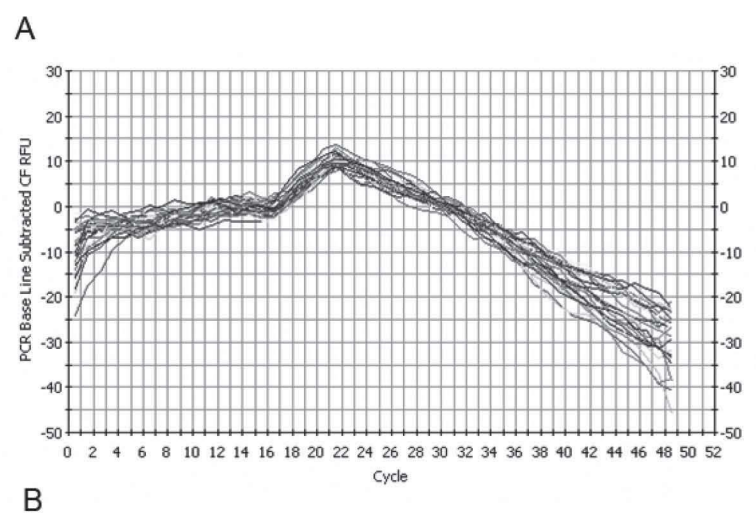

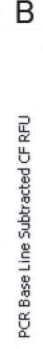

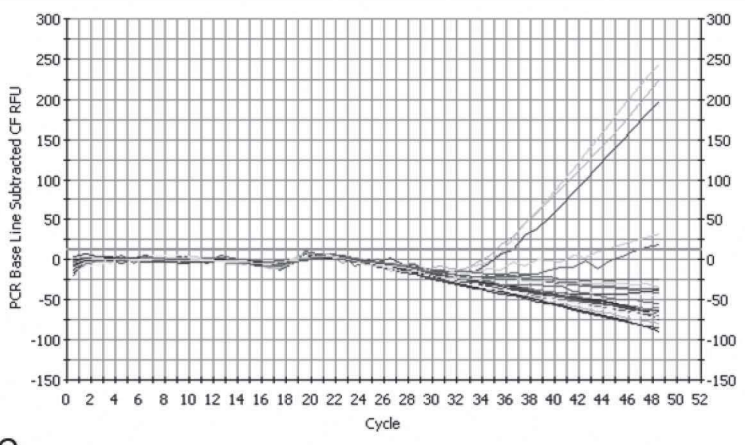

C

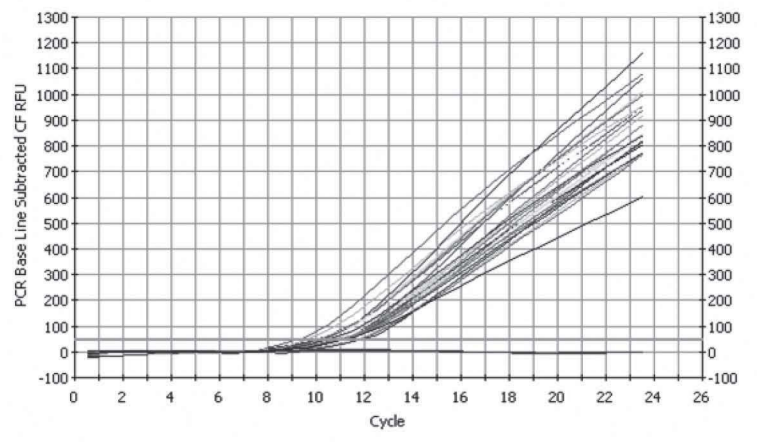

Figure 6. Estrogen receptor-alpha and beta mRNA expressions. Realtime PCR data for ER-alpha (A) and ER-beta (B) and 18S RNA signals of the samples $(\mathrm{C})$.

\section{$\underline{\text { DISCUSSION }}$}

The incidence of osteoporotic fractures remains to be high in the aging population..$^{13}$ So far it has not been clarified whether osteoporotic women are more prone to post-ischemic inflammatory bone complications than postmenopausal women receiving estrogen replacement therapy. In this study, we targeted this issue by applying an animal model of osteopenia combined with chronic estrogen replacement therapy. The periosteal microcirculatory consequences of tourniquet-caused ischemia were quantified by IVM after an adequately long-term follow-up of osteoporosis. The data show that osteoporosis or chronic estrogen deficit does not change the magnitude of the PMN-associated microcirculatory menace in 
the event of transient ischemia of the osteoporotic limb. In this condition, however, chronic estrogen supplementation ameliorates bone demineralization and also decreases systemic and PMN-driven local periosteal inflammatory reactions. The protective, anti-inflammatory effects of E2 regarding the PMN-endothelial interactions were evident without influencing the expressions of the adhesion molecule CD11b which plays a role in the adhesion process of the PMNs to the venular endothelium. In our previous studies we have shown the alleviation of ischemia-reperfusion-induced activation of leukocyteendothelial interactions after E2 treatment, but not the effect on ICAM-1 expression, the endothelial adhesion molecule being responsible to a final stage of leukocyte-endothelial interactions. Hence we extended the examinations on the effects of E2 on estrogen receptor expression changes in the PMNs.

To date little is known about the role of ER receptors during the course of neutrophil-mediated microcirculatory inflammatory reactions. In vitro studies generally agree on the positive effect of E2 and the modulatory role of ER receptors regarding the outcome of leukocyte-driven inflammatory processes. ${ }^{14}$ There are studies demonstrating that these reactions are dependent on ER-beta receptors. ${ }^{5}$ Others emphasized the significance of a biological (transcription) modulator effect, because E2 can modify (via ER-alpha) the phosphorilation of genes being responsible for the transcription of adhesion molecules that play roles in the process of leukocyteendothelial interactions. 15

In our studies, the expression of both ER receptor mRNA in the PMNs was under the detection limit of RT-PCR. Only a few papers were published on this issue, and the data are controversial. Considerable species differences were detected and $\mathrm{Yu}$ et al. demonstrated tissue-specific expression of ER-alpha and beta. ${ }^{16}$ Specifically, only the ER-beta protein was found in cows, but both subtypes could be traced at the mRNA level. ${ }^{17}$ In a human study only ER-beta mRNA was found, ${ }^{18}$ while in another study neither ER-alpha nor ER-beta mRNA were detected, though the proteins could be traced by Western blotting analysis. ${ }^{19}$ The levels of ER proteins were similarly low in our studies. In humans, both ER-alpha and ER-beta are present on PMNs, and E2 enhances the expression of both proteins. 20

\section{CONCLUSION}

In summary, chronic estrogen supplementation reduced the inflammatory complications caused by ischemia-reperfusion injury in the periosteal microcirculation, but the anti-inflammatory effects were mediated by mechanisms other than estrogen receptor expression changes on the circulating PMN leukocytes. As far as we are aware, this is the first report of leukocyte ER receptor expression in rats, and it is clear that further experiments are needed to improve the sensitivity of the methods to clearly define the potential role of estrogen receptors during the course of PMN-endothelial interactions.

\section{REFERENCES}

1. Burkhardt M, Slotta JE, Garcia P, et al. The effect of estrogen on hepatic microcirculation after ischemia/reperfusion. Int J Colorectal Dis 2008;23(1):113-9.

2. Tagawa H, Shimokawa H, Tagawa $T$, et al. Short-term estrogen augments both nitric oxide-mediated and non-nitric oxide-mediated endothelium-dependent forearm vasodilation in postmenopausal women. J Cardiovasc Pharmacol 1997;30(4):481-8.

3. Baruscotti I, Barchiesi F, Jackson EK, et al. Estradiol stimulates capillary formation by human endothelial progenitor cells: role of estrogen receptor- $\{$ alpha\} $/\{$ beta $\}$, heme oxygenase 1 , and tyrosine kinase. Hypertension 2010;56(3): 397-404.

4. Favre J, Gao J, Henry JP, et al. Endothelial estrogen receptor \{alpha\} plays an essential role in the coronary and myocardial protective effects of estradiol in ischemia/reperfusion. Arterioscler Thromb Vasc Biol 2010;30(12):2562-7.

5. Xing D, Feng W, Miller AP, et al. Estrogen modulates TNF-alphainduced inflammatory responses in rat aortic smooth muscle cells through estrogen receptor-beta activation. Am J Physiol 2007;292(6):H2607-12.

6. Arnal JF, Fontaine C, Billon-Galés A, et al. Estrogen receptors and endothelium. Arterioscler Thromb Vasc Biol 2010;30(8):1506-12.

7. Bolego C, Cignarella A, Sanvito P, et al. The acute estrogenic dilation of rat aorta is mediated solely by selective estrogen receptor-alpha agonists and is abolished by estrogen deprivation. J Pharmacol Exp Ther 2005;313(3):1203-8.

8. Stirone C, Duckles SP, Krause DN. Multiple forms of estrogen receptor-alpha in cerebral blood vessels: regulation by estrogen. Am J Physiol Endocrinol Metab 2003;284(1):E184-92.

9. Szabó A, Hartmann P, Varga R, et al. Periosteal microcirculatory action of chronic estrogen supplementation in osteoporotic rats challenged with tourniquet ischemia. Life Sci 2011;88(3-4): 156-62.

10. Sims NA, Morris HA, Moore RJ, et al. Estradiol treatment transiently increases trabecular bone volume in ovariectomized rats. Bone 1996;19(5),455-61.

11. Varga R, Török L, Szabó A, et al. Effects of colloid solutions on ischemia-reperfusion-induced periosteal microcirculatory and inflammatory reactions: comparison of dextran, gelatin, and hydroxyethyl starch. Crit Care Med 2008;36(10):2828-37.

12. Russo-Carbolante EMS, Azzolini AECS, Polizello ACM, et al. Comparative study of our isolation procedures to obtain rat neutrophils. Comparative Clin Pathol 2002;2: 71-6.

13. Gullberg B, Johnell O, Kanis JA. World-wide projections for hip fracture. Osteoporos Int 1997;7(5),407-13.

14. Eckhoff DE, Bilbao G, Frenette L, et al. 17-Beta-estradiol protects the liver against warm ischemia/reperfusion injury and is associated with increased serum nitric oxide and decreased tumor necrosis factor-alpha. Surgery 2002;132(2):302-9.

15. Geraldes P, Gagnon S, Hadjadj S, et al. Estradiol blocks the induction of CD40 and CD40L expression on endothelial cells and prevents neutrophil adhesion: an ERalpha-mediated pathway. Cardiovasc Res 2006;71(3):566-73.

16. Yu HP, Shimizu T, Hsieh YC, et al. Tissue-specific expression of estrogen receptors and their role in the regulation of neutrophil 
infiltration in various organs following trauma-hemorrhage. J Leukoc Biol 2006;79(5): 963-70.

17. Lamote I, Meyer E, De Ketelaere A, et al. Expression of the estrogen receptor in blood neutrophils of dairy cows during the periparturient period. Theriogenology 2006;65(6):1082-98.

18. Stefano GB, Cadet P, Breton C, et al. Estradiol-stimulated nitric oxide release in human granulocytes is dependent on intracellular calcium transients: evidence of a cell surface estrogen receptor. Blood
2000;95(12): 3951-8.

19. Stygar D, Westlund P, Eriksson $\mathrm{H}$, et al. Identification of wild type and variants of oestrogen receptors in polymorphonuclear and mononuclear leucocytes. Clin Endocrinol (Oxf) 2006;64(1):74-81.

20. Molero L, García-Durán M, Diaz-Recasens J, et al. Expression of estrogen receptor subtypes and neuronal nitric oxide synthase in neutrophils from women and men: regulation by estrogen. Cardiovasc Res 2002;56(1):43-51. 
II. 


\title{
Periosteal microcirculatory action of chronic estrogen supplementation in osteoporotic rats challenged with tourniquet ischemia
}

\author{
Andrea Szabó a,*, Petra Hartmann a , Renata Varga a, Kristóf Jánvári a , Zsanett Lendvai a , Irén Szalai a , \\ Izabella Gomez b , Gabriella Varga a , Ferenc Greksa ${ }^{c}$, István Németh ${ }^{\mathrm{d}}$, Zsolt Rázga ${ }^{\mathrm{d}}$, Margit Keresztes ${ }^{\mathrm{e}}$, \\ Dénes Garab ${ }^{a}$, Mihály Boros ${ }^{\mathrm{a}}$ \\ ${ }^{a}$ Institute of Surgical Research, University of Szeged, Hungary \\ ${ }^{\mathrm{b}}$ Institute of Inorganic and Analytical Chemistry, University of Debrecen, Hungary \\ c Department of Orthopaedics, University of Szeged, Hungary \\ d Department of Pathology, University of Szeged, Hungary \\ e Institute of Biochemistry, University of Szeged, Hungary
}

\section{A R T I C L E I N F O}

\section{Article history:}

Received 24 June 2010

Accepted 1 November 2010

Available online 7 November 2010

\section{Keywords:}

Ovariectomy

Inflammation

Ischemia-reperfusion

Neutrophil

Intravital microscopy

\begin{abstract}
A B S T R A C T
Aims: Transient ischemia of osteoporotic bones during elective orthopedic surgery or fracture repair carries risks for serious complications, and estrogen loss or replacement has a potential to influence ischemiareperfusion-induced inflammatory activation. To clarify this, we investigated the periosteal inflammatory changes in a clinically relevant time frame in ovariectomized rats, an experimental model of postmenopausal bone loss. Furthermore, the effects of chronic estrogen supplementation on the postischemic local and systemic inflammatory reactions were assessed.

Main methods: Bilateral ovariectomy or sham operation was performed in 3-month-old female SpragueDawley rats. Five months later, estrogen replacement therapy with $17 \beta$-estradiol $\left(20 \mu \mathrm{gg}^{-1} \mathrm{~kg}^{-1} \mathrm{day}^{-1}\right)$ or vehicle treatment was initiated. The microcirculatory inflammatory consequences of 60-min total hindlimb ischemia followed by 180-min reperfusion were examined 11 months after ovariectomy and were compared with those in 3-month-old animals.

Key findings: The osteoporosis that developed 5 months after ovariectomy was significantly ameliorated by estrogen replacement therapy. Both in ovariectomized and in non-ovariectomized animals, ischemiareperfusion elevated the neutrophil adherence $\sim 3$-fold in the postcapillary venules of the periosteum (intravital microscopy), with an 50-60\% increase in intravascular neutrophil activation (CD11b; FACS analysis), an enhanced TNF- $\alpha$ release (ELISA) and periosteal expression of ICAM-1 (the endothelial ligand of CD11b; immunohistochemistry). Exogenous $17 \beta$-estradiol considerably reduced TNF- $\alpha$ release and the number of neutrophil-endothelial interactions in the periosteum, without affecting the CD11b and ICAM-1 expression changes.

Significance: Osteoporosis itself does not increase the magnitude of the limb ischemia-reperfusion-associated periosteal inflammatory reaction. Chronic estrogen supplementation, however, reverses osteoporosis and significantly ameliorates the microcirculatory consequences of transient ischemia.
\end{abstract}

(C) 2010 Published by Elsevier Inc.

\section{Introduction}

The etiology of senile osteoporosis syndrome is multifactorial, but the reduced estrogen levels in peri-menopausal women are clearly associated with an accelerated bone mineral density loss (Richelson et al., 1984). The structural bone deficit is thought to be attributable to enhanced resorption and simultaneously decreased bone formation, and several early studies provided convincing evidence that these

\footnotetext{
* Corresponding author. Institute of Surgical Research, University of Szeged, H-6720 Szeged, Pécsi u. 6, Hungary. Tel.: +36 62 545103; fax: +36 62545743.

E-mail address: sza@expsur.szote.u-szeged.hu (A. Szabó).
}

changes can be suppressed or even prevented by restitution of the pre-menopausal estrogen levels (Christiansen et al., 1982).

The systemic and local consequences of endogenous estrogen loss and exogenous replacement in the circulatory system are more ambiguous. The incidence of septic, inflammatory complications is significantly lower in many trauma-hemorrhage conditions in females than in males (Sperry et al., 2008; Choudhry et al., 2005), and shortterm estrogen pretreatment confers significant protection from ischemia-reperfusion (IR) injury and leukocyte activation in males (Burkhardt et al., 2008). However, other lines of evidence support the notion that estrogen supplementation may increase the risk of intravascular clotting complications in post-menopausal women (Cushman, 2002). Although the underlying mechanistic details are 
still unclear and the concept is debated (Seelig et al., 2004; Canonico et al., 2008), it is obvious that the skeletal and anti-inflammatory benefits of hormone replacement therapies should be carefully weighed against the possible circulatory side-effects. Given this background, it is important to note that the consequences of chronic estrogen depletion and repletion on the human bone circulation are still unclear. Under certain compromised flow conditions, the periosteal microcirculation may be a good indicator of the perfusion changes of the whole bone, but the microcirculatory effects of osteoporosis in this tissue layer are also largely unknown. The patency of the periosteal microcirculation is of particular importance in transient ischemic states such as traumas, fractures, soft tissue injuries or limb operations involving tourniquet application (Varga et al., 2008; Zhang et al., 2003). In these cases, both the bone and the periosteum undergo microvascular events reflected by perfusion insufficiencies and severe antigen-independent inflammatory reactions. These processes are mainly initiated by the increased adhesion of polymorphonuclear (PMN) granulocytes to the microvascular endothelium (rolling and then firm adhesion), followed by their migration to and accumulation in the perivascular tissues (Wolfárd et al., 2002).

As the prevalence of skeletal injuries increases after menopause, our studies were designed to determine whether hormonal replacement therapy might be of microcirculatory benefit in this subset of the osteoporotic population. The ovariectomized (OVX) rat is a wellestablished animal model for osteoporosis research, as it shares many similarities with the human disease. These include an increased rate of bone turnover (Wronski et al., 1986), and an initial rapid phase of bone loss and similar skeletal responses to treatment with estrogen, calcitonin, bisphosphonates and many other agents (Fleisch, 1993; Allen et al., 2004). In this context, our first objective was to observe the effects of osteoporosis and the consequences of estrogen therapy in a clinically relevant time frame. To this end, we first determined if chronic treatment with estrogen influences the OVX-triggered local periosteal microcirculatory reactions.

Secondly, we hypothesized that the periosteal microcirculation of osteoporotic rats would be more sensitive to the detrimental consequences of transient limb ischemia than that of estrogentreated, age-matching controls. The results suggest that, even though osteoporosis itself does not amplify the IR-induced inflammatory responses, the periosteal granulocyte recruitment can be significantly reversed by chronic estrogen supplementation.

\section{Materials and methods}

\section{Animals and experimental design}

The experiments were carried out on female Sprague-Dawley rats housed in an environmentally controlled room with a 12-h light-dark cycle, and kept on commercial rat chow (Charles River, Wilmington, MA, USA) and tap water ad libitum. The experimental protocol was approved by the local animal rights protection authorities and followed the EC Directive 86/609/EEC and the National Institutes of Health guidelines for the care and use of laboratory animals.

In the first experimental series, 3-month-old animals (weighing 200-210 g) were ovariectomized (Group 1, OVX, $\mathrm{n}=12$ ), or shamoperation was performed (Group 2, Sham, $n=6$ ). Five months later (at the age of 8 months), chronic estrogen therapy (Sims et al., 1996) was initiated 5 days/week with $20 \mu \mathrm{gg}^{-1}$ sc $17 \beta$-estradiol (E2, Sigma, St. Louis, MO, USA) in 6 animals of the OVX group (Group 1a). The E2 substitution was continued weekly until the end of the experiments (see time scheme in Fig. 1). The remaining OVX (Group 1b) and Sham animals received the vehicle for E2 (100\% ethanol diluted in corn oil) in the same volume. Body weight changes and the development of osteoporosis were continuously followed in the proximal tibiae by means of ultrasonic densitometry (see later).
Series 1 (IVM)

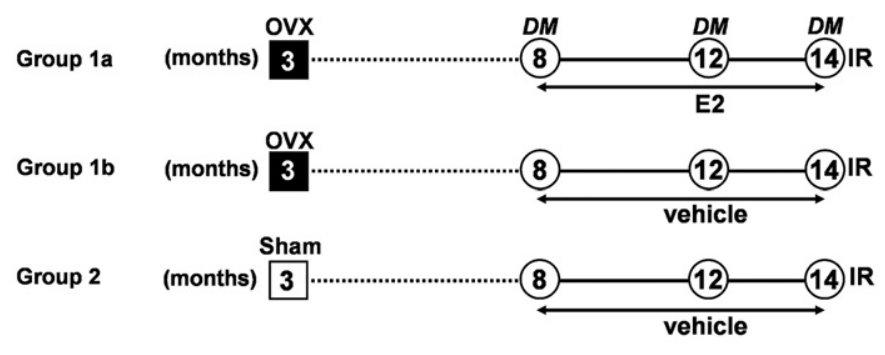

Group 3 (months) 3 IR

Fig. 1. The time sequence of surgical interventions, treatments and measurements in Series 1 . OVX = ovariectomy; Sham = sham operation; DM = densitometry; $\mathrm{IR}=$ ischemia-reperfusion; IVM = intravital microscopy, E2 $=17 \beta$-estradiol treatment. In Series 2 identical protocols were applied to detect adhesion molecule changes.

Eleven months after OVX, the animals were subjected to a 60-min complete hindlimb ischemia followed by a 180 -min reperfusion period (IR). Limb ischemia was induced by applying a tourniquet around the thigh and placing a miniclip on the femoral artery. Control hindlimb IR was conducted on another group of 3-month-old female rats (Group 3, $n=6$ ). In this group the microcirculatory consequences of limb IR alone were investigated using intravital video microscopy (IVM).

A second series of experiments (Groups 4a, 4b, 5, and 6), with identical protocols (OVX or Sham combined with IR, $n=7-10$ ), was performed to detect changes in the pro-inflammatory cytokine TNF- $\alpha$ concentrations in the plasma and in the expressions of adhesion molecules known to play a role in the process of PMN leukocyte adhesion to the endothelium. This was necessary because the fluorescent dyes used for IVM interfere with the flow-cytometry technique, and blood samples for the assessment of adhesion molecule expressions were therefore obtained separately. Tissue biopsies were also taken for detection of the tissue ICAM-1 changes by immunohistochemistry (see later).

\section{Surgical procedure of ovariectomy}

Animals were anesthetized with a combination of ketamine and xylazine ( $25 \mathrm{mg} \mathrm{kg}^{-1}$ and $75 \mathrm{mg} \mathrm{kg}^{-1}$ ip, respectively) and a median laparotomy was performed under sterile conditions. The connection of the Fallopian tubes was cut between hemostats, the ovaries were removed, and the stumps were then ligated. Thereafter, the abdomen was filled up with warm sterile physiological saline and the abdominal wall was closed in two layers. Sham-operated animals underwent identical procedures except that the Fallopian tubes and ovaries remained intact.

\section{Quantitative ultrasound bone densitometry (QUS)}

Under ketamine-xylazine anesthesia (as discussed earlier), bone density measurements were performed at the tibia and the tail with a DBM-Sonic 1200 (IGEA, Carpi, Italy) ultrasonic bone densitometry device; the changes in the average of the amplitude-dependent speed of sound (AD-SoS) were determined (Joly et al., 1999). After calibration, the AD-SoS values of the soft tissues (muscle and skin above the thigh) were determined, and the system deducted this value from the bone density. The AD-SoS values were calculated via a computer program and the average of 5 measurements was used at each time points. Twenty-one weeks after OVX, statistically significant density alterations were observed in the proximal tibia, and this location was therefore used for further QUS measurements at the ages of $8,9,12$ and 14 months. 


\section{Surgical procedure for IVM}

Intravital analysis of the periosteal microcirculation was performed at the end of the experimental protocol on 14-month-old animals. Anesthesia was induced with sodium pentobarbital ( $45 \mathrm{mg} \mathrm{kg}^{-1}$ ip) and sustained with small supplementary iv doses when necessary. The right carotid artery and the jugular vein were cannulated for the measurement of mean arterial pressure (MAP) and the administration of drugs and fluids, respectively. The animals were placed in a supine position on a heating pad to maintain the body temperature between 36 and $37^{\circ} \mathrm{C}$. Ringer's lactate was infused at a rate of $10 \mathrm{ml} \mathrm{kg}^{-1} \mathrm{~h}^{-1}$ during the experiments. The trachea was cannulated to facilitate respiration. The right femoral artery was dissected free, and the periosteum of the medial surface of the right tibia was exposed under a Zeiss $6 \times$ magnification operating microscope, using an atraumatic surgical technique (Varga et al., 2008).

\section{Experimental protocols}

In the first series, after a 30-min stabilization period, the baseline cardiovascular and microhemodynamic parameters were determined (baseline; $-60 \mathrm{~min}$ ). The periosteal microcirculation was observed every 60 min during the 180 -min reperfusion period.

In the second experimental series, blood samples from the carotid artery were taken at baseline and during the reperfusion period for the detection of changes in the plasma concentrations of TNF- $\alpha$ and in the expression of the adhesion molecule CD11b. TNF- $\alpha$ levels were determined from plasma samples taken at the 60th min of reperfusion. In a pilot study, the dynamics of the CD11b expression changes in response to limb IR were characterized; significant elevations were not found earlier than 120 or $180 \mathrm{~min}$ in the reperfusion period. Accordingly, this time frame was selected for flow cytometric evaluations of blood samples (see later).

\section{Intravital video microscopy}

The right hindlimb with the exposed tibial periosteum was positioned horizontally on an adjustable stage, and the microcirculation of the proximal tibia was visualized by IVM (Zeiss Axiotech Vario 100HD microscope, 100 W HBO mercury lamp, Acroplan 20× water immersion objective, Carl Zeiss $\mathrm{GmbH}$, Jena, Germany), using fluorescein isothiocyanate (Sigma, St. Louis, MO, USA)-labeled erythrocytes $(0.2 \mathrm{ml}$ iv) for red blood cell staining, and rhodamine 6G (Sigma, St. Louis, MO, USA, 0.2\%, $0.1 \mathrm{ml}$ iv) for leukocyte staining. The microscopic images were recorded with a charge-coupled device video camera (AVT HORN-BC 12, Aalen, Germany) attached to an S-VHS video recorder (Panasonic AG-MD 830, Matsushita Electric Industrial Co., Tokyo, Japan) and a personal computer.

\section{Video analysis}

Quantitative assessment of the microcirculatory parameters was performed off-line by frame-to-frame analysis of the videotaped images, using image analysis software (IVM, Pictron Ltd., Budapest, Hungary). Leukocyte-endothelial cell interactions were analyzed within 5 postcapillary venules (diameter between 11 and $20 \mu \mathrm{m}$ ) per animal. Adherent leukocytes (stickers) were defined in each vessel segment as cells that did not move or detach from the endothelial lining within an observation period of $30 \mathrm{~s}$, and are reported as the number of cells per $\mathrm{mm}^{2}$ of endothelial surface. Rolling leukocytes were defined as cells moving at a velocity less than $40 \%$ of that of the erythrocytes in the centerline of the microvessel, and given as the number of cells/vessel circumference in mm.

In the examined anatomical fields of the tibia, the majority of the vessels were not capillaries, but venules (see later); hence the total vascular density was calculated from the length of recognized vessels divided by the corresponding area (an average of 3 measurements per observation field was used).

\section{Immune labeling and flow cytometric analysis of CD11b expression}

The surface expression of $\mathrm{CD} 11 \mathrm{~b}$ on the peripheral blood granulocytes was determined through flow-cytometric analysis of whole blood in duplicate (Varga et al., 2008). One-hundred $\mu$ l of whole blood was incubated with $20 \mu \mathrm{l}$ of $\left(50 \mu \mathrm{g} \mathrm{ml}^{-1}\right)$ mouse anti-rat monoclonal antibody (BD Pharmingen, San Jose, CA, USA) for $20 \mathrm{~min}$. Negative controls were obtained by omitting the monoclonal antibody. The cells were then washed twice in Hanks buffer and centrifuged at 13,000 rpm for $5 \mathrm{~min}$ and the resuspended pellet was incubated with fluorescein isothiocyanate-conjugated polyclonal rabbit anti-mouse immunoglobulin $\left(10 \mu \mathrm{g} \mathrm{ml}{ }^{-1}\right.$; DAKO Cytomation, Glostrup, Denmark; $20-\mu \mathrm{l}$ aliquots of reagents to $180-\mu$ l aliquots of blood cells). The cells were again washed twice, and the erythrocytes were lysed with a Lysing kit (Biodesign, Saco, ME, USA), after which the cells were washed twice again $(6000 \mathrm{rpm}, 5 \mathrm{~min})$ and resuspended in $200 \mu \mathrm{l}$ Hanks buffer. Computer-assisted FACStar Plus Becton-Dickinson equipment was used for cytometry; the granulocytes were gated on the basis of their characteristic forward and sidescatter features. Generally, 10,000 events per sample were collected and recorded; the percentage of labeled (activated) granulocytes (relative to the overall marker-bearing cells) and the mean fluorescence intensity (average marker density) were calculated.

\section{TNF- $\alpha$ measurements}

TNF- $\alpha$ levels were measured in duplicate, using a commercially available anti-rat TNF- $\alpha$ ELISA kit (R\&D Systems, Minneapolis, MN, USA) according to the manufacturer's instructions.

\section{Detection of tissue ICAM-1 by immunohistochemistry}

At the end of the experiments, both the limb subjected to IR and the contralateral one were removed and the tibias and the surrounding muscles were fixed in $4 \%$ phosphate-buffered formalin for 2-3 days. The tissues were then decalcified with an electrophoretic apparatus (for $2 \times 4 \mathrm{~h}$ ) using a special decalcifying solution (Sakura TDE30; Sakura Finetek Corp. Torrance, CA, USA). The samples were embedded in paraffin, and the 4- $\mu \mathrm{m}$ sections were placed on silanized slides. After conventional methods of dewaxing and rehydration (initiated in xylene, followed by decreasing concentrations of ethanol and methanol), tissue endogenous peroxidase was blocked with a mixture of methanol and $1 \% \mathrm{H}_{2} \mathrm{O}_{2}$ for $5 \mathrm{~min}$, and the nonspecific tissue antigens with conventional $2.8 \%$ cow milk. For ICAM-1 immunohistochemistry, mouse monoclonal anti-rat ICAM-1 antibody (BD Pharmingen, BD Biosciences, San Jose, CA, USA) was used as primary antibody $(1: 200 ; 30 \mathrm{~min})$, this being followed by a biotinylated goat anti-mouse antibody conjugated to HRP polymer (Envision ${ }^{\circledR}$ System; Dako, Glostrup, Denmark) for 30 min which employs 3,3'diaminobenzidine as chromogen. The sections were counterstained with hematoxylin (for $1 \mathrm{~min}$ ) and examined by two independent histologists by means of light microscopy at $200 \times$ magnification. During the semiquantitative analysis, periosteal and intramuscular vessels were evaluated separately and the percentage of ICAM-1-positive vessels was calculated. The samples were allotted to one or another of the following semiquantitative categories (scores 1-8) (Table 1).

\section{Statistical analysis}

All data are expressed as means \pm standard error of the mean (SEM). Data analysis was performed with the SigmaStat statistical software (Jandel Corporation, San Rafael, CA, USA). Changes in 
Table 1

Scoring system for the analysis of ICAM-1 positivity in vessels from periosteal samples processed for immunohistochemistry.

\begin{tabular}{lll}
\hline Score & \% of ICAM-1-positive vessels & Staining \\
\hline 1 & $<5 \%$ & Local \\
2 & $5-25 \%$ & Diffuse \\
3 & & Local \\
4 & $25-50 \%$ & Diffuse \\
5 & & Local \\
6 & $>50 \%$ & Diffuse \\
7 & & Local \\
8 & & Diffuse \\
\hline
\end{tabular}

variables within and between groups were analyzed by one-way ANOVA followed by the Bonferroni test. $P$ values $<0.05$ were considered statistically significant.

\section{Results}

During the course of the experiments, the body weight of the animals increased in all groups (Fig. 2), but OVX was followed by a significantly higher weight gain as compared with that in the Sham group. After the initiation of the E2 therapy (at the age of 8 months), the weight gain decreased to the level for the non-OVX animals.

As shown by bone densitometry on the proximal tibia, osteoporosis developed 21 weeks after bilateral ovariectomy. The AD-SoS was significantly lower than that for the sham-operated animals (1674 \pm $33 \mathrm{~m} \mathrm{~s}^{-1}$ vs $1850 \pm 101 \mathrm{~m} \mathrm{~s}^{-1}$, respectively). The OVX-induced osteopenia was completely restored by E2 therapy (Fig. 3).

At the beginning of IVM, the baseline values of the macrohemodynamic variables (including heart rate and MAP) in the various groups did not differ significantly and there were no significant hemodynamic changes relative to the baseline values during the experimental period. In all groups subjected to IR, a moderate decrease in MAP was observed in the first few minutes of reperfusion, but MAP thereafter stabilized at the control level (data not shown).

The number of firmly adherent (sticking) leukocytes was significantly increased in the postcapillary venules of the tibial periosteum in the 3-month-old controls, the Sham rats and the OVX animals at the end of the reperfusion phase (120-180 min). This phenomenon was nearly completely prevented by chronic E2 supplementation in the OVX animals (Fig. 4).

In the examined anatomical fields of the tibia, the majority of the vessels were not capillaries, but venules (Fig. 5). No significant differences were found in total vascular density between the 3-month-old controls $\left(268.1 \pm 10.1 \mathrm{~cm}^{-1}\right)$, the Sham $\left(262.6 \pm 7.1 \mathrm{~cm}^{-1}\right)$, the OVX $(261.9 \pm$ $\left.7.6 \mathrm{~cm}^{-1}\right)$ or the OVX $+\mathrm{E} 2\left(265.1 \pm 1.1 \mathrm{~cm}^{-1}\right)$ groups.

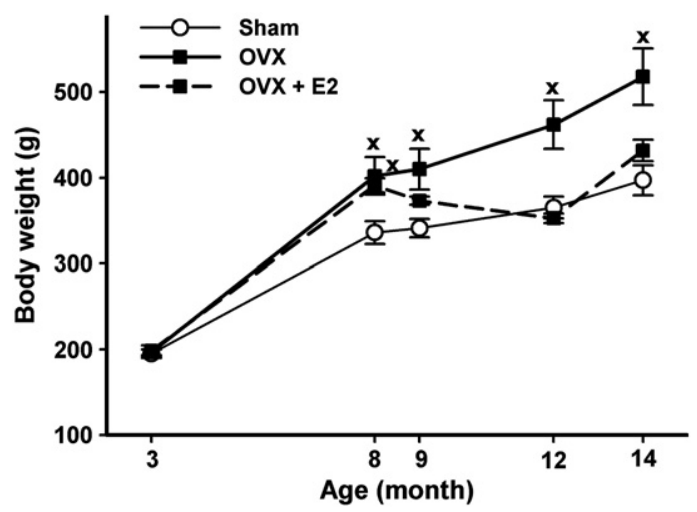

Fig. 2. Body weight changes in sham-operated (Sham) or ovariectomized animals treated with $17 \beta$-estradiol $(\mathrm{OVX}+\mathrm{E} 2)$ or vehicle (OVX). Data are presented as means $\pm \mathrm{SEM}$. ANOVA was followed by the Bonferroni test. ${ }^{\mathrm{X}} \mathrm{P}<0.05$ vs Sham group; differences $v s$ baseline (3 months of age) are not shown.

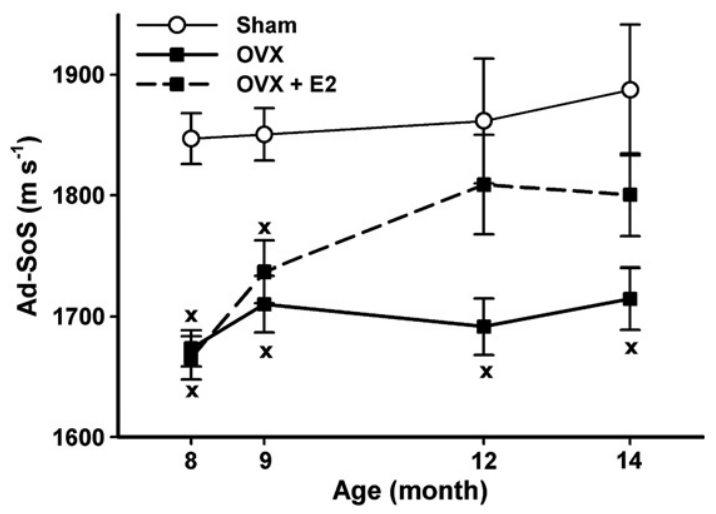

Fig. 3. Bone density changes in the proximal part of the tibia in sham-operated (Sham) or ovariectomized animals treated with $17 \beta$-estradiol (OVX +E2) or vehicle (OVX). Data are expressed as Ad-SoS and presented as means \pm SEM. ANOVA was followed by the Bonferroni test. ${ }^{x_{P}}<0.05$ vs Sham group.

An increased surface expression of adhesion molecule CD11b was observed after 120 and 180 min of reperfusion; no major differences could be detected between the findings for the OVX and the Sham or the 3-month-old rats (Fig. 6). Chronic E2 administration did not influence this parameter.

The plasma TNF- $\alpha$ reached similar concentrations (young animals: $21.24 \pm 3.30 \mathrm{pg} \mathrm{ml}^{-1}$; Sham: $22.16 \pm 5.79 \mathrm{pg} \mathrm{ml}^{-1}$; OVX: $19.84 \pm$ $1.35 \mathrm{pg} \mathrm{ml}^{-1}$ ) by the 60 th min of reperfusion. E2 treatment, however, resulted in significantly lower TNF- $\alpha$ values (OVX + E2: $11.14 \pm$ $1.19 \mathrm{pg} \mathrm{ml}^{-1}$ ) as compared with that for the OVX-challenged rats $(P<0.05)$. No TNF- $\alpha$ was detected in control samples taken before the ischemic insult.

As assessed by immunohistochemical analysis (Fig. 7), the tissue ICAM-1 density in the vessels of the periosteum was significantly higher in the limbs subjected to IR (young animals: $1.67 \pm 0.67$; Sham: $1.83 \pm 0.60$; OVX: $2.17 \pm 0.48$; OVX $+\mathrm{E} 2: 2.0 \pm 0.52$ ) than in the intact contralateral limbs in all experimental groups (young animals: $0.33 \pm 0.21$; Sham: $0.50 \pm 0.22$; OVX: $0.67 \pm 0.21$, OVX $+\mathrm{E} 2$ : $0.50 \pm 0.22$ ). The intensity of the IR-induced ICAM-1-positive reaction was only moderate in the muscle tissue, and the data for the 3-monthold controls, the Sham, OVX and the OVX animals treated with E2 were also similar.

\section{Discussion}

Females are more resistant to circulatory shock and inflammation than males, but this gender-related anti-inflammatory protection is

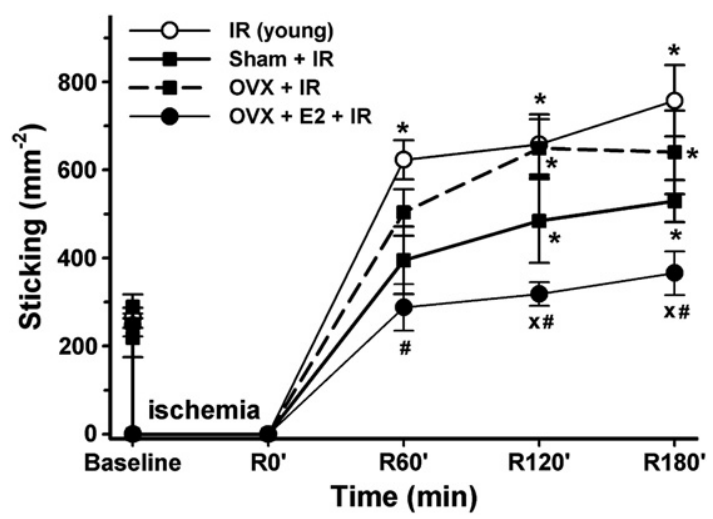

Fig. 4. Secondary leukocyte-endothelial cell interactions (sticking) in the postcapillary venules of the tibial periosteum in sham-operated (Sham +IR) or ovariectomized animals treated with $17 \beta$-estradiol $(\mathrm{OVX}+\mathrm{E} 2+\mathrm{IR})$ or vehicle $(\mathrm{OVX}+\mathrm{IR})$ in comparison with 3-month-old (young) female rats (IR). Data are presented as means \pm SEM. ANOVA was followed by the Bonferroni test. ${ }^{*} P<0.05$ vs baseline, ${ }^{\mathrm{X}} \mathrm{P}<0.05$ vs OVX + IR group, ${ }^{\#} P<0.05$ vs IR group. 

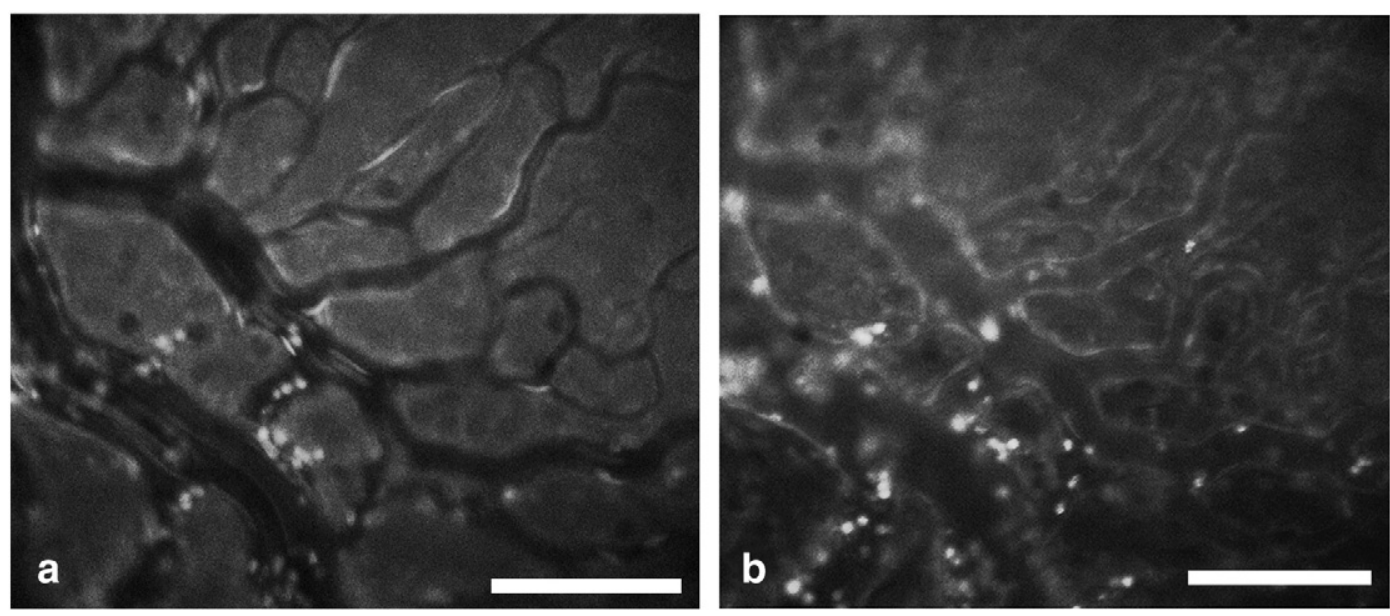

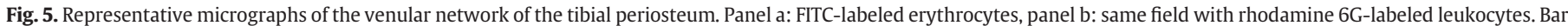
represents $100 \mu \mathrm{m}$.

lost during menopause or after OVX (Wichmann et al., 2000; Angele et al., 2000). As the incidence of traumas and osteoporotic fractures steadily rises in the elderly population (Gullberg et al., 1997), the question arises of whether osteoporotic women are more susceptible to postoperative or post-traumatic inflammatory bone complications than postmenopausal women receiving estrogen replacement therapy. We set out to answer this question by employing a chronic rat model of osteoporosis where the consequences of a long-term female hormone deficiency can be adequately estimated (Tan et al., 2003). The results showed that osteoporosis was reproducibly evolved after OVX, and the reversing efficacy of E2 therapy on osteopenia, together with the periosteal microcirculatory status of the tibia, could subsequently be evaluated in the long term. The data also showed, however, that the postischemic periosteal microcirculatory PMN recruitment and the expressions of the adhesion molecules CD11b and ICAM-1 (which play a role in the process of adhesion of the PMNs to the venular endothelium) undergo similar changes in this condition, irrespective of the age or the endogenous estrogen status of the animals. Thus, the primary message of our study is that a chronic estrogen deficit does not change the magnitude of the PMNassociated microcirculatory menace in the event of transient ischemia of the osteoporotic limb.

IVM allows direct observation and quantitative analysis of the microcirculation of the exposed tissues. With this technique, the consequences of an estrogen deficit and estrogen replacement have already been demonstrated in certain organs (Santizo et al., 2000;

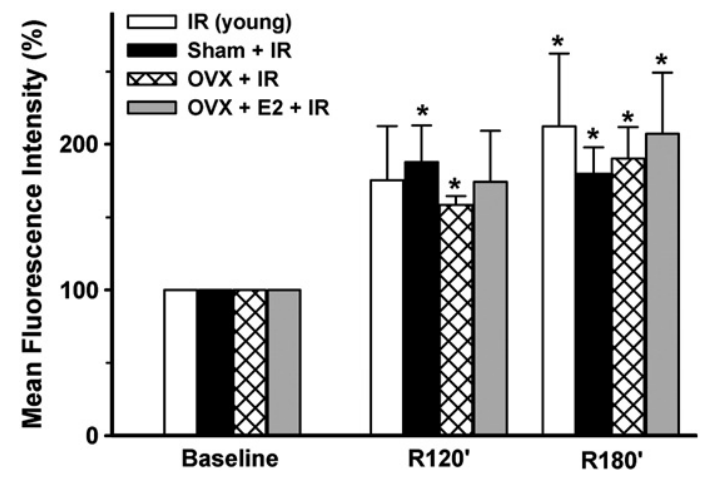

Fig. 6. Changes in expression of the $\mathrm{CD} 11 \mathrm{~b}$ adhesion molecule on the surface appearance of PMN leukocytes in response to $60 \mathrm{~min}$ of ischemia followed by $180 \mathrm{~min}$ of reperfusion in sham-operated (Sham + IR) or ovariectomized animals treated with $17 \beta$-estradiol $(\mathrm{OVX}+\mathrm{E} 2+\mathrm{IR})$ or vehicle $(\mathrm{OVX}+\mathrm{IR})$ in comparison with 3 -month-old (young) female rats (IR). Data are presented as means \pm SEM. ${ }^{*} P<0.05$ vs baseline.
Watanabe et al., 2001), but never in the periosteum, though the protecting and feeding functions of the periosteum are hallmarked by the fact that restoration of periosteal microcirculation guarantees bone survival even in an environment with limited blood supply (Berggren et al., 1982). Additionally, osteoporosis has been shown to develop on the basis of an imbalance between bone resorption and formation, the effector cells being derived from mesenchymal osteoprogenitor cells found in the periosteum and endosteum, the former displaying predominance in this respect (Brighton et al., 1992). Furthermore, the experimental and clinical evidence suggests an important role of the periosteum not only in the pathogenesis of osteoporosis itself, but also in the effects of different anti-osteoporotic approaches (Allen et al., 2004). The periosteal region of the cortical bones exhibits a better anti-fracture efficacy than that of the endosteal region and it is proposed that the major target of different bonereinforcing therapies is the periosteal site (Ferretti et al., 1995). Together with the nutritive functions of the periosteum, these observations underline the importance of the periosteum in the pathogenesis of different disorders also affecting the bone metabolism.

In our study, IR induced considerable increases in the periosteal leukocyte-endothelial interactions during the reperfusion phase, but these changes were similar in the aged OVX, the sham-OVX groups and the young animals. This observation adds a new aspect to the previous finding of enhanced PMN adhesion in the venules of the femur in the short run, i.e. 2 weeks after OVX in unstressed animals (Kasiyaphat et al., 2008). Similarly, an early enhancement of PMN infiltration has been demonstrated in the muscle of OVX rats after IR (Stupka and Tiidus, 2001). In fact, there is currently no consensus on the magnitude or pathologic role of leukocyte adhesion in nonskeletal tissues after OVX. OVX has been reported to enhance PMN accumulation in the brain of resting animals (Santizo et al., 2000) but other data indicated that OVX does not influence the PMN adherence in the brain tissue after transient ischemia (Xu et al., 2004). We suggest that these differences in baseline leukocyte adhesion might be explained by the different timelines. Use of a standardized experimental setup with matching sex, age and bone density conditions would solve this question.

The microcirculatory patency is influenced by functional and morphological changes in the microvasculature. As concerns the structural aspects, it has been shown that OVX leads to reduced blood flow in the bone (Kapitola et al., 1995) and a lower total capillary density in the heart (Jesmin et al., 2002) and brain (Jesmin et al., 2003), a phenomenon probably related to the well-known effect of estrogen on angiogenesis. In our chronic OXV rat model, the periosteal vessel density was not affected by OVX or E2 replacement therapy. It 

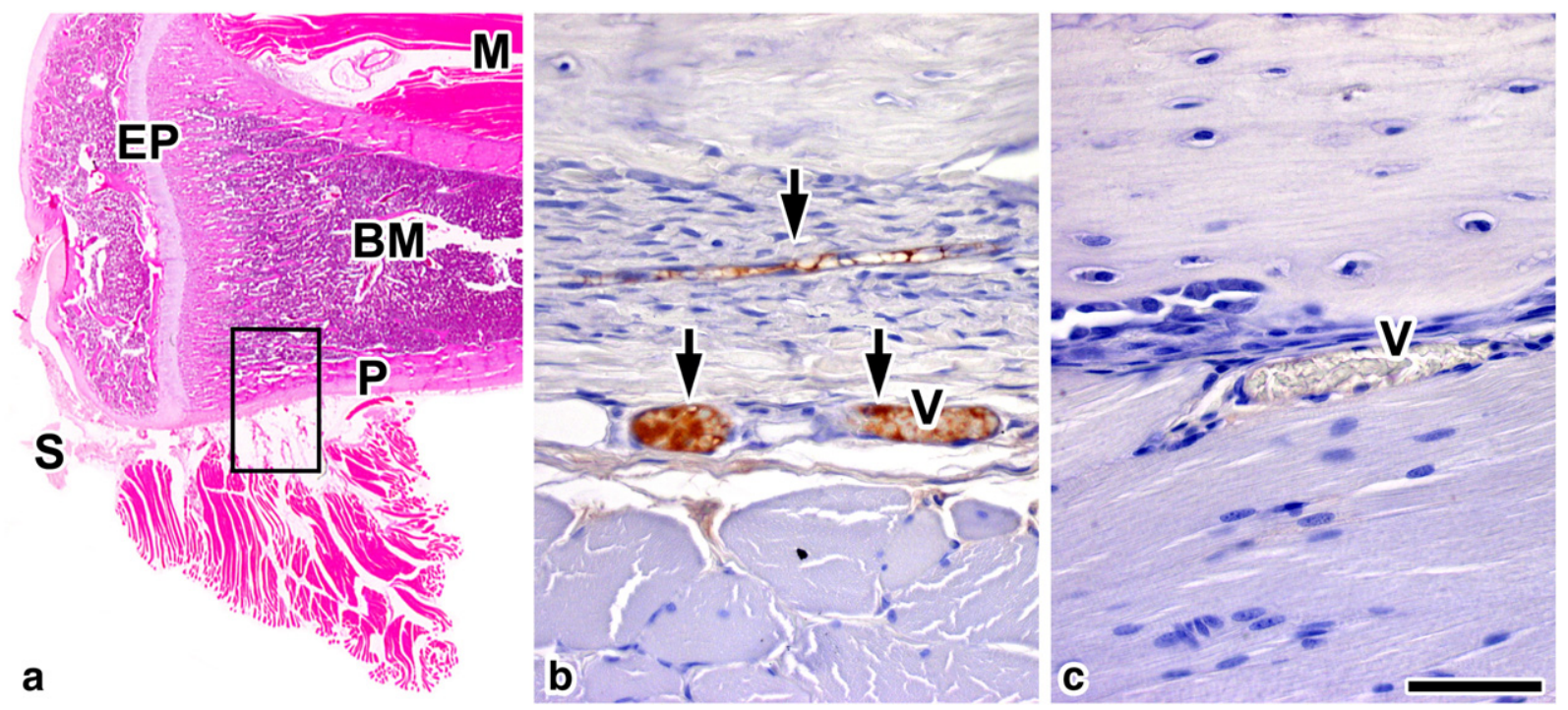

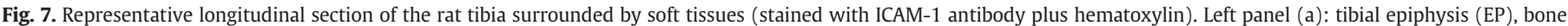

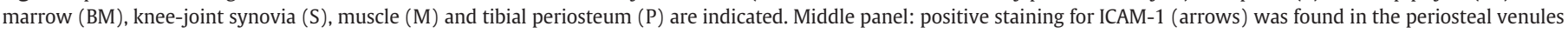
(V) after IR (b), but not in the contralateral (non-IR) limbs (c). Bar represents $50 \mu \mathrm{m}$.

is important to note that these changes were followed in the proximal tibial periosteum, where venules are the predominant vessel type. The postcapillary venules are predilectory sites for PMN-endothelial interactions, and thus a higher density may predispose to local inflammatory complications. The particularly high venular density of the periosteal microarchitecture may account, at least in part, for a tissue-specific response.

Although relatively little information is available on the effects of chronic OVX itself, there are numerous experimental studies on the microcirculatory changes of hormone substitution (e.g. E2). Since estradiol is protective in many forms of injury, it is possible that E2 is protective independently of the presence of OVX. Nonetheless, E2 has been shown to reduce leukocyte accumulation, infarct size (Jeanes et al., 2006) and oxygen free radical production (Florian et al., 2004) in OVX rats; PMN adherence and infiltration for instance can be effectively prevented by estrogen supplementation after OVX (Stupka and Tiidus, 2001).

The mechanism of action by which E2 influences PMN-endothelial interactions is not known in detail. It has been suggested that E2 reduces the expression of endothelium-derived adhesion factors such as P-selectin, vascular cell adhesion molecule-1, and ICAM-1 (Miller et al., 2004). Interestingly, some of these molecules also have a role in bone development, since LFA and ICAM-1 have been shown to influence the osteoclast function (Kurachi et al., 1993). It is hypothesized that an estrogen deficiency results in increased ICAM-1 expression on osteoclast precursors, which may contribute to the bone loss following menopause or OVX (Gao et al., 2000). The smaller diameter of the medullary resistance arterioles in OVX rats also suggests that endogenous estrogen exerts a significant dilator influence within the bone circulation (Soukhova-O'Hare et al., 2005). We investigated the changes in expression of $\mathrm{CD} 11 \mathrm{~b}$, a key determinant of PMN-mediated injuries (Hentzen et al., 2000). Upon activation, CD11b (the $\alpha \mathrm{M}$ part of the CD11b-CD18 complex) is transferred to the cell surface from preformed intracellular pools (Jones et al., 1988) and, as opposed to the constitutive CD11a, its expression is increased several-folds in response to IR stimuli. The considerably increased CD11b expression implies that complete limb ischemia leads to severe systemic inflammatory consequences in this model. The local expression of ICAM-1, the endothelial counterpart of $\mathrm{CD} 11 \mathrm{~b}$, was also enhanced in the postischemic periosteum, where the PMN-endothelial interactions were simultaneously and visibly increased. These reactions were not influenced by E2 repletion, which suggests that E2 exerts its anti-adhesive effect independently of CD11b or ICAM-1. The mechanism of how estrogen can modulate in vivo PMN reactions demands further attention, but our results are in agreement with those of in vitro studies, where OVX did not influence the CD11b expression of the PMNs (Deitch et al., 2006). There is evidence of a cellular sexual dimorphism in the activation of PMNs, implying that PMNs from females respond to trauma and humoral stimuli to a lower extent than do those from males (Deitch et al., 2006). Further, estrogen directly modulates the expression of the neuronal isoform of nitric oxide synthase in PMNs (García-Durán et al., 1999). In our study, E2 treatment clearly reduced the IR-induced secondary PMN-endothelial interactions (i.e. sticking), but this potentially protective effect was not mediated by a mechanism involving tissue ICAM-1 expression changes. Although an increased PMN-derived NO production might reduce PMN adhesion, this reaction is ICAM-1 dependent (Dal Secco et al., 2006). Overall, the earlier findings may implicate that chronic estrogen supplementation modulates PMN activation directly, through a novel, specific, estrogensensitive pathway.

In our rat model, OVX was followed by definite diagnostic signs of osteoporosis 21 weeks later. In this condition, the postischemic periosteal microcirculatory complications were not aggravated further relative to the non-OVX age-matched controls. Similar changes were observed in TNF- $\alpha$ release, providing further evidence that OVX itself does not modify the inflammatory complications, but E2 supplementation greatly reduces this reaction. It has also been demonstrated by others that E2 inhibits TNF- $\alpha$ gene transcription via the beta estrogen receptors (Srivastava et al., 1999) and via the TNF$\alpha$-mediated increases in the expressions of adhesion molecules and chemoattractants (Xing et al., 2007). A downregulation of nitric oxide synthesis by TNF- $\alpha$ may also contribute to the mechanisms of these microcirculatory reactions (Yoshizumi et al., 1993). Our present data indicating the positive effect of prolonged E2 substitution on the PMN reactions and TNF- $\alpha$ release, however, points to another clinical implication of our findings; ovarial hormone deprivation supplemented with estrogen therapy (apart from the well-known positive effect in reducing the risk of osteoporotic fractures) also affords marked protection against inflammatory mediator release.

\section{Conclusion}

The periosteal microcirculatory consequences of tourniquetcaused ischemia were first quantified by IVM in an adequately longterm follow-up of osteoporosis. The efficacy of E2 therapy was 
objectively judged in this condition. The overall message is that chronic estrogen supplementation not only ameliorates bone demineralization, but also decreases systemic and PMN-driven local periosteal inflammatory reactions.

\section{Conflict of interest statement}

The authors declare that there are no conflicts of interest.

\section{Acknowledgments}

The ultrasonic densitometric device (DBM-Sonic 1200) was kindly provided by L. Pap (Institute of Inorganic and Analytical Chemistry, University of Debrecen, Hungary).

Supported by a research grant from the Hungarian Scientific Research Fund (OTKA K 60752). AS and PH contributed equally to this work.

\section{References}

Allen MR, Hock JM, Burr DB. Periosteum: biology, regulation, and response to osteoporosis therapies. Bone 2004;35(5):1003-12, doi:10.1016/j.bone.2004.07.014.

Angele MK, Schwacha MG, Ayala A, Chaudry IH. Effect of gender and sex hormones on immune responses following shock. Shock 2000;14(2):81-90.

Berggren A, Weiland AJ, Dorfman H. The effect of prolonged ischemia time on osteocyte and osteoblast survival in composite bone grafts revascularized by microvascular anastomoses. Plast Reconstr Surg 1982;69(2):290-8.

Brighton CT, Lorich DG, Kupcha R, Reilly TM, Jones AR, Woodbury II RA. The pericyte as a possible osteoblast progenitor cell. Clin Orthop Relat Res 1992;275:287-99.

Burkhardt M, Slotta JE, Garcia P, Seekamp A, Menger MD, Pohlemann T. The effect of estrogen on hepatic microcirculation after ischemia/reperfusion. Int J Colorectal Dis 2008;23(1):113-9, doi:10.1007/s00384-007-0360-5.

Canonico M, Plu-Bureau G, Lowe GD, Scarabin PY. Hormone replacement therapy and risk of venous thromboembolism in postmenopausal women: systematic review and meta-analysis. BMJ 2008;10(336):1227-31, doi:10.1136/bmj.39555.441944.BE.

Choudhry MA, Schwacha MG, Hubbard WJ, Kerby JD, Rue LW, Bland KI, et al. Gender differences in acute response to trauma-hemorrhage. Shock 2005;24(1):101-6.

Christiansen C, Christensen MS, Larsen NE, Transbøl IB. Pathophysiological mechanisms of estrogen effect on bone metabolism. Dose-response relationships in early postmenopausal women. J Clin Endocrinol Metab 1982;55(6):1124-30.

Cushman M. Effects of hormone replace therapy and estrogen receptor modulators on markers of inflammation and coagulation. Am J Cardiol 2002;90(1, Suppl 1): F7-F10, doi:10.1016/S0002-9149(02)02419-0.

Dal Secco D, Moreira AP, Freitas A, Silva JS, Rossi MA, Ferreira SH, et al. Nitric oxide inhibits neutrophil migration by a mechanism dependent on ICAM-1: role of soluble guanylate cyclase. Nitric Oxide 2006;15(1):77-86, doi:10.1016/j.niox.2006.02.004

Deitch EA, Ananthakrishnan P, Cohen DB, Xu da Z, Feketeova E, Hauser CJ. Neutrophil activation is modulated by sex hormones after trauma-hemorrhagic shock and burn injuries. Am J Physiol 2006;291(3):H1456-65, doi:10.1152/ajpheart.00694.2005.

Ferretti JL, Frost HM, Gasser JA, High WB, Jee WS, Jerome C, et al. Perspectives on osteoporosis research: its focus and some insights from a new paradigm. Calcif Tissue Int 1995;57(6):399-404.

Fleisch H. New bisphosphonates in osteoporosis. Osteoporos Int 1993;3(2):S15-22.

Florian M, Freiman A, Magder S. Treatment with 17-beta-estradiol reduces superoxide production in aorta of ovariectomized rats. Steroids 2004;69(13-14):779-87, doi: 10.1016/j.steroids.2004.09.008.

Gao Y, Morita I, Kubota T, Murota S, Aso T. Expression of adhesion molecules LFA-I and ICAM-I on osteoclast precursors during osteoclast differentiation and involvement of estrogen deficiency. Climacteric 2000;3(4):278-87.

García-Durán M, de Frutos T, Díaz-Recasens J, García-Gálvez G, Jiménez A, Montón M, et al. Estrogen stimulates neuronal nitric oxide synthase protein expression in human neutrophils. Circ Res 1999;85(11):1020-6.

Gullberg B, Johnell O, Kanis JA. World-wide projections for hip fracture. Osteoporos Int 1997;7(5):407-13.

Hentzen ER, Neelamegham S, Kansas GS, Benanti JA, McIntire LV, Smith CW, et al. Sequential binding of CD11a/CD18 and CD11b/CD18 defines neutrophil capture and stable adhesion to intercellular adhesion molecule-1. Blood 2000;95(3):911-20.

Jeanes HL, Wanikiat P, Sharif I, Gray GA. Medroxyprogesterone acetate inhibits the cardioprotective effect of estrogen in experimental ischemia-reperfusion injury. Menopause 2006;13(1):80-6, doi:10.1172/JCI118307.
Jesmin S, Hattori Y, Sakuma I, Liu MY, Mowa CN, Kitabatake A. Estrogen deprivation and replacement modulate cerebral capillary density with vascular expression of angiogenic molecules in middle-aged female rats. J Cereb Blood Flow Metab 2003;23(2):181-9, doi:10.1097/01.WCB.0000043341.09081.37.

Jesmin S, Sakuma I, Hattori Y, Kitabatake A. In vivo estrogen manipulations on coronary capillary network and angiogenic molecule expression in middle-aged female rats. Arterioscler Thromb Vasc Biol 2002;22(10):1591-7, doi:10.1161/01. ATV.0000034929.42459.0D.

Joly J, Westhovens R, Borghs H, Peeters H, Tirry J, Nijs J, et al. Reference curve and diagnostic sensitivity for a new ultrasound device for the phalanges, the DBMsonic 1200, in Belgian women. Osteoporos Int 1999;9(4):284-9.

Jones DH, Anderson DC, Burr BL, Rudloff HE, Smith CW, Krater SS, et al. Quantitation of intracellular Mac-1 (CD11b/CD18) pools in human neutrophils. J Leukoc Biol 1988;44(6):535-44.

Kapitola J, Kubícková J, Andrle J. Blood flow and mineral content of the tibia of female and male rats: changes following castration and/or administration of estradiol or testosterone. Bone 1995;16(1):69-72.

Kasiyaphat A, Siriviriyakul P, Patumraj S. Preventive effects of genistein on leukocyte adhesion in femur venules and on bone-loss induced in ovariectomized female rats. Clin Hemorheol Microcirc 2008;38(4):235-43.

Kurachi T, Morita I, Murota S. Involvement of adhesion molecules LFA-1 and ICAM-1 in osteoclast development. Biochim Biophys Acta 1993;1178(3):259-66.

Miller AP, Feng W, Xing D, Weathington NM, Blalock JE, Chen YF, et al. Estrogen modulates inflammatory mediator expression and neutrophil chemotaxis in injured arteries. Circulation 2004;110(12):1664-9, doi:10.1161/01.CIR.0000142050.19488.C7.

Richelson LS, Wahner HW, Melton III LJ, Riggs BL. Relative contributions of aging and estrogen deficiency to postmenopausal bone loss. N Engl J Med 1984;311(20): 1273-5.

Santizo RA, Anderson S, Ye S, Koenig HM, Pelligrino DA. Effects of estrogen on leukocyte adhesion after transient forebrain ischemia. Stroke 2000;31(9):2231-5.

Seelig MS, Altura BM, Altura BT. Benefits and risks of sex hormone replacement in postmenopausal women. J Am Coll Nutr 2004;23(5):S482-96.

Sims NA, Morris HA, Moore RJ, Durbridge TC. Estradiol treatment transiently increases trabecular bone volume in ovariectomized rats. Bone 1996;19(5):455-61.

Soukhova-O'Hare G, Lei Z, Falcone JC, Barati MT, Feitelson JB, Rao ChV, et al. Bone medullary arterioles from ovariectomized rats have smaller baseline diameters but normal eNOS expression and NO-mediated dilation. Life Sci 2005;77(15): 1799-812, doi:10.1016/j.lfs.2004.10.083.

Sperry JL, Nathens AB, Frankel HL, Vanek SL, Moore EE, Maier RV, et al. Characterization of the gender dimorphism after injury and hemorrhagic shock: are hormonal differences responsible? Crit Care Med 2008;36(6):1838-45, doi:10.1097 CCM.0b013e3181760c14.

Srivastava S, Weitzmann MN, Cenci S, Ross FP, Adler S, Pacifici R. Estrogen decreases TNF gene expression by blocking JNK activity and the resulting production of c-Jun and JunD. Clin Invest 1999;104(4):503-13, doi:10.1172/JCI7094.

Stupka N, Tiidus PM. Effects of ovariectomy and estrogen on ischemia-reperfusion injury in hindlimbs of female rats. J Appl Physiol 2001;91(4):1828-35.

Tan Z, Wang TH, Yang D, Fu XD, Pan JY. Mechanisms of 17beta-estradiol on the production of ET-1 in ovariectomized rats. Life Sci 2003;73(21):2665-74.

Varga R, Török L, Szabó A, Kovács F, Keresztes M, Varga G, et al. Effects of colloid solutions on ischemia-reperfusion-induced periosteal microcirculatory and inflammatory reactions: comparison of dextran, gelatin, and hydroxyethyl starch. Crit Care Med 2008;36(10):2828-37, doi:10.1097/CCM.0b013e318186ff48.

Watanabe Y, Littleton-Kearney MT, Traystman RJ, Hurn PD. Estrogen restores postischemic pial microvascular dilation. Am J Physiol 2001;281(1):H155-60.

Wichmann MW, Inthorn D, Andress HJ, Schildberg FW. Incidence and mortality of severe sepsis in surgical intensive care patients: the influence of patient gender on disease process and outcome. Intensive Care Med 2000;26(2):167-72.

Wolfárd A, Császár J, Gera L, Petri A, Simonka JA, Balogh A, et al. Endothelin-a receptor antagonist treatment improves the periosteal microcirculation after hindlimb ischemia and reperfusion in the rat. Microcirculation 2002:9(6):471-6.

Wronski TJ, Walsh CC, Ignaszewski LA. Histologic evidence for osteopenia and increased bone turnover in ovariectomized rats. Bone 1986;7(2):119-23.

Xing D, Feng W, Miller AP, Weathington NM, Chen YF, Novak L, et al. Estrogen modulates TNF-alpha-induced inflammatory responses in rat aortic smooth muscle cells through estrogen receptor-beta activation. Am J Physiol 2007;292(6): H2607-12, doi:10.1152/ajpheart.01107.2006.

$\mathrm{Xu}$ HL, Baughman VL, Pelligrino DA. Estrogen replacement treatment in diabetic ovariectomized female rats potentiates postischemic leukocyte adhesion in cerebra venules. Stroke 2004;35(8):1974-8, doi:10.1161/01.STR.0000135016.24349.9F.

Yoshizumi M, Perrella MA, Burnett Jr JC, Lee ME. Tumor necrosis factor downregulates an endothelial nitric oxide synthase mRNA by shortening its half-life. Circ Res 1993;73(1):205-9.

Zhang L, Bail H, Mittlmeier T, Haas NP, Schaser K. Immediate microcirculatory derangements in skeletal muscle and periosteum after closed tibial fracture. J Trauma 2003;54(5):979-85. 
III. 


\title{
Remote ischemic preconditioning differentially affects NADPH oxidase isoforms during hepatic ischemia-reperfusion
}

\author{
Dénes Garab ${ }^{\mathrm{a}}$, Ngwi Fet ${ }^{\mathrm{b}}$, Andrea Szabó ${ }^{\mathrm{a}}$, René H. Tolba ${ }^{\mathrm{b}}$, Mihály Boros ${ }^{\mathrm{a}}$, Petra Hartmann ${ }^{\mathrm{a}, *}$ \\ a Institute of Surgical Research, University of Szeged, Szeged, Hungary \\ ${ }^{\mathrm{b}}$ Institute of Laboratory Animal Science and Experimental Surgery, RWTH Aachen University, Aachen, Germany
}

\section{A R T I C L E I N F O}

\section{Article history:}

Received 16 January 2014

Accepted 7 April 2014

Available online 24 April 2014

\section{Keywords:}

NOX2

NOX4

Microcirculation

Inflammation

Intravital video microscopy

Modified spectrophotometry

Polymorphonuclear leukocytes

\begin{abstract}
A B S T R A C T
Aims: We investigated the function of major superoxide-generating enzymes after remote ischemic preconditioning (IPC) and hepatic ischemia-reperfusion (IR), with the specific aim of assessing the importance of the most relevant NADPH oxidase (NOX) isoforms, NOX2 and NOX4, in the mechanism of action.

Main methods: 60-min partial liver ischemia was induced in Sprague-Dawley rats in the presence or absence of remote IPC $(2 \times 10$-min limb IR), and hepatic microcirculatory variables were determined through intravital video microscopy and lightguide spectrophotometry during reperfusion. Inflammatory enzyme activities (myeloperoxidase (MPO) and xanthine oxidoreductase (XOR)), cytokine production (TNF- $\alpha$ and HMGB-1), liver necroenzyme levels (AST, ALT and LDH) and NOX2 and NOX4 protein expression changes (Western blot analysis) were assayed biochemically.

Key findings: In this setting, remote IPC significantly decreased the IR-induced hepatic NOX2 expression, but the NOX4 expression remained unchanged. The remote IPC provided significant, but incomplete protection against the leukocyte-endothelial cell interactions and flow deterioration. Hepatocellular damage (AST, ALT and LDH release), cytokine levels, and XOR and MPO activities also diminished.

Significance: Remote IPC limited the IR-induced microcirculatory dysfunction, but the protective effect did not affect all NOX homologs (at least not NOX4). The residual damage and inflammatory activation could well be linked to the unchanging NOX4 activity.
\end{abstract}

(C) 2014 Elsevier Inc. All rights reserved.

\section{Introduction}

The application of repetitive short periods of ischemia, referred to as ischemic preconditioning (IPC), is a well-established approach to the achievement of increased ischemic tolerance in various tissues. Interestingly, remote, inter-organ IPC also confers protection against subsequent ischemia-reperfusion (IR) injury (Koti et al., 2002). The elements and the sequence of events through which IPC exerts distant beneficial effects have not been fully explored, but adaptation of the gene expression of the cellular redox homeostasis is one of the key protective mechanisms through which a lower degree of radical formation can be attained in the endothelial compartment (Koti et al., 2002; Mallick et al., 2005). Signaling processes catalyzed by oxygen and nitrogen radical-producing enzymes, including neuronal nitric oxide synthase (nNOS), endothelial NOS (eNOS) and xanthine oxidase (XO) (Abu-Amara et al., 2011; Yuan et al., 2012), have been demonstrated in the course of defensive action

\footnotetext{
* Corresponding author at: Institute of Surgical Research, University of Szeged, Szőkefalvi-Nagy Béla u. 6., H-6720 Szeged, Hungary. Tel.: + 3662 545103; fax: + 3662 545743.

E-mail address: hartmann.petra@med.szote.u-szeged.hu (P. Hartmann).
}

of IPC, and a number of additional data have also established the decisive roles of NADPH oxidases (NOXs) (Wang et al., 2007; Tejima et al., 2007). With variation in the catalytic subunits, the NOXs comprise 7 family members (NOX1 to NOX5 and DUOX1 and DUOX2), which exhibit tissue-specific differences in their baseline expression (Bedard and Krause, 2007). In the case of liver parenchyma, NOX2 and NOX4 proteins have been found in hepatocytes, NOX2 predominates in the Kupffer cells, while NOX4 is more abundant in the microvessels (Bengtsson et al., 2003; Ellmark et al., 2005). Furthermore, the expression of NOX4 is at least 20 -fold greater than that of NOX2 in the endothelial cells (Sorescu and Griendling, 2002), while the expression of NOX2 cannot be detected in the vascular smooth muscle cells (Görlach et al., 2000; Lassègue et al., 2001).

NOXs are specifically activated by many stimuli that are known to cause an endothelial dysfunction (Anilkumar et al., 2009), and previous studies have provided evidence of elevated mRNA levels of both NOX2 and NOX4 in response to a liver IR injury (Marden et al., 2008). Moreover, the mortality rate due to hepatic ischemia was reduced in NOX2-deficient mice (Harada et al., 2004) and the role of the phagocytic form of NOX in Kupffer cells has been demonstrated after preconditioning with a chemical agent that induces hypoxia (Tejima et al., 2007). Collectively, these data suggest that influencing NOX4 (derived from hepatocytes and/or 
vascular cells) and NOX2 (produced by phagocytic PMN leukocytes and/ or Kupffer cells) may contribute to the protective mechanism of remote IPC. We therefore hypothesized that the effects of remote IPC can be linked to an alleviated inflammatory reaction in the postischemic hepatic microcirculation associated with NOX2 and NOX4 activation. To address this issue, we set out to investigate the consequences of limb IPC on major intracellular superoxide-generating enzyme systems in a rat model of hepatic IR injury, with special emphasis on changes in expression of NOX2 and NOX4 proteins.

\section{Materials and methods}

The experiments were carried out on male Sprague-Dawley rats (Charles River, Sulzfeld, Germany; average weight $300 \pm 20$ g) housed in an environmentally controlled room with a 12-h light-dark cycle, and kept on commercial rat chow (Charles River, Wilmington, MA, USA) and tap water ad libitum. The experimental protocol was in accordance with EU directive 2010/63 for the protection of animals used for scientific purposes and was approved by the Animal Welfare Committee of the University of Szeged. This study also complied with the criteria of the US National Institutes of Health Guidelines for the Care and Use of Laboratory Animals.

\section{Surgical procedures}

Anesthesia was induced with a combination of $25 \mathrm{mg} \mathrm{ml}^{-1}$ (S)-ketamine (Ketanest; Parke Davis, Berlin, Germany) and $20 \mathrm{mg} \mathrm{ml}^{-1}$ xylazine (Rompun; Bayer, Leverkusen, Germany) in a ratio of 8:1, injected i.p. and sustained with small supplementary i.v. doses every $30 \mathrm{~min}$. The trachea was intubated to facilitate respiration, and the right jugular vein and carotid artery were cannulated for fluid and drug administration and for the measurement of arterial pressure, respectively. The animals were placed in a supine position on a heating pad to maintain the body temperature between 36 and $37{ }^{\circ} \mathrm{C}$, and lactated Ringer's solution was infused at a rate of $10 \mathrm{ml} \mathrm{kg}^{-1} \mathrm{~h}^{-1}$ during the experiment.

Before surgery, the fur over the abdomen was shaved, and the skin was disinfected with povidone iodide. After midline laparotomy and bilateral subcostal incisions, the liver was carefully freed from all ligamentous attachments and the liver was exposed and the left branches of the portal vein and the hepatic artery were mobilized. Complete ischemia of the median and left hepatic lobes was achieved by clamping the left lateral branches of the hepatic artery and the portal vein with a microsurgical clip for $60 \mathrm{~min}$. After the ischemic period, the clips were removed and the wound was temporarily covered with water-impermeable foil during the 180-min reperfusion period (Taniguchi et al., 2007).

\section{Experimental protocols}

The experiments were performed in two major series, with the animals randomly assigned to one or another of the following experimental groups. In the first series, we evaluated the microcirculatory consequences of partial hepatic ischemia by using the noninvasive modified spectrometric $\mathrm{O} 2 \mathrm{C}$ method ( $\mathrm{O} 2 \mathrm{C}$ system, see later). In one group, the hepatic microcirculatory responses to 60 -min complete ischemia followed by a 180 -min reperfusion period were examined (IR group, $\mathrm{n}=6$ ). After recording of the baseline microcirculatory variables $(t=-100 \mathrm{~min})$, ischemia was induced in the median and left hepatic lobes. The occlusions were then released ( $\mathrm{t}=0 \mathrm{~min})$, and the microcirculation in the affected lobes was observed via $\mathrm{O} 2 \mathrm{C}$ at $\mathrm{t}=$ 60,120 and $180 \mathrm{~min}$ in the reperfusion phase. In another group, 2 cycles of a 10-min complete hindlimb ischemia and 10-min reperfusion was used as a preconditioning trigger before the induction of liver ischemia (remote IPC + IR group, $n=6$ ). Limb ischemia was achieved by placing a tourniquet around the proximal femur, with simultaneous occlusion of the femoral artery with a miniclip (Szabó et al., 2009). The animals in a third group were subjected to the same surgical procedures, except for the induction of liver or limb ischemia (Sham group, $n=6$ ). Blood samples for biochemical determinations were taken at $\mathrm{t}=0,60,120$ and $180 \mathrm{~min}$ of the experiments. Tissue biopsies for enzyme activity and Western-blot analyses were taken at the end of the experiments. Tissue biopsies were stored at $-80{ }^{\circ} \mathrm{C}$, and plasma samples at $-20{ }^{\circ} \mathrm{C}$ before later analysis.

In the second series of experiments, the groups ( $n=6$ each) and the protocols were identical with those in the first series, with the exception that the microcirculation in the affected liver lobes was investigated by means of intravital video microscopy (IVM, see later) at $t=60 \mathrm{~min}$ in the reperfusion phase.

\section{Modified lightguide spectrophotometry (O2C) device}

We used the O2C system (LEA Medizintechnik, Gießen, Germany) for noninvasive and online examination of the microcirculation, which allows the simultaneous recording of tissue oxygen saturation $\left(\mathrm{S}_{\mathrm{O}_{2}}\right.$ percentage, absolute value), tissue hemoglobin ( $\mathrm{rHb}, \mathrm{AU}$ ), capillary blood flow (AU) and capillary blood flow velocity (RBCV, AU). The O2C device combines white light spectroscopy with laser-Doppler measurement in one flat probe. To prevent the influence of regional heterogeneity and temporal blood flow variations, measurements were performed at three predetermined locations on the liver surface for 30 s each (Schreinemachers et al., 2009) with an ambient light correction before measurement.

\section{IVM}

Polymorphonuclear (PMN) leukocytes of individual vessels were examined by means of conventional fluorescence IVM (Zeiss Axiotech Vario 100HD microscope, 100 W HBO mercury lamp, Acroplan $20 \times$ water immersion objective), using in vivo fluorescence labeling. The posterior surface of the left liver lobe was exteriorized and placed on a specially designed pedestal, providing a suitable horizontal plane (Ábrahám et al., 2008). PMNs were stained in vivo by means of rhodamine-6G (Sigma, St. Louis, MO; 0.2\%, $0.1 \mathrm{ml}$, i.v.). The microscopic images were recorded with a charge-coupled device video camera (AVT HORN-BC 12) attached to a personal computer. The microcirculatory parameters were assessed off-line by frame-to-frame analysis of the recorded images, using image analysis software (IVM, Pictron Ltd., (Budapest, Hungary). The microcirculatory inflammatory reaction was assessed by calculating the number of rolling and sticking PMN leukocytes within 5 central acinar venules (diameter between 20 and $40 \mu \mathrm{m}$ ) per animal (Ábrahám et al., 2008). Rolling leukocytes were defined as cells moving at a velocity less than $40 \%$ of that of the erythrocytes in the centerline of the microvessel passing through the observed vessel segment within $30 \mathrm{~s}$, and their number was given as the number of non-adherent leukocytes per second per vessel circumference. Adherent leukocytes (stickers) were defined in each vessel segment as cells that did not move or detach from the endothelial lining within an observation period of $30 \mathrm{~s}$, and are given as the number of cells per $\mathrm{mm}^{2}$ of endothelial surface.

\section{Xanthine oxidoreductase (XOR) activity}

Tissue biopsies were homogenized in phosphate buffer ( $\mathrm{pH} 7.4$ ) containing $50 \mathrm{mM}$ Tris- $\mathrm{HCl}, 0.1 \mathrm{mM}$ EDTA, $0.5 \mathrm{mM}$ dithiothreitol, $1 \mathrm{mM}$ phenylmethylsulfonyl fluoride, $10 \mu \mathrm{g} \mathrm{ml}{ }^{-1}$ soybean trypsin inhibitor and $10 \mu \mathrm{g} \mathrm{ml}^{-1}$ leupeptin. The homogenate was centrifuged at $4{ }^{\circ} \mathrm{C}$ for $20 \mathrm{~min}$ at $24,000 \mathrm{~g}$ and the supernatant was loaded into centrifugal concentrator tubes. The activity of XOR was determined in the ultrafiltered supernatant by fluorometric kinetic assay based on the conversion of pterine to isoxanthopterine in the presence (total XOR) or absence (XO activity) of the electron acceptor methylene blue (Beckman et al., 1989). 
Myeloperoxidase (MPO) activity

Tissue MPO activity was measured in liver biopsies by the method of Kuebler et al. (1996). Briefly, the tissue was homogenized with Tris- $\mathrm{HCl}$ buffer ( $0.1 \mathrm{M}, \mathrm{pH} 7.4)$ containing $0.1 \mathrm{M}$ polymethylsulfonyl fluoride to block tissue proteases, and then centrifuged at $4{ }^{\circ} \mathrm{C}$ for $20 \mathrm{~min}$ at $24,000 \mathrm{~g}$. The MPO activities of the samples were measured at $450 \mathrm{~nm}$ (UV-1601 spectrophotometer; Shimadzu, Japan), and the data were referred to the protein content.

\section{TNF- $\alpha$ and HMGB1 levels}

Blood samples $(0.5 \mathrm{ml})$ were taken from the carotid artery into precooled DTA-containing polypropylene tubes. Samples were centrifuged at $1000 \mathrm{~g}$ for $30 \mathrm{~min}$ at $4{ }^{\circ} \mathrm{C}$, and then stored at $-70{ }^{\circ} \mathrm{C}$ until assay. Plasma TNF- $\alpha$ and HMGB1 concentrations were determined with commercially available enzyme-linked immunosorbent assays (Quantikine Ultrasensitive ELISA kit for rat TNF- $\alpha$; Biomedica Hungaria Kft, Hungary and Shino-Test Corporation ELISA kit for HMGB1; Kanagawa, Japan).

\section{Western blot analysis of NOX2 and NOX4}

Liver samples were homogenized and then lysed with RIPA buffer (Santa Cruz Biotech). Protein extracts (20 $\mu \mathrm{g}$ of total protein) were heated at $95{ }^{\circ} \mathrm{C}$ for $10 \mathrm{~min}$, then placed in ice to cool, electrophoresed in $4-15 \%$ gradient sodium dodecyl sulfate-polyacrylamide gels, and transferred onto nitrocellulose membranes (Millipore). Membranes were blocked with Tris-buffered saline (TBS) and 5\% skim milk at room temperature for $1 \mathrm{~h}$ prior to overnight incubation at $4{ }^{\circ} \mathrm{C}$ with primary antibodies against gp91phox (1:2000 dilution; Epitomics, Burlingame, CA, USA), and NOX4 (1:2000 dilution; Epitomics, Burlingame, CA, USA). After washing with TBS-T, membranes were incubated for $1 \mathrm{~h}$ at room temperature with horseradish peroxidase-conjugate-corresponding secondary antibodies (anti-rabbit, 1:2500 dilution; Promega, Madison, WI, USA). The membranes were then developed with the SuperSignal West Pico horseradish peroxidase substrate kit (Pierce, Rockford, IL, USA) and intensities of protein bands were quantitated and photographed on a Lumi-Imager ${ }^{\mathrm{TM}}$ (Roche-Diagnostics, Boehringer Mannheim, Germany) image station. For the control of sample loading and protein transfer, the membranes were stripped and reprobed with $\beta$-actin antibody (1:1000 dilution; Sigma-Aldrich, St. Louis, MO, USA).

\section{Liver transaminase (AST, ALT and $L D H$ ) release}

Blood samples withdrawn from the carotid artery were analyzed for aspartate-aminotransferase (AST), alanine-aminotransferase (ALT) and lactate-dehydrogenase ( $\mathrm{LDH})$ by standard photometric procedures (Vitros 250 analyzer, Ortho-Clinical Diagnostics, Raritan, NJ).

\section{Statistical analysis}

Data analysis was performed with the SigmaStat statistical software (Jandel Corporation, San Rafael, CA, USA). Changes in microcirculatory parameters and liver enzyme activities between groups and within groups were analyzed by two-way ANOVA, followed by the Bonferroni test. For the evaluation of biochemical assays and ELISA data, changes in variables between groups were analyzed by one-way ANOVA on ranks, followed by the Holm-Sidak test. Western blot data were analyzed with no normal distribution with the Mann-Whitney test. $P$ values $<0.05$ were regarded as significant.

\section{Results}

\section{Microcirculatory changes}

\section{Modified lightguide spectrophotometry}

The microhemodynamic parameters, capillary blood flow, capillary blood flow velocity (RBCV), tissue oxygen saturation $\left(\mathrm{S}_{\mathrm{O}_{2}}\right)$, and tissue hemoglobin content ( $\mathrm{rHb}$ ) were assessed simultaneously and on-line in the left liver lobes (Fig. 1). Reperfusion after 60-min ischemia was not associated with significant changes in intrahepatic blood flow (Fig. 1A) as compared with the Sham group. When IR was preceded by remote IPC, however, the postischemic hepatic blood flow was significantly higher than the pre-ischemic values throughout the examination period. The RBCV in the IR group was significantly lower during reperfusion in comparison with the pre-ischemic values, and no recovery was observed during the examination period (Fig. 1B). Remote IPC, however, reversed the RBCV changes to the level measured in the Sham group. Taken together, the flow and velocity changes caused by the 60-min partial ischemia were manifested in deteriorated levels of tissue $\mathrm{S}_{\mathrm{O}_{2}}$ and $\mathrm{rHb}$, which were restored by the remote IPC protocol (Fig. 1C, D).

\section{Fluorescent IVM data}

Due to the lack of selectin molecules in the post-sinusoidal endothelium, "classical rolling" cannot be observed, but the number of PMNs exhibiting the rolling phenomenon could nevertheless be determined in the central venules. Liver IR was accompanied by an approximately 4-fold increase in the number of rolling leukocytes relative to that of the sham-operated animals (Fig. 2A). In accordance with this, the number of sticking cells also displayed a significant increase in response to liver IR (Fig. 2B). Remote IPC resulted in significant improvements in both forms of cell-to-cell interactions.

\section{Inflammatory enzyme (MPO and XOR) levels}

The PMN deposition analyzed via the MPO activity was increased significantly $180 \mathrm{~min}$ after the ischemia, together with the XOR activity, which was elevated approximately 2 -fold as compared with the shamoperated group. Remote IPC applied prior to the partial liver IR insult reduced the MPO and XOR activities almost to the sham-operated levels (Fig. 3A, B).

\section{Plasma HMGB1 and TNF- $\alpha$ levels}

Following 60-min partial liver ischemia, significantly increased HMGB1 and TNF- $\alpha$ levels were observed at $180 \mathrm{~min}$ of the reperfusion period (Fig. 4A, B). The IR-induced elevations of the plasma HMGB1 and TNF- $\alpha$ were effectively attenuated by remote IPC (Fig. 4A).

\section{NOX2 and NOX4 protein expression}

Western blot analysis of the NOX2 and NOX4 proteins revealed significant increases after partial liver IR in comparison with the shamoperated animals. The application of remote IPC before IR decreased the expression of NOX2 significantly (Fig. 5A), but did not affect the level of NOX4 expression (Fig. 5B).

\section{Hepatic enzymes in the plasma}

The animals in the sham-operated group displayed minimally increased necroenzyme levels throughout the experimental protocol as compared with the baseline values. In comparison, the IR group exhibited significantly higher AST, ALP and LDH activities during the reperfusion period, indicating significant functional damage. When the remote IPC protocol preceded liver IR (remote IPC group), the plasma levels of necroenzymes were significantly reduced in comparison with the IR group (Fig. 6). 

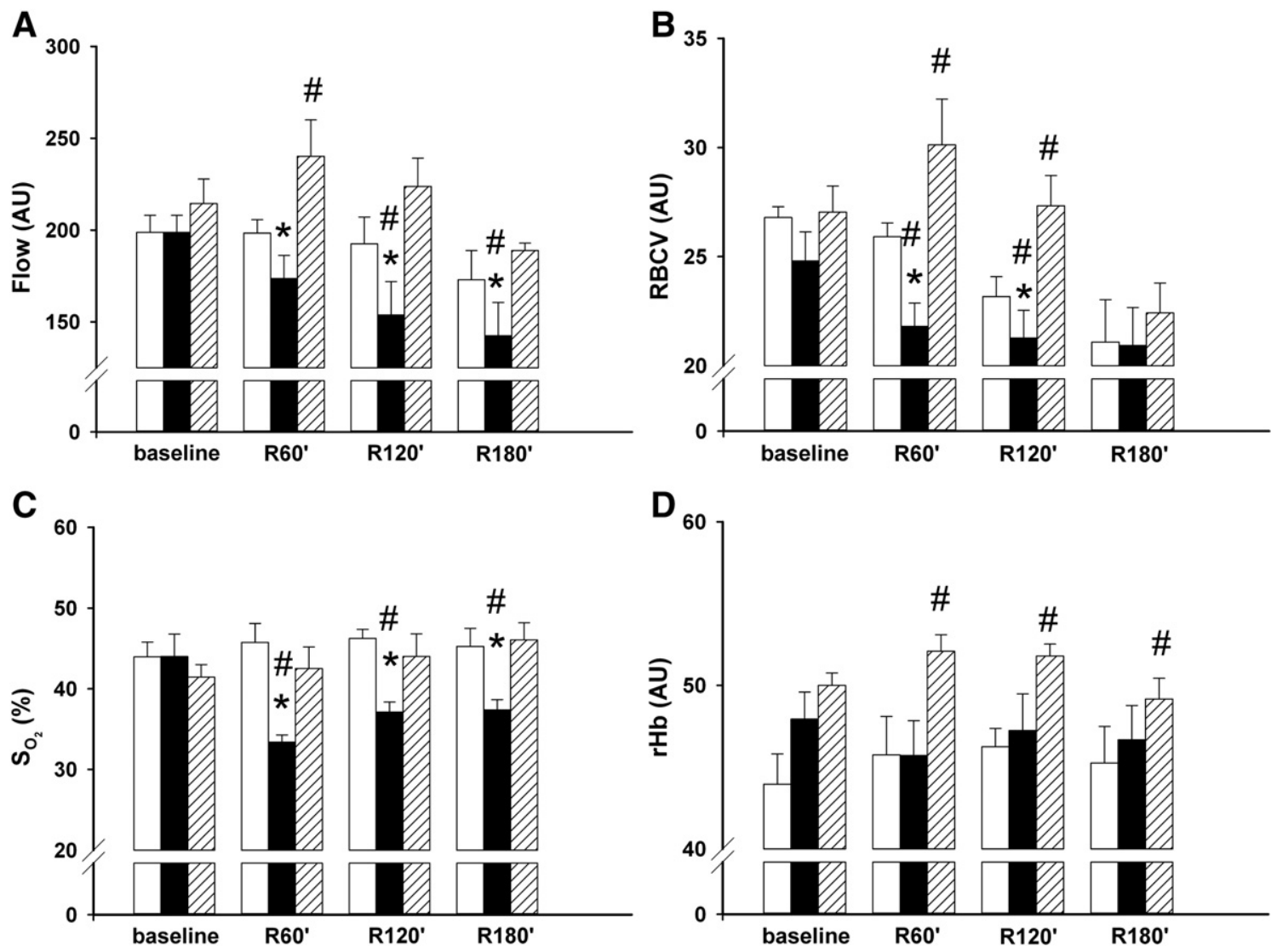

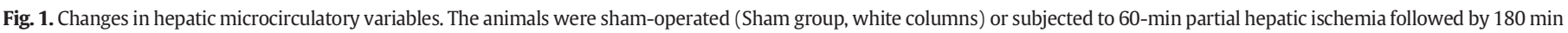

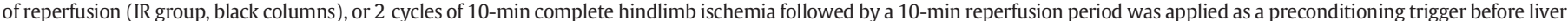

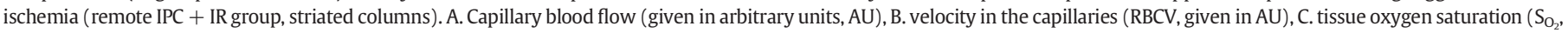
given in \%), D. tissue hemoglobin ( $\mathrm{rHb}$, given in AU). Data are presented as means \pm SEM. ${ }^{*} \mathrm{P}<0.05$ vs baseline; \#P $<0.05$ vs Sham group (two-way ANOVA, Bonferroni test).

\section{Discussion}

The major aim of this study was to investigate the effects of remote IPC after partial liver IR on enzymes that generate intracellular reactive oxygen species (ROS). The scope of this project was narrowed down to the most likely ROS-producing sources, and we focused on the most relevant isoforms, NOX2 and NOX4, whose roles in the mechanisms of IR damage or IPC have already been implicated. A partial hepatic ischemia model was used to evaluate the effects solely in response to IR, excluding poorly tolerated mesenteric congestion with the concomitant mediator release and deterioration of the systemic hemodynamics (Vollmar et al., 1994). We previously characterized the microcirculatory effects of IPC achieved by using 2 cycles of complete hindlimb ischemia on IR-induced periosteal microcirculatory derangement and systemic inflammatory responses (Szabó et al., 2009). As beneficial local effects were observed, the identical protocol was utilized to investigate the consequences of limb IPC on IR-induced inflammatory responses in a distant organ, and our study clearly demonstrated the microcirculatory benefits of remote IPC. The IR-related increases in the levels of necroenzymes and inflammatory cytokines were ameliorated and the activities of potential sources of ROS production, i.e. XOR, MPO and NOX2, were significantly reduced. The most interesting finding, however, was that the enhanced NOX4 expression was not influenced by remote IPC.

There are several possible explanations of this result. Firstly, the present findings are consistent with those of other research, which revealed that IPC inhibits the effects of mediators involved in the microcirculatory dysfunction, including ROS (Cutrn et al., 2002; Jabs et al., 2010). The main cellular sources of ROS generation in the blood vessels are the NOXs in the smooth muscle cells (Griendling et al., 2000), endothelial cells (Bayraktutan et al., 2000) and adventitial fibroblasts (Pagano et al., 1998). Among the NOX homologs, NOX4 has been reported to be the main isoform in the vascular cells (Bengtsson et al., 2003; Ellmark et al., 2005), although the expression of NOX2 or even NOX1 has also been demonstrated. Enhanced NOX4 activity has been implicated in the development of various cardiovascular pathologies, because NOX-derived superoxide rapidly reduces the bioavailability of endothelium-derived NO, thereby promoting vasoconstriction and enhancing the vascular resistance (Dusting et al., 1998; Zicha et al., 2001). Nevertheless, NOX4 within the vessel wall generates a low level of ROS continuously, even in the absence of extrinsic stimulation, and unlike phagocytic NOXs, is involved in physiological vascular processes such as maintenance of the vascular tone, regulation of the endothelium-dependent vasodilator function, oxygen sensing and modulation of the redox-sensitive signaling pathways (Dworakowski et al., 2008; Cave et al., 2006). Moreover, endothelial NOX4 acts as a constitutive endothelial generator of $\mathrm{H}_{2} \mathrm{O}_{2}$, which positively affects the vascular function, linked to signaling events that promote vasodilatation and cell protection (Dikalov et al., 2008; Takac et al., 2011). The exact factors determining the action of NOX4 in producing superoxides or $\mathrm{H}_{2} \mathrm{O}_{2}$ are unclear, but in overexpression systems NOX4 releases predominantly $\mathrm{H}_{2} \mathrm{O}_{2}$ (Ray et al., 2011). Additionally, molecular mechanisms implicated in NOX4 vasoprotection include the activation of eNOS and the increased production of NO, and the increased expression of antioxidant systems such as Nrf-2 (Schröder et al., 2012). Indeed, a significant decrease in myocardial infarct size was recently observed in NOX2- and NOX1/NOX2-, but not in NOX4-deficient mice (Braunersreuther et al., 2013). Thus, data are accumulating concerning a Janus-faced mechanism by which NOX4 can protect or cause harm to the circulatory system (Schmidt et al., 2012) and, if a defensive action of 


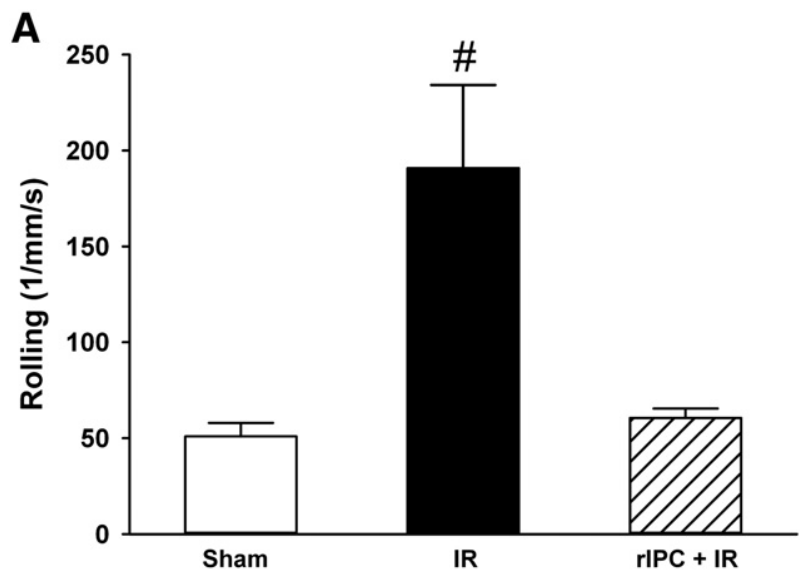

B

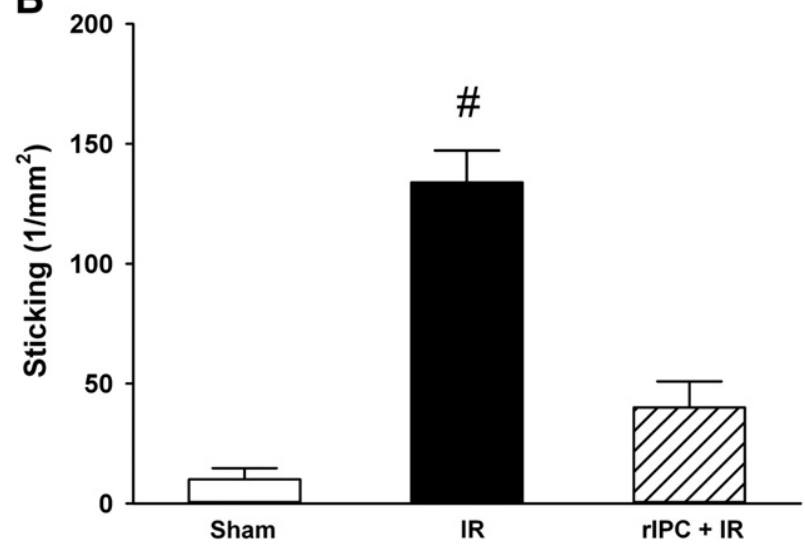

Fig. 2. Changes in PMN-endothelial interactions. A. The number of rolling PMNs in the central venules of the liver (rolling, given in $\mathrm{mm}^{-1} \mathrm{~s}^{-1}$ ), B. number of sticking PMNs (sticking, given in $\mathrm{mm}^{-2}$ ). Data are presented as means \pm SEM. $\# P<0.05$ vs Sham group (one-way ANOVA, Holm-Sidak test).

NOX4 activity is possible, it could be hypothesized that the potentially vasoprotective characteristics of NOX4 could, at least in part, explain the ineffectiveness of remote IPC in reducing the IR-related NOX4 expression.

Another possibility is that the influence of IPC is not universally effective, in consequence of the different sensitivities of the various target genes and enzymes. The remote IPC provided significant, but incomplete protection, and the residual damage and IR-induced inflammatory activation could therefore well be linked to the unchanging NOX4 activity. In this sense, the effect of IPC does not extend to all homologs (at least not to NOX4). Recent findings suggest that, unlike other ROS-generating NOXs, the tightly-assembled active conformation of NOX4 cannot be disrupted by conventional means, because the membrane-bound subunit does not require interaction with the cytosolic subunits (Csányi and Pagano, 2013).

Previous studies demonstrated that the beneficial effect of IPC extends to reducing the adherence of PMNs to the ischemic-reperfused sinusoidal endothelium, attenuating the PMN-mediated endothelial dysfunction, and limiting leukocyte accumulation in the postischemic liver tissue (Yuan et al., 2005). In accordance with these observations, the influx of activated PMNs into the postsinusoidal venules was observed in the present model, and as a result of remote IPC, the extent of rolling and sticking of the leukocytes was significantly reduced in the central venules. The mechanisms underlying PMN trafficking after IR and remote IPC can be explained in terms of several pathways leading to a modified adhesion molecule expression. The characteristic of the hepatic sinusoidal endothelium may contribute to leukocyte trapping: non-classical rolling and mainly vascular adhesion molecule-1 (VCAM1)-mediated strong adhesion occur in response to inflammation (Lee et al., 2004). NOXs have been shown to be particularly involved in regulating VCAM1 expression
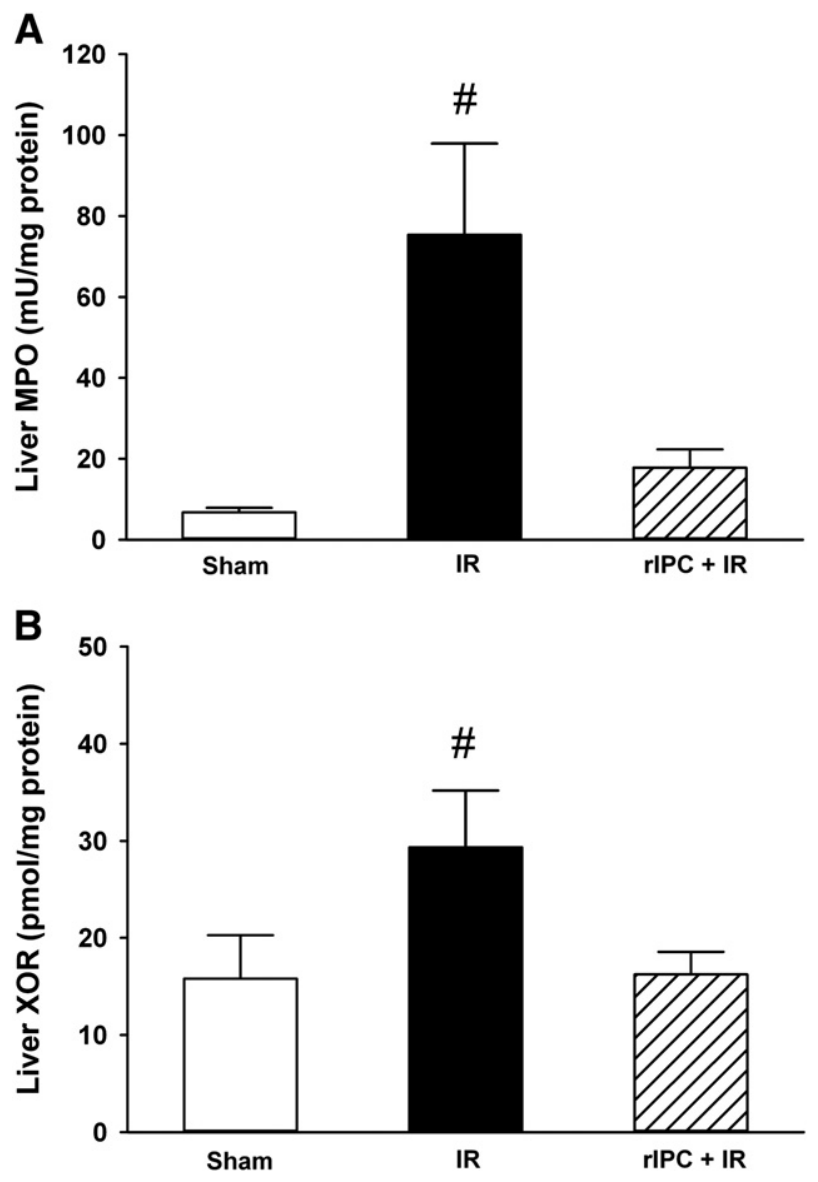

Fig. 3. Hepatic MPO and XOR activities. A. XOR activity, B. MPO activity. Data are presented as means $\pm \mathrm{SEM}$. $\# P<0.05$ vs Sham group (one-way ANOVA, Holm-Sidak test).

through TNF- $\alpha$ release (Cayatte et al., 2001). When applied in vitro, S17834, a flavonoid NOX inhibitor, directly repressed the vascular NOX activity, and it reduced TNF- $\alpha$-stimulated VCAM, ICAM- 1 and E-selectin expression in vivo (Cayatte et al., 2001). Further, the lower degree of ROS formation after remote IPC partially produced by NOXs can also be linked to reduced adhesion molecule expression. Via mineral corticoid receptor activation, aldosterone induced adhesion molecule expression also involves activation of the NOXs (Hashikabe et al., 2006). Moreover, LPS induces the expression of surface adhesion molecules through the activation of TLR4, which has been shown to be involved in the NOX-dependent activation of NF- $\kappa B$ (Park et al., 2006).

The activity of MPO, the commonly used index of PMN priming and activation (Yuan et al., 2005), further strengthened our IVM observations. As shown in the present study, the activity of MPO is significantly correlated with the number of visualized PMNs. This observation is in agreement with a previous report that accumulated PMNs were positively correlated with the development of hepatocellular damage after IR (Yuan et al., 2005). Upon activation, the prototypic isoform NOX2 has been proven to be responsible for the superoxide generation of PMNs (Babior, 1999). This isoform, also referred to as "respiratory burst oxidase", was first described in PMNs as the starting point of ROS production (Babior, 1999). The effects of NOX2-derived ROS and proteases released from activated PMNs in promoting cell death in the liver have been widely documented (Yuan et al., 2005; De Minicis et al., 2010). In the present study, remote IPC attenuated both arms of PMN-related injury: it lowered the PMN priming/MPO activity and reduced the expression of NOX2. This is in accordance with previous observations where preconditioning was induced via NOX2 in ischemic brain, myocardium and endothelial cells (Kawano et al., 2007; Milovanova et al., 2008; Thirunavukkarasu et al., 2012). 
A
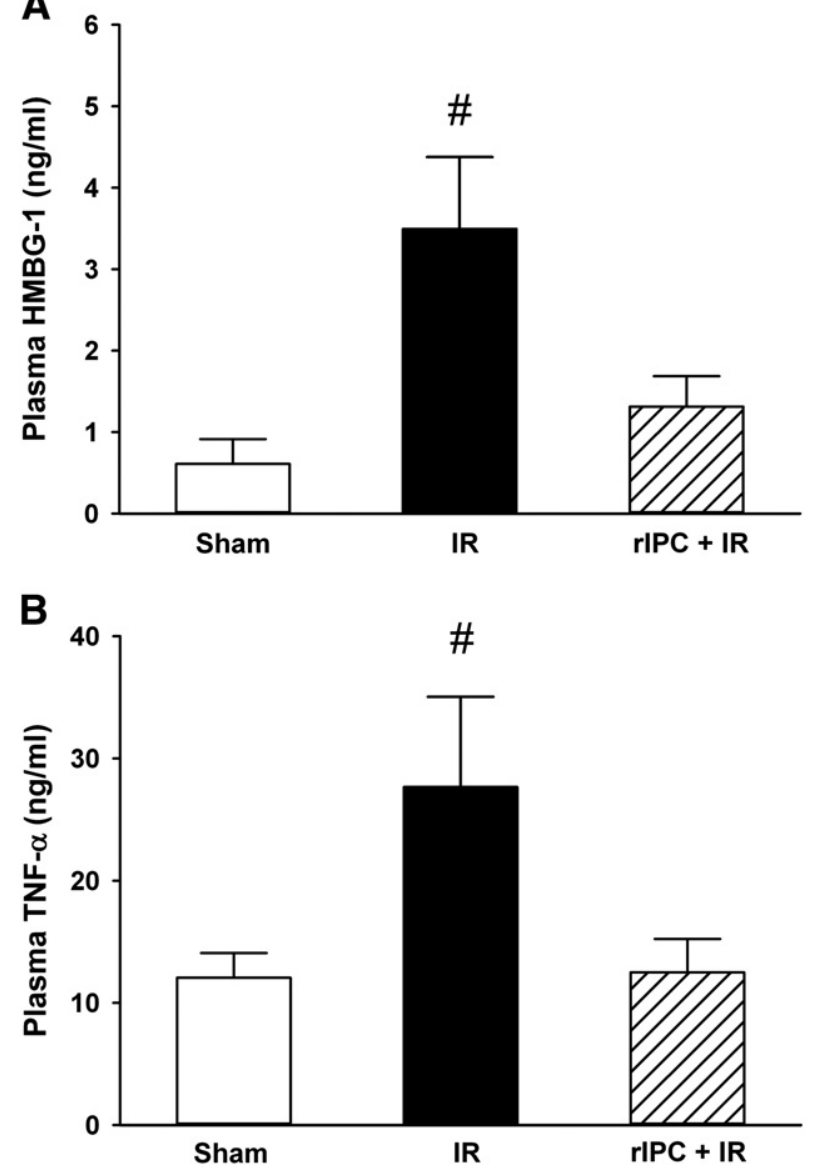

Fig. 4. Plasma cytokine levels. A. TNF- $\alpha$ level; B. HMGB1 level. Data are presented as means \pm SEM. $\# P<0.05$ vs Sham group (one-way ANOVA, Holm-Sidak test).

Cellular ROS (superoxide and $\mathrm{H}_{2} \mathrm{O}_{2}$ ) are now well recognized as playing an integral role in several growth factors and cytokine signal transduction pathways (Lander, 1997) and serve as second messengers for cellular tyrosine kinase signaling (Goldstein et al., 2005). NOXs appear to be especially involved in redox signaling because they are the only enzymes (among the many intracellular sources of superoxide formation) whose primary function is to generate ROS (Lambeth, 2004). The tissue specificity and difference in catalytic subunits offer an opportunity for the development of NOX inhibitors that do not compromise the essential physiological signaling and phagocytic functions carried out by ROS.

In this study, remote IPC significantly attenuated systemic cytokine release. It has previously been shown that NOX-mediated ROS production has a major role in the ischemia-induced inflammatory responses involving activation of the NF- $k B$ (Dworakowski et al., 2008). TNF- $\alpha$ and HMGB1 have a common NF-kB-dependent transcription; both are involved in inflammatory responses (Dworakowski et al., 2008; Kamo et al., 2013). Moreover, hepatocytes have been demonstrated to produce TNF- $\alpha$ in a NOX-dependent manner following hypoxia-reoxygenation and liver IR (Spencer et al., 2013). The relationship between TNF- $\alpha$ and HMGB1 expression and ROS production is bidirectional: TNF- $\alpha$ and HMGB1 are involved in regulating the expression of cytokines and other mediators that participate in acute inflammatory responses, many of which are associated with the increased generation of ROS (Kamo et al., 2013). On the other hand, oxidative stress has been reported to up-regulate the expression of cytokines that promote inflammatory responses during reperfusion. These antigen-independent responses interact and amplify each other, finally leading to impaired microhemodynamics, functional and structural cell damage, and remote or systemic inflammatory complications.
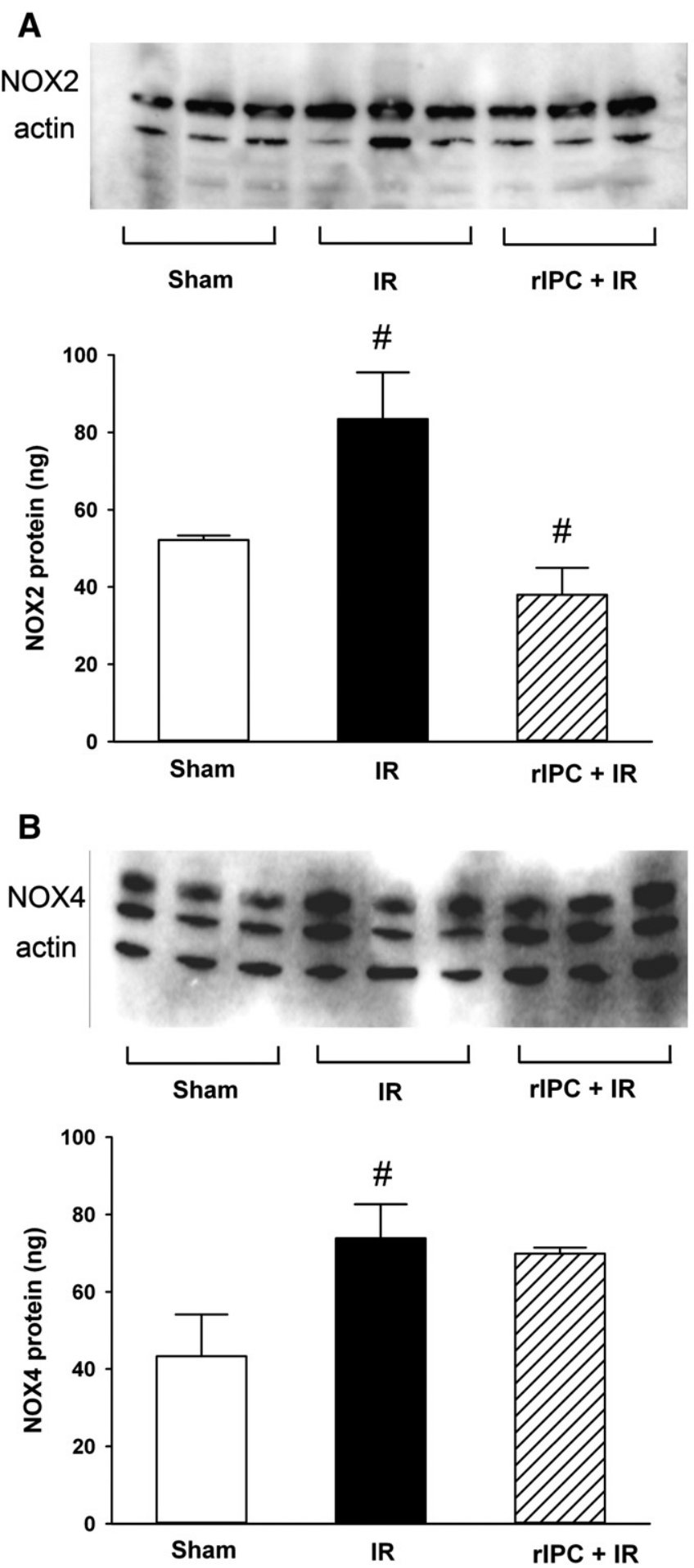

Fig. 5. Hepatic expressions of NOX2 and NOX4 proteins. A. NOX2 expression; B. NOX4 expression. Data are presented as medians \pm SD. $\# P<0.05$ vs Sham group (Mann-Whitney test)

\section{Conclusions}

Remote IPC exerted marked protection against the potentially detrimental microcirculatory consequences of hepatic IR. This accords with the lower levels of generation of inflammatory mediators, preserved liver blood flow and oxygenation. The signs of PMN activation and the induction of NOX2 were likewise weaker, but in contrast with expectations, the expression of NOX4, the main vascular NOX isoform, was not 

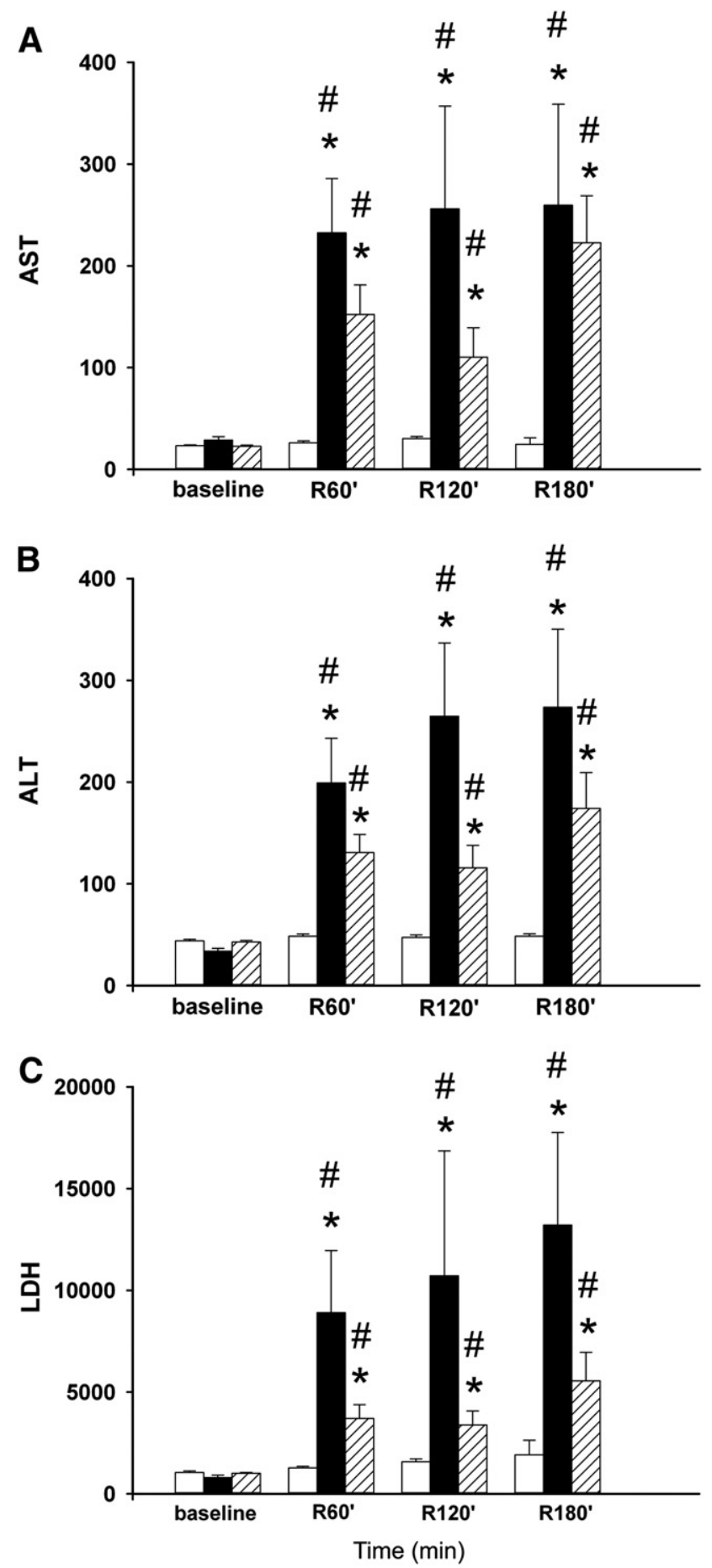

Fig. 6. Time courses of plasma AST, ALT and LDH changes. The animals were shamoperated (Sham group, white columns) or subjected to 60-min partial hepatic ischemia followed by 180 min of reperfusion (IR group, black columns) or 2 cycles of 10-min complete hindlimb ischemia followed by a 10 -min reperfusion period was applied as a preconditioning trigger before liver ischemia (remote IPC + IR group, striated columns). A. AST levels (AST, given in U/L), B. ALT levels (ALT, given in U/L), C. LDH levels (LDH given in $\mathrm{U} / \mathrm{L}$ ). Data are presented as means \pm SEM. ${ }^{*} P<0.05$ vs baseline; $\# P<0.05$ vs Sham group (two-way ANOVA, Bonferroni test).

attenuated. Several questions remain unanswered, but further characterization of "ischemia-specific" enzymatic sources may lead to the preventive targeting of oxido-reductive stress, rather than the scavenging of ROS after they have been formed.
Conflict of interest statement

The authors declare that there are no conflicts of interest.

\section{Acknowledgments}

PH was supported by a European Society for Surgical Research (ESSR) Fellowship Award. The study was supported by Hungarian Science Research Fund (OTKA) grant K104656 and Social Renewal Operational Programs (TÁMOP)-4.2.2/A-11/1/KONV-2012-0035 and (TÁMOP)-4.2.2/ A-11/1/KONV-2012-0073.

\section{References}

Ábrahám S, Szabó A, Kaszaki J, Varga R, Eder K, Duda E, et al. Kupffer cell blockade improves the endotoxin-induced microcirculatory inflammatory response in obstructive jaundice. Shock 2008;30:69-74. http://dx.doi.org/10.1097/SHK.0b013e31815dceea. [PMID: 18562926].

Abu-Amara M, Yang SY, Quaglia A, Rowley P, Fuller B, Seifalian A, et al. Role of endothelial nitric oxide synthase in remote ischemic preconditioning of the mouse liver. Liver Transpl 2011;17:610-9. http://dx.doi.org/10.1002/lt.22272. [PMID: 21506249].

Anilkumar N, Sirker A, Shah AM. Redox sensitive signaling pathways in cardiac remodeling, hypertrophy and failure. Front Biosci (Landmark Ed) 2009;14:3168-87. [PMID: 19273265].

Babior BM. NADPH oxidase: an update. Blood 1999;93:1464-76. [PMID: 10029572]

Bayraktutan U, Blayney L, Shah AM. Molecular characterization and localization of the $\mathrm{NAD}(\mathrm{P}) \mathrm{H}$ oxidase components gp91-phox and p22-phox in endothelial cells. Arterioscler Thromb Vasc Biol 2000;20:1903-11. http://dx.doi.org/10.1161/01.ATV.20. 8.1903. [PMID: 10938010].

Beckman JS, Parks DA, Pearson JD, Marshall PA, Freeman BA. A sensitive fluorometric assay for measuring xanthine dehydrogenase and oxidase in tissues. Free Radic Biol Med 1989;6:607. [PMID: 2753392].

Bedard K, Krause KH. The NOX family of ROS-generating NADPH oxidases: physiology and pathophysiology. Physiol Rev 2007;87:245-313. http://dx.doi.org/10.1152/ physrev.00044.2005. [PMID: 17237347\}.

Bengtsson SH, Gulluyan LM, Dusting GJ, Drummond GR. Novel isoforms of NADPH oxidase in vascular physiology and pathophysiology. Clin Exp Pharmacol Physiol 2003; 30:849-54. http://dx.doi.org/10.1046/j.1440-1681.2003.03929.x. [PMID: 14678249].

Braunersreuther V, Montecucco F, Ashri M, Pelli G, Galan K, Frias M, et al. Role of NADPH oxidase isoforms NOX1, NOX2 and NOX4 in myocardial ischemia/reperfusion injury. Mol Cell Cardiol 2013;64:99-107. http://dx.doi.org/10.1016/j.yjmcc.2013.09.007. [PMID: 24051369].

Cave AC, Brewer AC, Narayanapanicker A, Ray R, Grieve DJ, Walker S, et al. NADPH oxidases in cardiovascular health and disease. Antioxid Redox Signal 2006;8:691-728. http://dx.doi. org/10.1089/ars.2006.8.691. [PMID: 16771662].

Cayatte AJ, Rupin A, Oliver-Krasinski J, Maitland K, Sansilvestri-Morel P, Boussard MF, et al. S17834, a new inhibitor of cell adhesion and atherosclerosis that targets NADPH oxidase. Arterioscler Thromb Vasc Biol 2001;21:1577-84. http://dx.doi.org 10.1161/hq1001.096723. [PMID: 11597929].

Csányi G, Pagano PJ. Strategies aimed at Nox4 oxidase inhibition employing peptides from Nox4 B-loop and C-terminus and p22 (phox) N-terminus: an elusive target. Int J Hypertens 2013:842827. http://dx.doi.org/10.1155/2013/842827. [PMID: 23606947].

Cutrn JC, Perrelli MG, Cavalieri B, Peralta C, Rosell Catafau J, Poli G. Microvascular dysfunction induced by reperfusion injury and protective effect of ischemic preconditioning Free Radic Biol Med 2002;33:1200-8. http://dx.doi.org/10.1016/S0891-5849(02) 01017-1. [PMID: 12398928].

De Minicis S, Seki E, Paik YH, Osterreicher CH, Kodama Y, Kluwe J, et al. Role and cellular source of nicotinamide adenine dinucleotide phosphate oxidase in hepatic fibrosis Hepatology 2010;52:1420-30. http://dx.doi.org/10.1002/hep.23804. [PMID: 20690191].

Dikalov SI, Dikalova AE, Bikineyeva AT, Schmidt HH, Harrison DG, Griendling KK. Distinct roles of Nox1 and Nox4 in basal and angiotensin II-stimulated superoxide and hydrogen peroxide production. Free Radic Biol Med 2008;45:1340-51. http://dx.doi.org/10 1016/j.freeradbiomed.2008.08.013. [PMID: 18760347].

Dusting GJ, Fennessy P, Yin ZL, Gurevich V. Nitric oxide in atherosclerosis: vascular protector or villain? Clin Exp Pharmacol Physiol Suppl 1998;25:S34-41. [PMID: 9809190]

Dworakowski R, Alom-Ruiz SP, Shah AM. NADPH oxidase-derived reactive oxygen species in the regulation of endothelial phenotype. Pharmacol Rep 2008;60:21-8. [PMID: 18276982].

Ellmark SHM, Dusting GJ, Ng TangFui M, Guzzo-Pernell N, Drummond GR. The contribution of Nox4 to NADPH oxidase activity in mouse vascular smooth muscle. Cardiovasc Res 2005;65:495-504. http://dx.doi.org/10.1016/j.cardiores.2004.10.026. [PMID: 15639489].

Goldstein BJ, Mahadev K, Wu X. Redox paradox: insulin action is facilitated by insulinstimulated reactive oxygen species with multiple potential signaling targets. Diabetes 2005;54:311-21. http://dx.doi.org/10.2337/diabetes.54.2.311. [PMID: 15677487].

Görlach A, Brandes RP, Nguyen K, Amidi M, Dehghani F, Busse R. A gp91phox containing NADPH oxidase selectively expressed in endothelial cells is a major source of oxygen radical generation in the arterial wall. Circ Res 2000;87:26-32. http://dx.doi.org/10. 1161/01.RES.87.1.26. [PMID: 10884368].

Griendling KK, Sorescu D, Lassègue B, Ushio-Fukai M. Modulation of protein kinase activity and gene expression by reactive oxygen species and their role in vascular physiology and pathophysiology. Arterioscler Thromb Vasc Biol 2000;20:2175-83. http://dx.doi.org/10.1161/01.ATV.20.10.2175. [PMID: 11031201]. 
Harada H, Hines IN, Flores S, Gao B, McCord J, Scheerens H, et al. Role of NADPH oxidasederived superoxide in reduced size liver ischemia and reperfusion injury. Arch Biochem Biophys 2004;423:103-8. http://dx.doi.org/10.1016/j.abb.2003.08.035. [PMID: 14871473].

Hashikabe Y, Suzuki K, Jojima T, Uchida K, Hattori Y. Aldosterone impairs vascular endothelia cell function. J Cardiovasc Pharmacol 2006;47:609-13. http://dx.doi.org/10.1097/01.fjc. 0000211738.63207.c3. [PMID: 16680076].

Jabs A, Fasola F, Muxel S, Münzel T, Gori T. Ischemic and non-ischemic preconditioning: endothelium-focused translation into clinical practice. Clin Hemorheol Microcirc 2010;45:185-91. http://dx.doi.org/10.3233/CH-2010-1297. [PMID: 20675899].

Kamo N, Ke B, Ghaffari AA, Shen XD, Busuttil RW, Cheng G, et al. ASC/caspase-1/IL-1ß signaling triggers inflammatory responses by promoting HMGB1 induction in liver ischemia/ reperfusion injury. Hepatology 2013;58:351-62. http://dx.doi.org/10.1002/hep.26320. [PMID: 23408710].

Kawano T, Kunz A, Abe T, Girouard H, Anrather J, Zhou P, et al. NOS-derived NO and Nox2 derived superoxide confer tolerance to excitotoxic brain injury through peroxynitrite. J Cereb Blood Flow Metab 2007;27:1453-62. http://dx.doi.org/10.1038/sj.jcbfm. 9600449. [PMID: 17293848].

Koti RS, Yang W, Dashwood MR, Davidson BR, Seifalian AM. Effect of ischemic preconditioning on hepatic microcirculation and function in a rat model of ischemia reperfusion injury. Liver Transpl 2002;8:1182-91. http://dx.doi.org/10.1053/jlts.2002.36846. [PMID: 12474159].

Kuebler WM, Abels C, Schuerer L, Goetz AE. Measurement of neutrophil content in brain and lung tissue by a modified myeloperoxidase assay. Int J Microcirc Clin Exp 1996;16:89. [PMID: 8737712].

Lambeth JD. NOX enzymes and the biology of reactive oxygen. Nat Rev Immunol 2004;4: 181-9. http://dx.doi.org/10.1038/nri1312. [PMID: 15039755].

Lander HM. An essential role for free radicals and derived species in signal transduction. FASEB J 1997;11:118-24. [PMID: 9039953].

Lassègue B, Sorescu D, Szöcs K, Yin Q Akers M, Zhang Y, et al. Novel gp91(phox) homologues in vascular smooth muscle cells: Nox1 mediates angiotensin II-induced superoxide formation and redox-sensitive signaling pathways. Circ Res 2001;88:888-94. http://dx. doi.org/10.1161/hh0901.090299. [PMID:11348997].

Lee YS, Kang YS, Lee JS, Nicolova S, Kim JA. Involvement of NADPH oxidase-mediated generation of reactive oxygen species in the apototic cell death by capsaicin in HepG2 human hepatoma cells. Free Radic Res 2004;38:405-12. [PMID: 15190937].

Mallick IH, Yang W, Winslet MC, Seifalian AM. Ischaemic preconditioning improves microvascular perfusion and oxygenation following reperfusion injury of the intestine. $\mathrm{Br} \mathrm{J}$ Surg 2005;92:1169-76. http://dx.doi.org/10.1002/bjs.4988. [PMID: 16044427].

Marden JJ, Zhang Y, Oakley FD, Zhou W, Luo M, Jia HP, et al. JunD protects the liver from ischemia/reperfusion injury by dampening AP-1 transcriptional activation. J Biol Chem 2008;283:6687-95. http://dx.doi.org/10.1074/jbc.M705606200. [PMID: 18182393].

Milovanova T, Chatterjee S, Hawkins BJ, Hong N, Sorokina EM, Debolt K, et al. Caveolae are an essential component of the pathway for endothelial cell signaling associated with abrupt reduction of shear stress. Biochim Biophys Acta 2008;1783:1866-75. http:// dx.doi.org/10.1016/j.bbamcr.2008.05.010. [PMID: 18573285].

Pagano PJ, Chanock SJ, Siwik DA, Colucci WS, Clark JK. Angiotensin II induces p67phox mRNA expression and NADPH oxidase superoxide generation in rabbit aortic adventitial fibroblasts. Hypertension 1998;32:331-7. http://dx.doi.org/10.1161/01.HYP.32. 2.331. [PMID: 9719063].

Park HS, Chun JN, Jung HY, Choi C, Bae YS. Role of NADPH oxidase 4 in lipopolysaccharideinduced proinflammatory responses by human aortic endothelial cells. Cardiovasc Res 2006;72:447-55. http://dx.doi.org/10.1016/j.cardiores.2006.09.012. [PMID: 17064675]
Ray R, Murdoch CE, Wang M, Santos CX, Zhang M, Alom-Ruiz S, et al. Endothelial Nox4 NADPH oxidase enhances vasodilatation and reduces blood pressure in vivo. Arterioscler Thromb Vasc Biol 2011;31:1368-76. http://dx.doi.org/10.1161/ATVBAHA.110.219238. [PMID: 21415386]

Schmidt HH, Wingler K, Kleinschnitz C, Dusting G. NOX4 is a Janus-faced reactive oxygen species generating NADPH oxidase. Circ Res 2012;111:e15-6. http://dx.doi.org/10. 1161/CIRCRESAHA.112.271957. [PMID: 22723224].

Schreinemachers MC, Doorschodt BM, Florquin S, van den Bergh Weerman MA, Reitsma JB, Lai W, et al. Improved preservation and microcirculation with polysol after transplantation in a porcine kidney autotransplantation model. Nephrol Dial Transplant 2009;24:816. http://dx.doi.org/10.1093/ndt/gfn559. [PMID: 18849394].

Schröder K, Zhang M, Benkhoff S, Mieth A, Pliquett R, Kosowski J, et al. Nox4 is a protective reactive oxygen species generating vascular NADPH oxidase. Circ Res 2012;110: 1217-25. http://dx.doi.org/10.1161/CIRCRESAHA.112.267054. [PMID: 22456182].

Sorescu D, Griendling KK. Reactive oxygen species, mitochondria, and NAD(P)H oxidases in the development and progression of heart failure. Congest Heart Fail 2002;8: 132-40. http://dx.doi.org/10.1111/j.1527-5299.2002.00717.x. [PMID: 12045381].

Spencer NY, Zhou W, Li Q, Zhang Y, Luo M, Yan Z, et al. Hepatocytes produce TNF- $\alpha$ following hypoxia-reoxygenation and liver ischemia-reperfusion in a NADPH oxidase- and c-Src-dependent manner. Am J Physiol Gastrointest Liver Physiol 2013;305:G84-94. http://dx.doi.org/10.1152/ajpgi.00430.2012. [PMID: 23639811].

Szabó A Varga R, Keresztes M, Vízler C, Németh I Rázga Z et al. Ischemic limb preconditioning downregulates systemic inflammatory activation. J Orthop Res 2009;27: 897-902. http://dx.doi.org/10.1002/jor.20829. [PMID: 19105227].

Takac I, Schröder K, Zhang L, Lardy B, Anilkumar N, Lambeth JD, et al. The E-loop is involved in hydrogen peroxide formation by the NADPH oxidase Nox4. J Biol Chem 2011;286:13304-13. http://dx.doi.org/10.1074/jbc.M110.192138. [PMID: 21343298].

Taniguchi M, Uchinami M, Doi K, Yoshida M, Sasaki H, Tamagawa K, et al. Edaravone reduces ischemia-reperfusion injury mediators in rat liver. J Surg Res 2007;137:69. http://dx.doi.org/10.1016/j.jss.2006.06.033. [PMID: 17064733].

Tejima K, Arai M, Ikeda H, Tomiya T, Yanase M, Inoue Y, et al. Induction of ischemic tolerance in rat liver via reduced nicotinamide adenine dinucleotide phosphate oxidase in Kupffer cells. World J Gastroenterol 2007;13:5071-8. [PMID: 17876872].

Thirunavukkarasu M, Adluri RS, Juhasz B, Samuel SM, Zhan L, Kaur A, et al. Novel role of NADPH oxidase in ischemic myocardium: a study with Nox2 knockout mice. Funct Integr Genomics 2012;12:501-14. http://dx.doi.org/10.1007/s10142-011-0256-x. [PMID: 22038056].

Vollmar B, Glasz J, Leiderer R, Post S, Menger MD. Hepatic microcirculatory perfusion failure is a determinant of liver dysfunction in warm ischemia-reperfusion. Am J Pathol 1994;145:1421-31. [PMID: 7992845].

Wang Q, Sun AY, Simonyi A, Kalogeris TJ, Miller DK, Sun GY, et al. Ethanol preconditioning protects against ischemia/reperfusion-induced brain damage: role of NADPH oxidase-derived ROS. Free Radic Biol Med 2007;43:1048-60. http://dx.doi.org/10. 1016/j.freeradbiomed.2007.06.018. [PMID: 17761301].

Yuan GJ, Ma JC, Gong ZJ, Sun XM, Zheng SH, Li X. Modulation of liver oxidant-antioxidant system by ischemic preconditioning during ischemia/reperfusion injury in rats. World J Gastroenterol 2005;11:1825-8. [PMID: 15793874]

Yuan HJ, Zhu XH, Luo Q Wu YN, Kang Y, Jiao JJ, et al. Noninvasive delayed limb ischemic preconditioning in rats increases antioxidant activities in cerebral tissue during severe ischemia-reperfusion injury. J Surg Res 2012;174:176-83. http://dx.doi.org/ 10.1016/j.jss.2010.11.001. [PMID: 21195427].

Zicha J, Dobesová Z, Kunes J. Relative deficiency of nitric oxide-dependent vasodilation in salt-hypertensive Dahl rats: the possible role of superoxide anions. J Hypertens 2001; 19:247-54. [PMID: 11212967]. 
IV. 


\section{The 49th Congress of the European Society for Surgical Research}

May 21-24, 2014, Budapest, Hungary

\section{Abstracts}

Congress Organizing Committee

Attila Szijártó, Budapest

Péter Ónody, Budapest

Prof. Dr. György Wéber, Budapest

\section{Contents}

\section{Walter Brendel}

94 Abstracts WB 01_WB 06

Young Investigator

97 Abstracts YI 01_YI 06

Best Clinical Research

99 Abstracts BC 01_BC 06

\section{B.Braun}

102 Abstracts YI 01_YI 06

Oral Presentations

105 Abstracts OP 01_OP 215

Poster Presentations

193 Abstracts PP 01_PP 150 
Result: For $50 \mathrm{kPa}$ indentation the percentage reduction of the submucosal depth increased with increasing time ( $15 \%$ for $5 \mathrm{~s}, 28 \%$ for 30 s and $45 \%$ for 60 s). In the $160 \mathrm{kPa}$ indentation the submucosal depth also reduced by $45 \%$ over a 60 s indentation even despite a sample with a thick submucosal layer. In $255 \mathrm{kPa}$ samples the longitudinal muscle and serosal depth were affected but not as markedly (20\% reduction over 5 seconds and $27 \%$ reduction over 60 seconds). The $255 \mathrm{kPa}$ samples were unique as in the 30 s and 60 s group there were slides with completely obliterated longitudinal muscle, indicating that at this level the submucosal layer may be unable to withhold the applied stress.

Conclusion: Mechanical stresses, equivalent to those in laparoscopic grasping, result in changes to the depth of the colon wall, particularly in the submucosa and at longer durations of stress application. Further analysis will determine safe tissue handling thresholds.

\section{OP 61}

\section{Effects of Limb Ischaemic Preconditioning in Ovariectomized Rats}

Dénes Garabㄹ, Dóra Bodnár ${ }^{1}$, Sándor Nyíri ${ }^{1}$, Levente Pócs ${ }^{2}$, Ágnes Janovszky ${ }^{3}$, Mihály Boros ${ }^{1}$, Andrea Szabó ${ }^{1}$

\footnotetext{
${ }^{1}$ Institute of Surgical Research, University of Szeged, Szeged, Szeged, Hungary

${ }^{2}$ Department of Traumatology, County Hospital of Kecskemét, Kecskemét, Kecskemét, Hungary

${ }^{3}$ Department of Oral and Maxillofacial Surgery, University of Szeged, Szeged, Szeged, Hungary
}

Background: During elective orthopedic surgery or fracture repair, tourniquet ischaemia of osteoporotic bones may carry the risk of postischaemic inflammatory complications. We previously demonstrated that exogenous estrogen and ischaemic preconditioning (IPC) ameliorates periosteal inflammatory reactions induced by limb ischaemiareperfusion (IR). In the present experiments, the effect of IPC in these reactions was examined during experimental osteoporosis.

Material and Methods: Three-month old female Sprague-Dawley rats were bilaterally ovariectomized (OVX) or sham-operated (SH). 12 weeks later, the periosteal microcirculatory consequences (neutrophil leukocyteendothelial interactions) of 60-min complete limb ischaemia and 180 min reperfusion were examined by fluorescence intravital microscopy in sham-operated (SH+IR) and OVX animals $(\mathrm{OVX}+\mathrm{IR})$. In further groups, limb IPC $\left(2 \times 10^{\prime} / 10^{\prime \prime}\right.$ $\mathrm{I}-\mathrm{R})$ was elicited before I-R in sham-operated (SH+IPC+IR) and OVX rats $(\mathrm{OVX}+\mathrm{IPC}+\mathrm{IR})(\mathrm{n}=6-9)$. In another series, intravascular neutrophil leukocyte activation (CD11b adhesion molecule expression) changes were assessed by flow cytometry ( $n=7-9)$.

Result: Rolling and adhesion of leukocytes to the periosteal postcapillary venules and leukocyte CD11b expression were increased after limb IR; these reactions were attenuated by
IPC. In OVX animals, the number of rolling leukocytes was moderately reduced, but adherent leukocyte numbers and CD11b expression were not affected by IPC.

Conclusion: Our data shows that the ameliorating effects of IPC against limb IR-induced inflammatory complications are partially lost in the presence of chronic estrogen withdrawal. These data suggest a limited efficacy of IPC to improve the postischaemic microcirculatory inflammatory consequences of tourniquet ischaemia in osteoporotic situations. (Supported by: OTKA K104656, TÁMOP 4.2.4. A/2-11-1-2012-0001, TÁMOP 4.2.2A-11/1/KONV-2012-0035, TÁMOP 4.2.2A-11/1/KONV-2012-0073).

\section{OP 62}

\section{Postconditioning Is Able to Improve Small Intestinal Microcirculation after Lower Limb \\ Ischemia \\ Zsolt Turóczi ${ }^{1}$, András Fülöp ${ }^{1,}$ Zoltán Czigány ${ }^{1}$ Gabriella Varga², Olivér Rosero', Tünde Tökés ${ }^{2}$ József Kaszaki², Gábor Lotz³, László Harsányi ${ }^{1}$, Attila Szijártó ${ }^{1}$}

\footnotetext{
1 1st Department of Surgery, Semmelweis University, Budapest, Hungary

${ }^{2}$ Institute of Surgical Research, University of Szeged,

Szeged, Hungary

${ }^{3}$ 2nd Department of Pathology, Semmelweis University, Budapest, Hungary
}

Background: Major lower limb vascular surgeries may result in severe, remote injury of the gastrointestinal system, which has high mortality rates. Postconditioning is a technique with potential capability of reducing remote gastrointestinal complications. Our aim was to assess the remote macro- and micro-hemodynamic changes of the small intestine following an infrarenal aortic occlusion and to evaluate the effects of postconditioning on these alterations.

Material and Methods: Male Wistar rats underwent 3 hours of infrarenal aortic occlusion followed by 4 hours of reperfusion. In one group, postconditioning was applied. During the experiment blood pressure, superior mesenteric artery flow and mucosal microcirculation of duodenum, jejunum and ileum were assessed. At the end of the experiment, samples were taken from each intestinal segment for histological examinations.

Result: Superior mesenteric artery flow, as well as segmental small bowel microcirculation showed significant impairment in the IR group in contrast to the sham-operated group, (flow: $\mathrm{p}=0.012$; microcirculation(duodenum): $\mathrm{p}=0.012$; microcirculation(jejunum): $\mathrm{p}=0.008$; microcirculation(ileum): $\mathrm{p}=0.002$ ), while histological damage was significantly elevated. Strong negative correlation was found between microcirculatory values and histological damage $(r=-0.911$, $\mathrm{p}<0.001$ ). Postconditioning was able to limit flow reduction in all small bowel segments and in the superior mesenteric artery (flow: $p=0.009$; microcirculation(duodenum): $p=0.009$; 